FINITE ELEMENT ANALYSIS OF A DEEP EXCAVATION: A CASE STUDY

A THESIS SUBMITTED TO

THE GRADUATE SCHOOL OF NATURAL AND APPLIED SCIENCES

$\mathrm{OF}$

MIDDLE EAST TECHNICAL UNIVERSITY

BY

TUĞÇE AKTAŞ ENGIN

IN PARTIAL FULFILLMENT OF THE REQUIREMENTS

FOR

THE DEGREE OF MASTER OF SCIENCE

IN

CIVIL ENGINEERING

JULY 2019 

Approval of the thesis:

\section{FINITE ELEMENT ANALYSIS OF A DEEP EXCAVATION: A CASE STUDY}

submitted by TUĞÇE AKTAŞ ENGIN in partial fulfillment of the requirements for the degree of Master of Science in Civil Engineering Department, Middle East Technical University by,

Prof. Dr. Halil Kalıpçılar

Dean, Graduate School of Natural and Applied Sciences

Prof. Dr. Ahmet Türer

Head of Department, Civil Engineering

Prof. Dr. Erdal Çokça

Supervisor, Civil Engineering, METU

\section{Examining Committee Members:}

Prof. Dr. Tamer Topal

Geological Engineering Dept., METU

Prof. Dr. Erdal Çokça

Civil Engineering, METU

Prof. Dr. Nihat Sinan Işık

Civil Engineering Dept., Gazi University Technology Faculty

Assoc. Prof. Dr. Nejan Huvaj Sarıhan

Civil Engineering Dept., METU

Assist. Prof. Dr. Onur Pekcan

Civil Engineering Dept., METU

Date: 10.07.2019 
I hereby declare that all information in this document has been obtained and presented in accordance with academic rules and ethical conduct. I also declare that, as required by these rules and conduct, I have fully cited and referenced all material and results that are not original to this work.

Name, Surname: Tuğçe Aktaş Engin

Signature: 


\title{
ABSTRACT \\ FINITE ELEMENT ANALYSIS OF A DEEP EXCAVATION: A CASE STUDY
}

\author{
Aktaş Engin, Tuğçe \\ Master of Science, Civil Engineering \\ Supervisor: Prof. Dr. Erdal Çokça
}

July 2019, 138 pages

The optimum use of safety and economy in deep excavation design is possible with the selection of the appropriate system, and modelling of the selected system and soil properties properly. Therefore, soil parameters selection has a crucial effect in deep excavation analyses. The realistic estimation of the displacements with the finite element software is only possible by using the realistic deformation modulus values during analyses. However, in stiff clays for which undisturbed sampling is very difficult, displacements calculated with laboratory deformation modulus parameters may be higher than the measured values. Objective of this study is to determine the constant that shows linear relationship between SPT-N and deformation modulus parameter of Ankara clay by using three constitutive soil model of Plaxis-2D, namely Mohr-Coulomb (MC), hardening soil model (HS) and hardening soil model with small strain stiffness (HSsmall). For this purpose, back analysis of a 25 m deep excavation was performed by using inclinometer measurement results. To be more precise in numerical analysis, instead of using the idealized soil profile the soil is divided into layers according to SPT- $\mathrm{N}_{60}$ measurements. Additionally, each displacement measured by the inclinometer along the depth is compared with the analysis results to minimize the error. In case trial-error method is used in the study, time loss and the possibility of not reaching the correct result were taken into consideration; therefore, 
the analysis was done by writing a Python code. As a result of analyses, the soil models were compared with each other and it is concluded that displacements curves obtained from the MC model could not converge to the real displacements. HSsmall model results are closest to the real displacements. Moreover, displacement curves obtained from HS and HSsmall models are very close to each other, and the linear correlation formula is determined as $\mathrm{E}_{50}{ }^{\mathrm{ref}}=780 \mathrm{xN}_{60} \mathrm{kPa}$ for this excavation of the case study in Ankara clay.

Keywords: deep excavation, Ankara clay, back analysis, python code, constitutive soil model 


\title{
$\ddot{\mathbf{O Z}}$
}

\section{DERINN KAZI SONLU ELEMANLAR ANALİİ: ÖRNEK OLAY INCELEMESI}

\author{
Aktaş Engin, Tuğçe \\ Yüksek Lisans, İnşaat Mühendisliği \\ Tez Danışmanı: Prof. Dr. Erdal Çokça
}

Temmuz 2019, 138 sayfa

İnşaat mühendisliği tasarımının iki ana kuralı olan emniyet ve ekonominin derin kazı tasarımında optimum seviyede kullanılması; uygun sistem seçimi, seçilen sistemin ve özellikle zemin koşullarının gerçeğe yakın modellenmesiyle mümkün olmaktadır. $\mathrm{Bu}$ durumda derin kazı analizlerinde zemin parametrelerinin seçimi kritik önem taşımaktadır. Temeli sonlu elemanlar metoduna dayalı yazılımlarla deplasmanların gerçeğe yakın tahmini ancak analizlerde gerçekçi deformasyon modülü değerlerinin kullanılmasıyla mümkündür. Öte yandan örselenmemiş numune alımının oldukça zor olduğu sert killerde, laboratuvar deneyleriyle belirlenen deformasyon parametrelerinin kullanılması sonucunda elde edilen deplasmanlar yerinde gerçekleşen değerlerin üzerinde kalabilmektedir. Bu çalışmanın amacı, bir sonlu elemanlar programı Plaxis2D'nin 3 temel modeli olan Mohr-Coulomb (MC), pekleşen zemin modeli (HS) ve düşük birim deformasyonla pekleşen zemin modelini (HSsmall) kullanarak, Ankara kilinin SPT-N60 değeriyle deformasyon modülü arasındaki doğrusal bağıntı sabitini bulmaktır. Bu amaç doğrultusunda, Ankara kilinde 25.0m derinliğindeki bir kazının inklinometre okuma sonuçlarının geri analizi yapılmıştır. Analizlerde daha gerçekçi olmak adına genel bir yaklaşım olan idealize zemin profili kullanmak yerine, SPT-N ölçüm aralıklarına göre zemin, tabakalara ayrılmıştır. Ayrıca, inklinometre ile derinlik boyunca ölçülen her bir yanal deplasman değeri, 
analiz sonuçlarıyla karşılaştırılarak hatanın en aza indirgenmesi amaçlanmıştır. Çalışmanın deneme-yanılma yöntemiyle yapılması durumundaki zaman kaybı ve doğru sonuca ulaşamama ihtimali göz önünde tutulmuş ve analizlerin Python kodu yazılarak otomasyonu sağlanmıştır. Yapılan analizler sonucunda, modeller birbirleri ile kıyaslanmış ve MC modelden elde edilen deplasman eğrileri gerçek dağılımı yakalayamamıştır. HSsmall modeli gerçek deplasman dağılımına en yakın sonuçları veren model olmuștur. HS ve HSsmall modelden elde edilen deplasman eğrileri birbirlerine çok yakın olmakla birlikte, Ankara kilinde yapılan bu örnek olay incelemesinde elde edilen doğrusal bağıntı $\mathrm{E}_{50}{ }^{\mathrm{ref}}=780 \times \mathrm{N}_{60} \mathrm{kPa}$ olarak belirlenmiştir.

Anahtar Kelimeler: derin kazı, Ankara kili, geri analiz, python kodu, temel zemin modelleri 
To my husband Zafer Engin 


\section{ACKNOWLEDGEMENTS}

I would like to express my deepest gratitude to my supervisor Prof. Dr. Erdal Çokça for his encouragement, expertise, understanding and support throughout this research. This thesis would not have been possible without his expertise. It was a pleasure for me working with him. Also, I would like to give special thanks to Civil Engineering Department instructors for their valuable teaching.

Additional and greatest thanks go to Dr. Oğuz Çalışan for his guiding, endless support, finding time to reply my questions and being my idol throughout my life. Even if I put all elegant words in here, I cannot sufficiently express my gratitude and thanks to him. I would also like to express my gratitude to my mother Huriye Aktaş, my father Nuri Aktaş and my dear sister who is also my best friend Ayşe Aktaş. They always supported me, not only for this thesis but throughout my life. I would like to thank them for everything. I am very lucky to have a family like you. Finally, I would like to express my deepest thanks to my life partner, friend and beloved husband Zafer Engin for his love, patience and support during my studies. Zafer, I love you with all my heart. 
TABLE OF CONTENTS

ÖZ

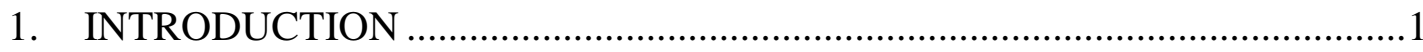

1.1. Research Objectives ..................................................................................

1.2. Outline of the Thesis ...................................................................................

2. LITERATURE REVIEW ........................................................................

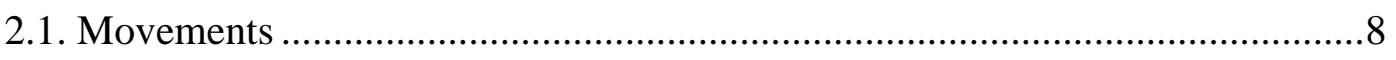

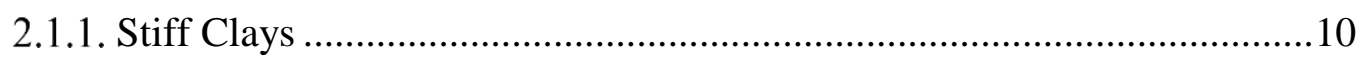

2.1.2. Soft and Medium Stiff Clays ..................................................................... 14

2.2. Studies on Ankara Clay ………………………………........................... 19

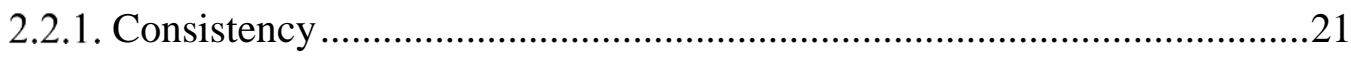

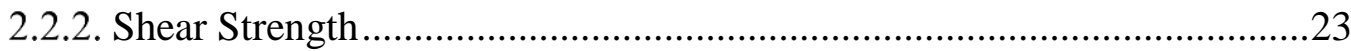

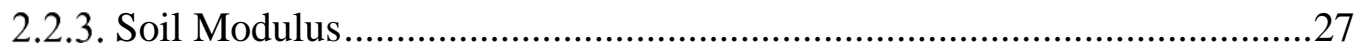




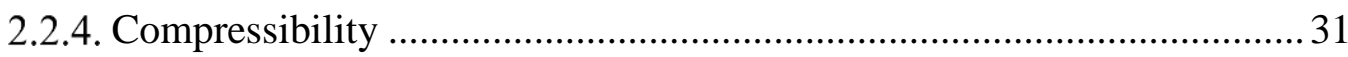

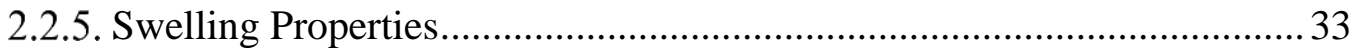

2.3. Back Analysis of Deep Excavations ................................................................ 33

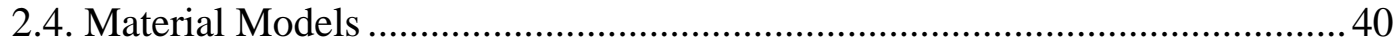

2.4.1. Mohr-Coulomb Model (MC)........................................................... 40

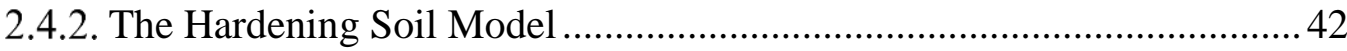

2.4.3. The Hardening Soil Model with Small Strain Stiffness .......................... 47

2.4.4. Comparison of the models: Simple Benchmark Problem ....................... 49

3. GEOLOGICAL ASSESMENT OF THE STUDY AREA ................................55

3.1. General Properties of the Back Analyzed Section .........................................5 57

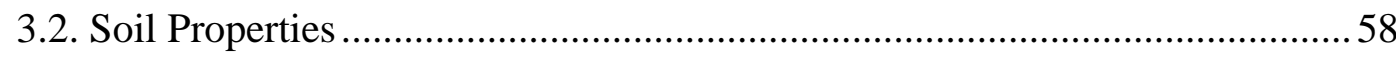

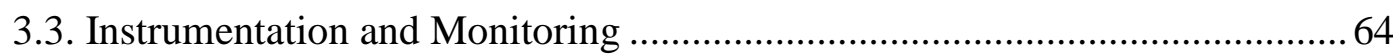

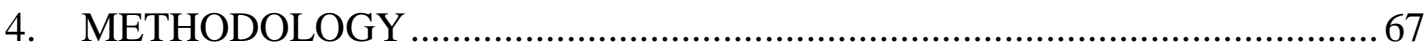

4.1. Finite Element Modelling with Plaxis 2D...................................................67

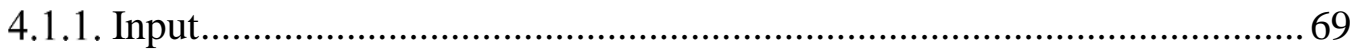

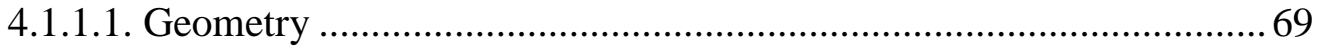

4.1.1.2. Material Parameters Used in Plaxis ............................................... 71

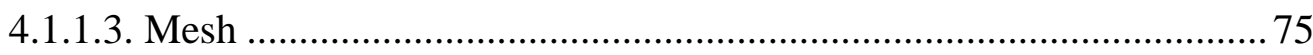

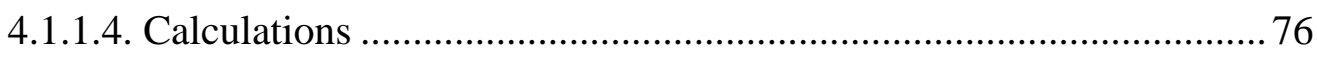

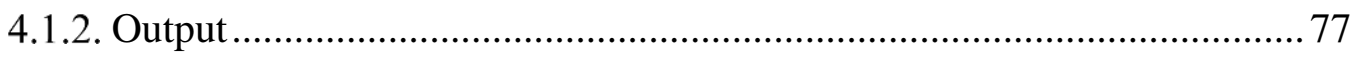

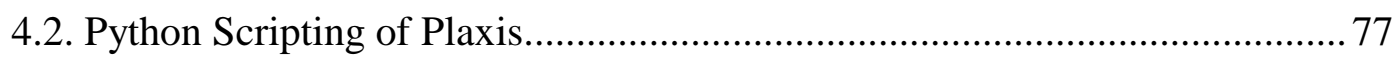

4.2.1. Remote Scripting Server ............................................................... 78

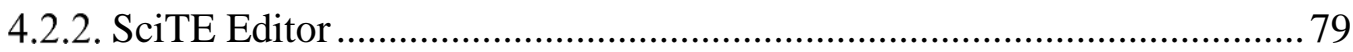

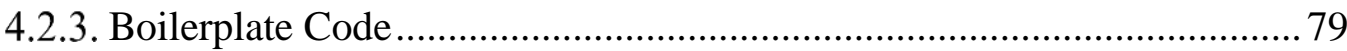




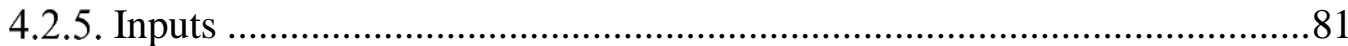

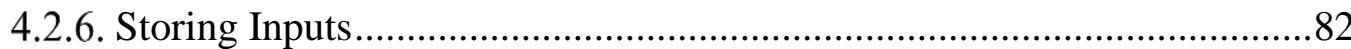

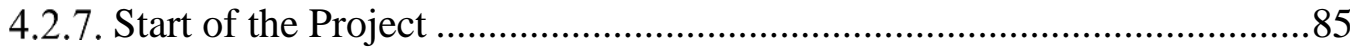

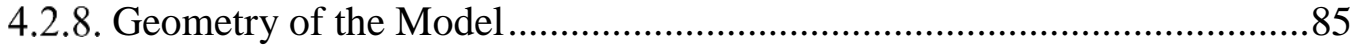

4.2.9. Defining and Assigning Material Properties ......................................... 88

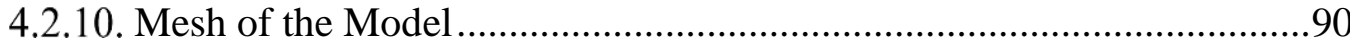

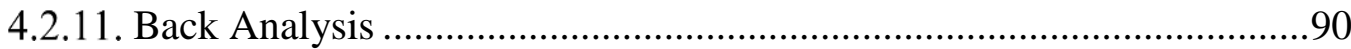

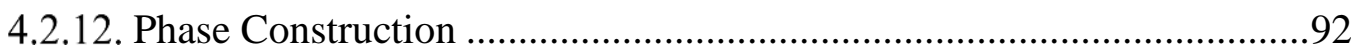

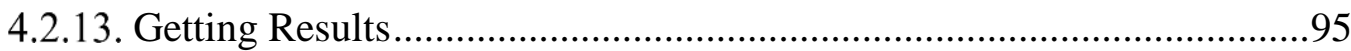

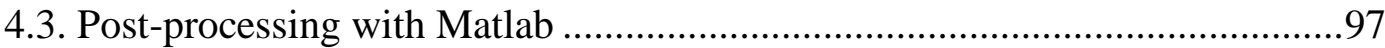

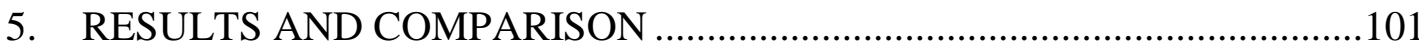

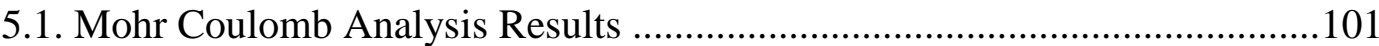

5.2. Hardening Soil Model Analysis Results ....................................................107

5.3. Hardening Soil Model with Small Strain Stiffness ......................................112

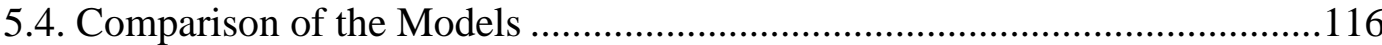

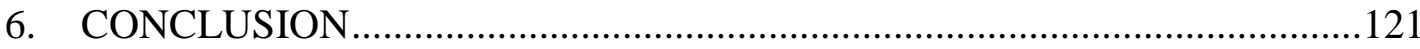

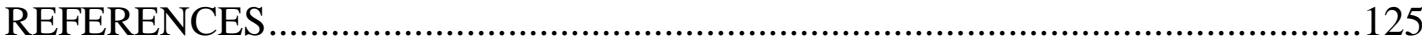

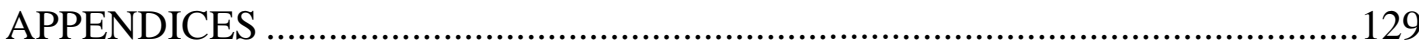

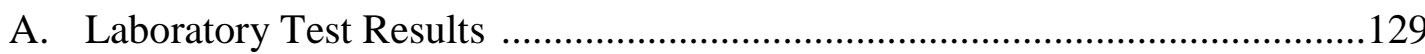

B. Inclinometer Measurements, Estimated Displacements and Errors .................133 


\section{LIST OF TABLES}

\section{TABLES}

Table 2.1. Instrumentation and Monitoring of Deep Excavations (Ergun, 2008) .......9 Table 2.2. Shear Strength Parameters Obtained from Triaxial Test Results (Mirata,

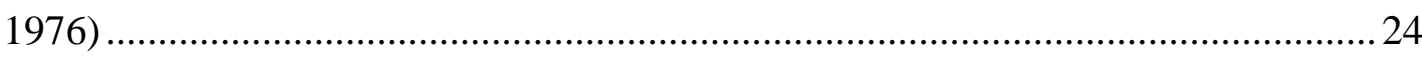

Table 2.3. Shear Strength Parameters Obtained from Direct Shear Test Results

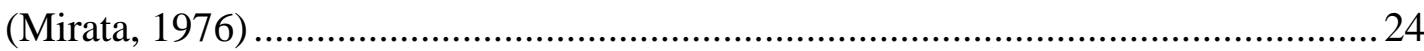

Table 2.4. Typical $\mathrm{E}_{\mathrm{s}}$ and $\mathrm{c}_{\mathrm{u}}$ Correlation (Bowles, 1988) ......................................... 28

Table 2.5. Ranges of Poisson's Ratio for Different Materials (Bowles, 1988) ......... 30

Table 2.6. Ranges of Poisson's Ratio (Industrial Floors and Pavements Guidelines,

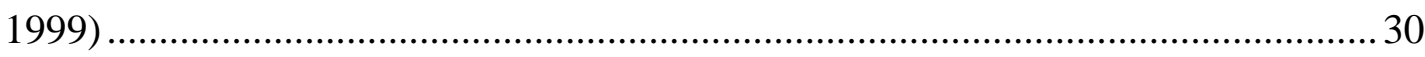

Table 2.7. Input Parameters for the MC Model (Hsiung and Dao, 2014) ................. 38

Table 2.8. Input Parameters for the HS Model (Hsiung and Dao, 2014) .................. 38

Table 2.9. Input Parameters for the HSsmall Model (Hsiung and Dao, 2014).......... 38

Table 2.10. Sand Parameters of the Simple Benchmark Problem .............................52

Table 2.11. Clay Parameters of the Simple Benchmark Problem ............................52

Table 4.1. Plaxis Parameters Used in Parametric Studies ......................................... 73

Table 4.2. Input Data of the Structural Element (Plate Element) ............................. 74

Table 4.3. Specific Characteristic Strengths of 7 Wire Strands (BS8081) ................ 74

Table 5.1. HSsmall Model Obtained $\gamma_{0.7}$ Values ................................................... 112 


\section{LIST OF FIGURES}

\section{FIGURES}

Figure 1.1. Excavation After Failure Nicoll Highway Singapore on April 2004 (source:newcivilengineer.com ) .........................................................................

Figure 1.2. Deep Excavation Failure in Ankara a). Before the Failure b). After the

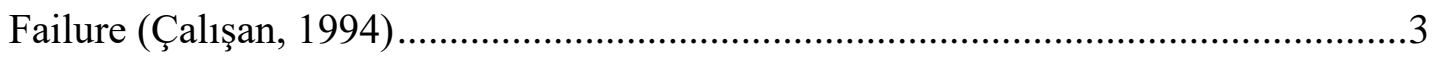

Figure 2.1. Observed Maximum Lateral Displacements in Stiff Clays, Sands and

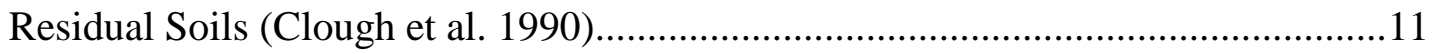

Figure 2.2. Observed Maximum Settlements in Stiff Clays, Sands and Residual Soils

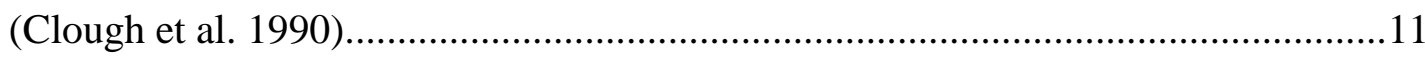

Figure 2.3. Finite Element Analysis Results to Predict Maximum Lateral Wall

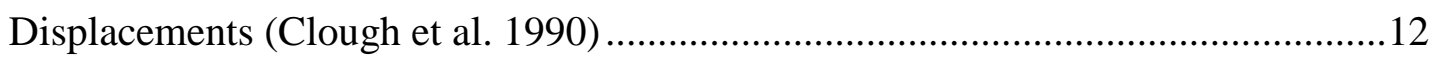

Figure 2.4. Normalized Maximum Horizontal Movement vs. Depth (Long 2001) ...13 Figure 2.5. Normalized Maximum Lateral Movement vs. Clough et al. (1989) System

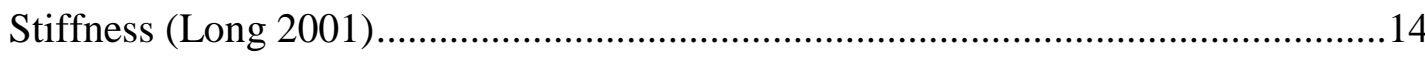

Figure 2.6. Factor of Safety Against Basal Heave vs. Normalized Maximum Wall

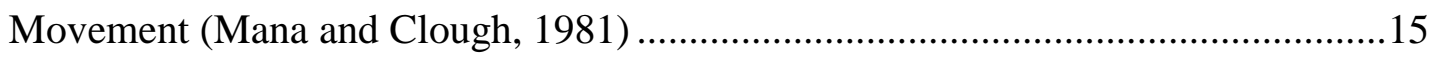

Figure 2.7. Design Curves to Obtain Maximum Horizontal Displacement (Clough et

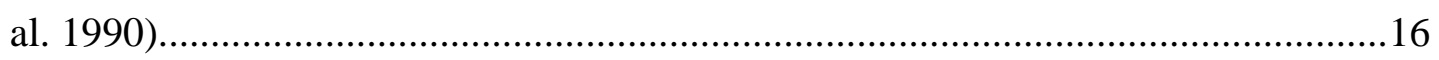

Figure 2.8. Normalized Maximum Lateral Movement vs. Clough et al. (1989) System for Soft Soils with High F.S. against Base Heave and Stiff Soil at the Dredge Level (Long 2001). .17

Figure 2.9. Normalized Maximum Lateral Movement vs. Clough et al. (1989) System for Soft Soils with High FS Against Base Heave and Soft Soils at the Dredge Level (Long 2001)...... .18

Figure 2.10. Maximum Lateral Wall Movements and Vertical Settlements Behind Walls (Ergun, 2008) .19 
Figure 2.11. Geology Map of Ankara (Cokca, 2000) 20

Figure 2.12. Atterberg Limits and Water Content of Ankara Clay (Ordemir et al. 1965) .22

Figure 2.13. Plasticity Chart of Ankara Clay (Ordemir et al. 1965) ......................... 22

Figure 2.14. Variation of $\mathrm{f}_{1}$ Value with PI (\%) (Stroud, 1974) ................................26

Figure 2.15. Correlation Between $\phi$ ' and IP for Normally Consolidated Clays ........ 26

Figure 2.16. Undrained Stiffness of Over-Consolidated Clays (after Duncan \&

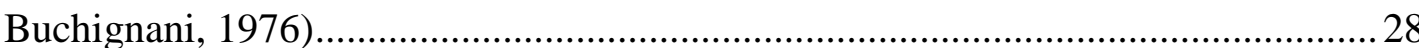

Figure 2.17. Characteristic Strain-Stiffness Behavior in Logarithmic Scale (Atkinson,

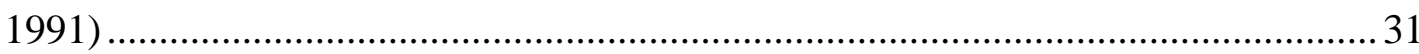

Figure 2.18. Variation of Preloading Pressure with Depth....................................... 32

Figure 2.19. Picture from the Deep Excavation Site (Çalışan, 2009)........................ 36

Figure 2.20. (a) Mohr-Coulomb Model Soil Behavior (b) Comparison of MohrCoulomb Soil Behavior with Real Soil Behavior, (c) Unrealistic Aspects of MohrCoulomb Model, (d) Mohr-Coulomb Model Yield Surface in Principal Stress Space 42

Figure 2.21. (a) Deviatoric Stress-Axial Strain Graph (b) Axial Stress-Strain Graph of HS Model 45

Figure 2.22. (a) Cone and Cap Hardening Behavior in HS Model (b) Failure Surfaces

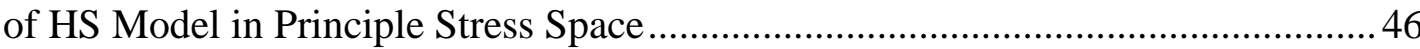

Figure 2.23. Stiffness Parameters of HSsmall Model [PLAXIS] ............................ 48

Figure 2.24. Soil Stiffness Behavior in Cyclic Shear Test (Plaxis, 2017) ................ 49

Figure 2.25. Geometry of the Benchmark Problem.................................................5 50

Figure 3.1. Satellite View of the Study Area .........................................................56

Figure 3.2. Cross Sectional View of the Shoring System......................................58

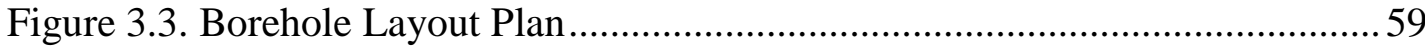

Figure 3.4. Variation of SPT N Values with Depth.................................................. 61

Figure 3.5. Receiving Undisturbed Sample from the Site for Oedometer Test......... 62 
Figure 3.6. Variation of SPT N, Sand Percent (>\#4 (\%)), Clay Percent $(<\# 200(\%))$, Water Content (W (\%)), Liquid Limit (LL(\%)) and Plasticity Index (PI (\%)) Values

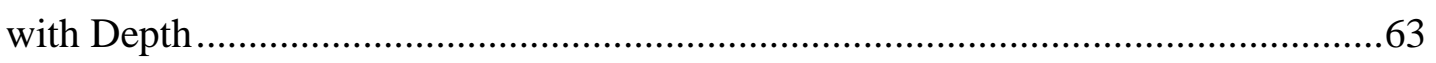

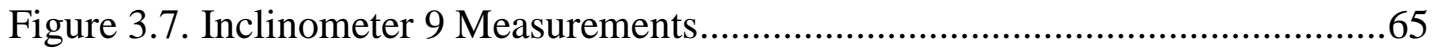

Figure 4.1. Geometry of the Model (Scale: 1/750) …….........................................70

Figure 4.2. Applied Mesh to the System (Scale:1/750) …......................................76

Figure 4.3. Configure Remote Scripting Server of Plaxis 2D .................................78

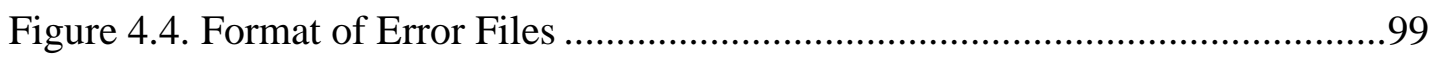

Figure 5.1. Deformed Mesh of the Final Excavation Stage (Scale: 1/750) .............102

Figure 5.2. Comparison of Horizontal Displacements - Mohr Coulomb Model- ...103

Figure 5.3. Horizontal Displacement of the Pile - Mohr Coulomb Model- ............104

Figure 5.4. Vertical Displacement of the Soil in the Final Excavation Stage - Mohr

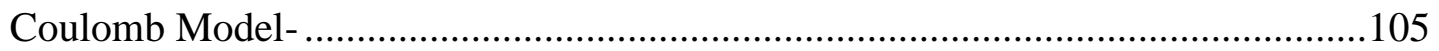

Figure 5.5. Bending Moment of the Pile - Mohr Coulomb Model- ........................106

Figure 5.6. Shear Diagram of the Pile - Mohr Coulomb Model- ............................ 106

Figure 5.7. Comparison of Horizontal Displacements - HS Model -......................109

Figure 5.8. Horizontal Displacement of the Pile - HS Model -...............................110

Figure 5.9. Vertical Displacement of the Soil in the Final Excavation Stage - HS

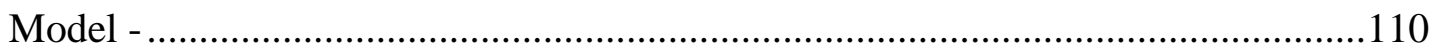

Figure 5.10. Bending Moment of the Pile - HS Model -.......................................111

Figure 5.11. Shear Diagram of the Pile - HS Model -........................................111

Figure 5.12. Comparison of Horizontal Displacements - HSsmall Model - ..........113

Figure 5.13. Horizontal Displacement of the Pile - HSsmall Model - .................... 114

Figure 5.14. Vertical Displacement of the Pile - HSsmall Model - ........................114

Figure 5.15. Bending Moment of the Pile - HSsmall Model - ...............................115

Figure 5.16. Shear Forces of the Pile - HSsmall Model - .....................................116

Figure 5.17. Comparison of Material Models in terms of Horizontal Displacements

Figure 5.18. Comparison of Material Models in terms of Surface Heave in front of the Wall .118 


\section{LIST OF ABBREVIATIONS}

FS

LL

LI

$\mathrm{MC}$

HS

HSsmall

PI

PL

OCR

USCS
Factor of safety

Liquid limit

Liquidity index

Mohr-Coulomb

Hardening soil

Hardening soil with small strain stiffness

Plasticity index

Plastic limit

Over-consolidation ratio

Unified Soil Classification System 


\section{LIST OF SYMBOLS}

\begin{tabular}{|c|c|}
\hline A & area \\
\hline$\alpha$ & Internal model parameter \\
\hline $\mathrm{c}$ & Cohesion \\
\hline$c^{\prime}$ & Effective cohesion \\
\hline $\mathrm{C}_{\mathrm{B}}$ & Borehole diameter factor \\
\hline $\mathrm{C}_{\mathrm{c}}$ & Compression index \\
\hline $\mathrm{C}_{\mathrm{R}}$ & Sampling method factor \\
\hline $\mathrm{C}_{\mathrm{S}}$ & Correction factor for rod length \\
\hline $\mathrm{c}_{\mathrm{u}}$ & Undrained shear strength \\
\hline $\mathrm{D}$ & Damping ratio \\
\hline $\mathrm{e}$ & Void ratio \\
\hline $\mathrm{E}$ & Young's modulus \\
\hline $\mathrm{E}_{0}$ & Initial slope of the stress strain curve \\
\hline$E^{\prime}$ & Young's modulus (effective) \\
\hline $\mathrm{E}_{50}$ & $\begin{array}{l}\text { Confining stress dependent stiffness modulus for primary } \\
\text { loading }\end{array}$ \\
\hline $\mathrm{E}_{50}{ }^{\mathrm{ref}}$ & $\begin{array}{l}\text { Reference stiffness modulus corresponding to the reference } \\
\text { confining pressure, } \mathrm{p}^{\text {ref }}\end{array}$ \\
\hline $\mathrm{E}_{\mathrm{i}}$ & Initial stiffness \\
\hline$E_{\text {oed }}$ & Oedometer modulus \\
\hline$E_{\text {oed }}{ }^{\text {ref }}$ & The reference Young's modulus \\
\hline $\mathrm{E}_{\mathrm{u}}$ & Young's modulus (for undrained loading) \\
\hline $\mathrm{E}_{\mathrm{ur}}$ & Unloading/reloading stiffness modulus \\
\hline $\mathrm{E}_{\mathrm{ur}}^{\mathrm{ref}}$ & $\begin{array}{l}\text { The reference Young's modulus for unloading and } \\
\text { reloading }\end{array}$ \\
\hline $\mathrm{f}$ & Yield function \\
\hline
\end{tabular}


$\mathrm{G}_{0}$

$\mathrm{G}_{0}{ }^{\text {ref }}$

$\mathrm{G}_{\mathrm{s}}$

$\mathrm{G}_{\mathrm{ur}}$

H

I

K

$\mathrm{K}_{0}$

$\mathrm{K}_{0}{ }^{\mathrm{nc}}$

M

m

$\mathrm{m}_{\mathrm{v}}$

n

N

$\mathrm{N}_{60}$

$\mathrm{p}^{\mathrm{ref}}$

$\mathrm{R}_{\mathrm{f}}$

$\gamma$

$\gamma_{0.7}$

$\gamma^{\mathrm{p}}$

$\gamma_{\text {sat }}$

$\gamma_{\text {unsat }}$

$\delta_{\mathrm{h}, \mathrm{m}}$
Variable which relies on the plasticity of the soil

Shear modulus

The initial or very small-strain shear modulus

Reference shear modulus at very small strains

Secant shear modulus

Unloading/reloading shear modulus

Depth of Excavation

Moment of inertia

Bulk modulus

Coefficient of lateral earth pressure (initial stress state)

Coefficient of lateral earth pressure for a normally

consolidated stress state

Modulus multiplier

Power in stress dependent stiffness relation

Coefficient of volume compressibility

Porosity

SPT N-value; blows of standard hammer to drive the SPT sampler or cone $300 \mathrm{~mm}$

SPT N-value corrected for rod energy ratio of $60 \%$ rod energy

Reference pressure

Failure ratio

Unit weight of soil

Threshold shear strain at which $\mathrm{G}_{\mathrm{s}}=0.722 \mathrm{G}_{0}$

Function of plastic strains

Saturated unit weight of soil

Unsaturated unit weight of soil

Maximum lateral wall displacement 


$\begin{array}{ll}\delta_{\mathrm{v}, \mathrm{m}} & \text { Maximum soil settlement } \\ \varepsilon_{1}{ }^{\mathrm{e}}, \varepsilon_{2}{ }^{\mathrm{e}}, \varepsilon_{3}{ }^{\mathrm{e}} & \text { Elastic components of the strain } \\ \mu, \nu & \text { Poisson's ration } \\ \nu_{\mathrm{ur}} & \text { Unloading/reloading Poisson's ratio } \\ \phi & \text { Friction angle } \\ \phi, & \text { Effective friction angle } \\ \psi & \text { Dilatancy angle }\end{array}$





\section{CHAPTER 1}

\section{INTRODUCTION}

World population increases day by day. In order to meet this increasing population's basic needs such as transportation, sheltering and social activities, the necessity for underground structures gradually increase while excavations deepen. On the other hand, the increase of excavation depth brings along some risks both for the excavation and the surrounding building and utilities. The major risk is the possibility of excessive horizontal displacements of the deep excavation system, which may cause some severe damage to adjacent buildings and failure of the system. There are many examples of deep excavation failures and damage of structures caused by deep excavations throughout the world. The failure of cut and cover tunnel of Nicoll Highway in Singapore (Figure 1.1), the collapse of deep excavation in Klang Valley area in Malaysia, deep excavation failures of soft clay in Taiwan (Do et al., 2013) are only a few examples of these failures. Although all of these excavations were performed in different soil types and supported by different retaining systems, the main reason behind these failures was the misinterpretation of soil properties (Ma'ruf and Darjanto, 2017). Deep excavation failure during excavation process of the shopping mall construction in Ankara can be seen in Figure 1.2. The main reason behind this failure was also related to the misinterpretation of soil properties and it was resulted in the collapse of the system due to inappropriate design of the project.

There is no "universal" material model for soils. Many researches exist in the literature that simulates soil behavior with different formulations and although only a part of them was practiced solving boundary value problems, it is still not easy for one to decide which soil model should be used for a problem to be handled. Failure of cut and cover tunnel of Nicoll Highway in Singapore, Figure 1.1, also shows the importance of the careful selection of constitutive soil model and engineering 
parameters of the soil. After this failure, an international committee was set up to investigate the causes of the failure. Several finite element analyses were performed by various committee members and they concluded that reasons behind the failure are poor workmanship and inappropriate simulation of soil with finite element model (Schweiger et al. [2009]).

Reliable input data to determine stress-strain relationship of soils tend to be very limited because of the significant expense of soil testing. Several researchers (Charles et al. [1998], Schanz et al. [1999], Brinkgreve [2005]) stated that in most instances of daily geotechnical engineering, one may have a good data on strength parameters; however, there is little or no data on stiffness parameters. Also, determination of soil deformation modulus with laboratory tests is difficult and often inaccurate because of the soil disturbance and differences between laboratory and site conditions (size effect, water condition and nonhomogeneous nature of soils) (Burland [1979], Duncan et al. [2014]). As a consequence, back analysis is suggested in order to determine representative soil modulus parameters based on site observations in practice (Peck [1969]). Then, the parameters obtained from the back analysis can be used in the subsequent prediction of movements in similar soils. However, there are also other soil parameters to be selected and some of them may be affected interactively. Therefore, it is not easy to determine soil modulus parameters by back analysis method. Modeling soil with a proper material model of the desirable finite element software is an important aspect of the back-analysis study (Charles et al., 1998).

In this thesis, $25.0 \mathrm{~m}$ depth of excavation supported by contiguous bored piles and multilayered anchorages system in an Ankara Clay is back analyzed by automizing the system using Python programming language interacted with Plaxis finite element software. The back analyzed section is in Söğ̈̈tözü district of Ankara, and the movements of the system were recorded by an inclinometer. This process would help to improve and refine our understanding about the soil deformation modulus parameters of Ankara Clay and which soil model would give a more accurate result. 


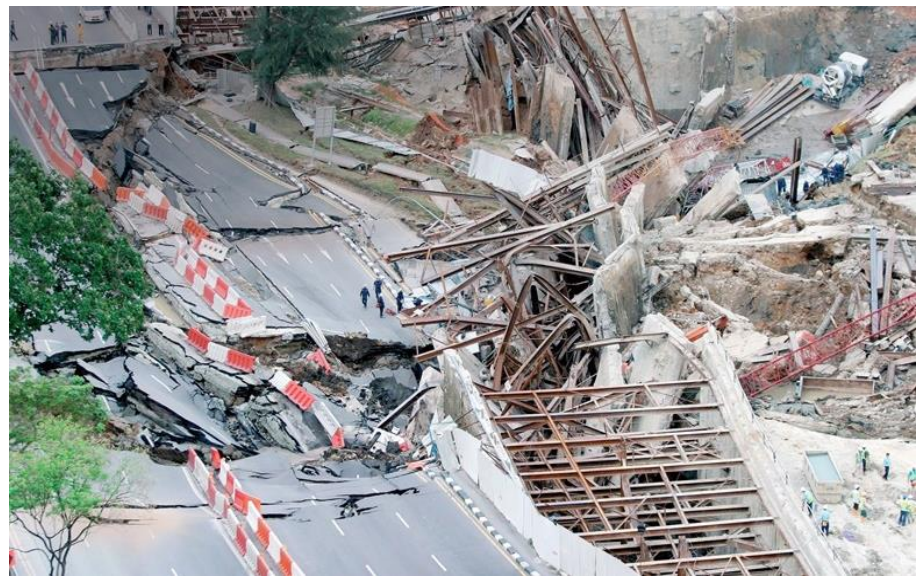

Figure 1.1. Excavation After Failure Nicoll Highway Singapore on April 2004 (source:newcivilengineer.com )

a).

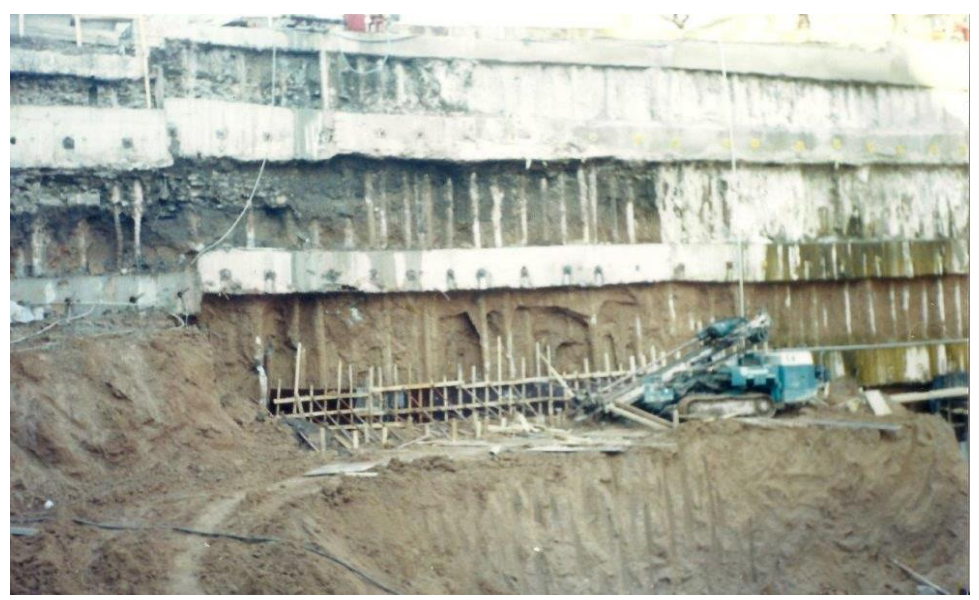

b).

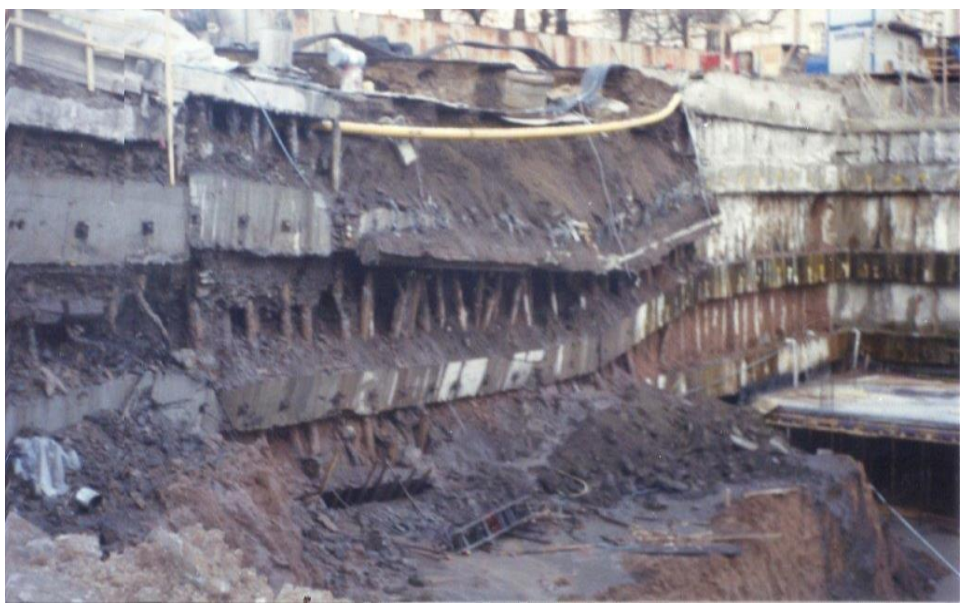

Figure 1.2. Deep Excavation Failure in Ankara a). Before the Failure b). After the Failure (Çalışan, 1994) 


\subsection{Research Objectives}

The objectives of this thesis are given below:

- Determining the linear relationship between $\mathrm{SPT} \mathrm{N}_{60}$ value and deformation modulus parameter of Ankara clay (E' and $\mathrm{E}_{50}{ }^{\text {ref }}$ ) by writing a Python code in Plaxis 2D for three constitutive soil models, which are Mohr Coulomb (MC) model, hardening soil (HS) model and hardening soil model with small strain stiffness (HSsmall).

- Evaluating the performance of soil models in terms of their ability to estimate the measured displacement distribution along the depth from the field.

- Comparing the performances of each soil model according to measured and predicted displacements.

\subsection{Outline of the Thesis}

This thesis includes six (6) chapters. It starts with the literature review part in Chapter 2. First, movements predicted by several researchers according to field measurements are given to provide awareness of expected movements of deep excavations in stiff and soft clays. Then, in order to understand the engineering properties of the Ankara clay, studies that show index and stiffness properties of Ankara clay are summarized. Chapter 2 continues with the results of similar back analysis studies carried out in different soils. In the final part of this chapter, background information about constitutive soil models used in the back analysis is included.

In Chapter 3, properties of the field for which back analysis study will be performed are summarized. Details of the shoring and support system are given. Also, the results of some laboratory and field tests conducted on the site are presented. Finally, instrumentation of the shoring system is mentioned and the inclinometer measurement of the back analyzed section is presented. 
In Chapter 4, creation of the model geometry and input parameters used in Plaxis 2D analyses are presented. Also, details about the Python code which provides remote control of Plaxis is explained in detail.

In Chapter 5, results of the back-analysis studies and discussion of results are given.

In Chapter 6, a summary of the thesis and conclusions are presented, and brief information about future work is given. 



\section{CHAPTER 2}

\section{LITERATURE REVIEW}

Deep excavations, especially performed in urban areas, may cause excessive ground displacements that can damage surrounding structures and soils. Therefore, it is significant to predict these movements to minimize the effect of ground displacements. Unfortunately, the estimation of these displacements is not easy, since there are several factors that affect the movements of deep excavations such as type of retaining wall, soil conditions, dewatering, construction sequences, climate conditions, time effect, etc. (Wang et al. [2010]). It is difficult to consider all these factors while evaluating the performance of deep excavations. Therefore, several researchers (Peck [1969], Goldberg et al. [1976], Clough et al. [1990], Long [2001]) made some predictions, based on site observations, for stiff and soft clays to find the displacement magnitudes of the surrounding soil. Studies of these researchers are summarized to better understand the behavior of stiff clays, like Ankara clay which is presented in Section 2.1.

The uncertainties of the engineering properties of soils (consolidation, stiffness, strength and flow) result with inaccurate predictions of soil movements. According to Christian [1989], there are two main reasons of these uncertainties: (1) inadequate number of laboratory and field tests that show properties of all soil layers; and (2) approximation of soil behavior utilized in finite element analysis. Therefore, in finite element analysis, the selection of appropriate engineering parameters of soils and modeling of soil layers with suitable constitutive soil models are very important to obtain more realistic movements. Thus, having detailed information about soil parameters of the site to be studied becomes crucial. Studies of several researchers on the engineering properties of Ankara clay are investigated and given in section 2.2. Also, for better predicting the soil parameters, back analysis plays an important role 
which is explained in detail with some relevant studies in Section 2.3. Furthermore, for better understanding the capabilities of commonly used soil models of Plaxis (MC, HS and HSsmall), theory of each model is explained in Section 2.4.

\subsection{Movements}

The general behavior of deep excavations can be explained as follows. During excavation with the removal of soil, weight on the soil below the cut is reduced, as a result, the soil in the excavation level has a tendency of moving upwards. Moreover, while soil on the side has a tendency of moving toward excavated area, soil on the ground surface has a tendency to move down and toward excavation horizontally. These movements may damage adjacent structures or surface installations; therefore, estimation of the magnitude and the distribution pattern of these movements have an utmost importance.

In order to control the behavior of wall and surrounding facilities, instrumentation of deep excavations is performed before any excavation work starts in the field. There are many instrumentations and monitoring equipment summarized in Table 2.1. Inclinometers, piezometers, vertical and horizontal extensometers, EDM are instruments frequently used in deep excavation projects to measure vertical and horizontal movements of both wall and adjacent facilities. Also, in deep excavation projects load cells can be placed on struts or anchor heads to check the project load.

Clough et al. (1990) state that movements of in-situ walls are affected by several factors. These factors include depth and shape of the excavation, construction methods of the wall, the groundwater and soil conditions, surcharge loads, stiffness and type of the wall, and type of wall support. According to Clough et al. (1990), all possible factors should be considered to estimate wall movements. In this part of the thesis, these movements and factors mentioned above will be considered for stiff and soft clays. 
Table 2.1. Instrumentation and Monitoring of Deep Excavations (Ergun, 2008)

\begin{tabular}{|c|c|}
\hline Measurement & Suitable instruments \\
\hline $\begin{array}{l}\text { 1. Settlement of ground } \\
\text { surface,structures and top of } \\
\text { supporting wall }\end{array}$ & $\begin{array}{l}\text { *Surveying methods and instruments } \\
\text { (i.e. transit, level) } \\
\text { *Rod settlement gauges }\end{array}$ \\
\hline $\begin{array}{l}\text { 2. Horizontal deformation of ground } \\
\text { surface, structure and exposed part } \\
\text { of supporting wall }\end{array}$ & $\begin{array}{l}\text { *Surveying methods (transit, tape, } \\
\text { EDM) } \\
\text { *Convergence gages } \\
\text { *Plumb lines } \\
\end{array}$ \\
\hline $\begin{array}{l}\text { 3. Subsurface horizontal } \\
\text { deformation of ground }\end{array}$ & $\begin{array}{l}\text { *Inclinometer } \\
\text { *In-place inclinometer } \\
\text { *Fixed borehole extensometers } \\
\text { *Borehole settlement gauges }\end{array}$ \\
\hline $\begin{array}{l}\text { 4. Subsurface settlement of ground } \\
\text { and utilities }\end{array}$ & $\begin{array}{l}\text { *Subsurface settlement points } \\
\text { *Probe extensometers } \\
\text { *Fixed borehole extensometers } \\
\text { *Borehole settlement gauges }\end{array}$ \\
\hline 5. Earth pressure acting on walls & *Total pressure cells \\
\hline 6. Flexural stresses on walls & $\begin{array}{l}\text { *Differential strain gages } \\
\text { *Reinforcing bar gauges }\end{array}$ \\
\hline $\begin{array}{l}\text { 7. Load in bracing (struts) or } \\
\text { anchors }\end{array}$ & $\begin{array}{l}\text { *Surface mounted vibrating wire } \\
\text { strain gauges } \\
\text { *Surface mounted mechanical strain } \\
\text { gages } \\
\text { *Calibrated hydraulic jack and load } \\
\text { cell } \\
\text { *Load cells }\end{array}$ \\
\hline 8. Groundwater pressure & $\begin{array}{l}\text { *Piezometers } \\
\text { *Auto water level recorder } \\
\text { *Electric water level sensors }\end{array}$ \\
\hline 9. Bottom heave & $\begin{array}{l}\text { *Magnet-reed switch gauges } \\
\text { *Mechanical heave gauges } \\
\text { *Fixed borehole extensometer } \\
\text { *Inclinometer }\end{array}$ \\
\hline $\begin{array}{l}\text { 10. Change in width of cracks in } \\
\text { structures and utilities }\end{array}$ & *Crack gauges \\
\hline 11. Temperature of strut & *Differential thermometer \\
\hline
\end{tabular}




\subsubsection{Stiff Clays}

Basal stability is not an important concern in stiff clays, sands and residual soils except in unusual cases (Clough et al. 1990). According to Peck's 1969 data, horizontal movements of excavation support systems in stiff clays were restricted by $1.0 \% \mathrm{H}$, where $\mathrm{H}$ is the excavation depth. Later, Goldberg et al. (1976) indicated that the settlements of the retained soil masses in stiff clays and residual soils, and the maximum lateral displacements for in-situ walls were usually less than $0.5 \% \mathrm{H}$. Then Clough et al. (1990) prepared a graph that includes Goldberg's data by adding new information on conventional walls and including soil nailed wall movements (Figure 2.1 and Figure 2.2). According to these figures, it can be understood that the maximum lateral displacements tend to average about $0.2 \mathrm{H} \%$, while the maximum settlements tend to average about $0.15 \% \mathrm{H}$, although there is some scatter. This means that lateral displacements are higher than the vertical displacements in stiff clays. Moreover, lateral and vertical displacements are not significantly dissimilar for different types of walls.

Clough et al. (1990) also emphasize that the data approximately follow a linear relationship with a depth of excavation around the $0.2 \mathrm{H} \%$ trend line. Therefore, the authors performed finite element analyses using elastic soil behavior assumption by considering several parameters significant to in-situ wall performance, which are support spacing, wall stiffness, soil stiffness and the coefficient of lateral earth pressure. The estimated maximum lateral wall displacement $\left(\delta_{h, \max }\right)$ as a function of depth of excavation $(\mathrm{H})$ can be seen from Figure 2.3. Clough et al. (1990) observed that the predicted response shown in Figure 2.3 provides consistent results with the average observed behavior in Figure 2.1. It is also understood that stiffness of the wall and spacing between struts have a little impact while a coefficient of lateral earth pressure and soil modulus have a significant influence on displacements of stiff clays. 


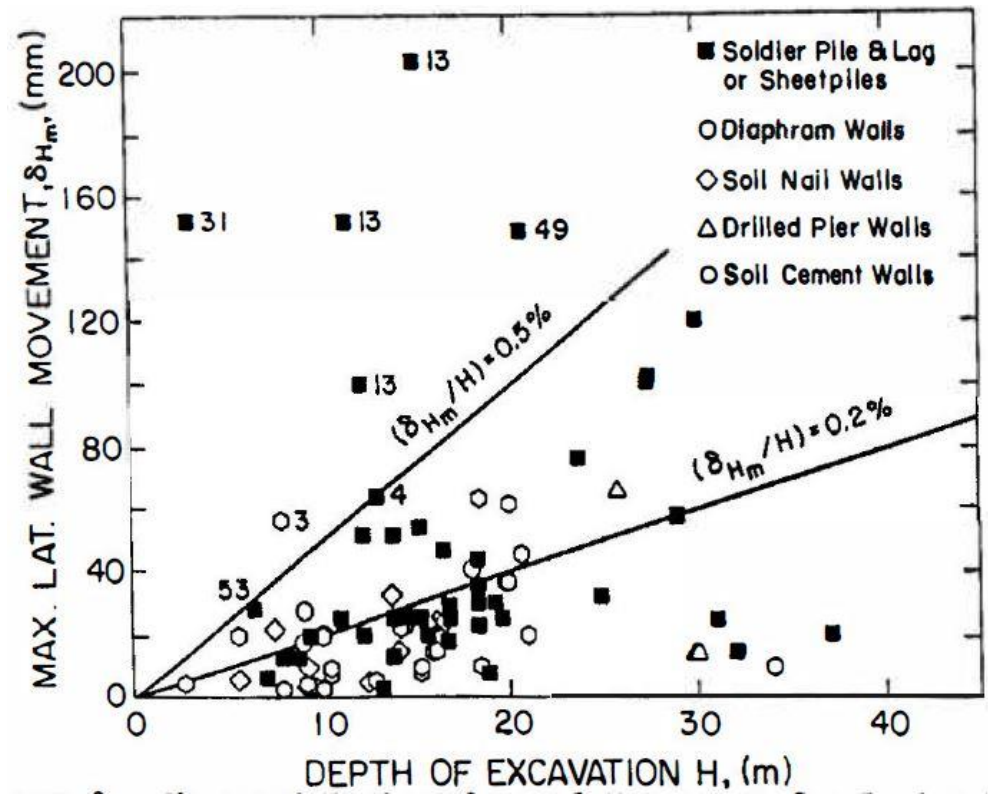

Figure 2.1. Observed Maximum Lateral Displacements in Stiff Clays, Sands and Residual Soils (Clough et al. 1990)

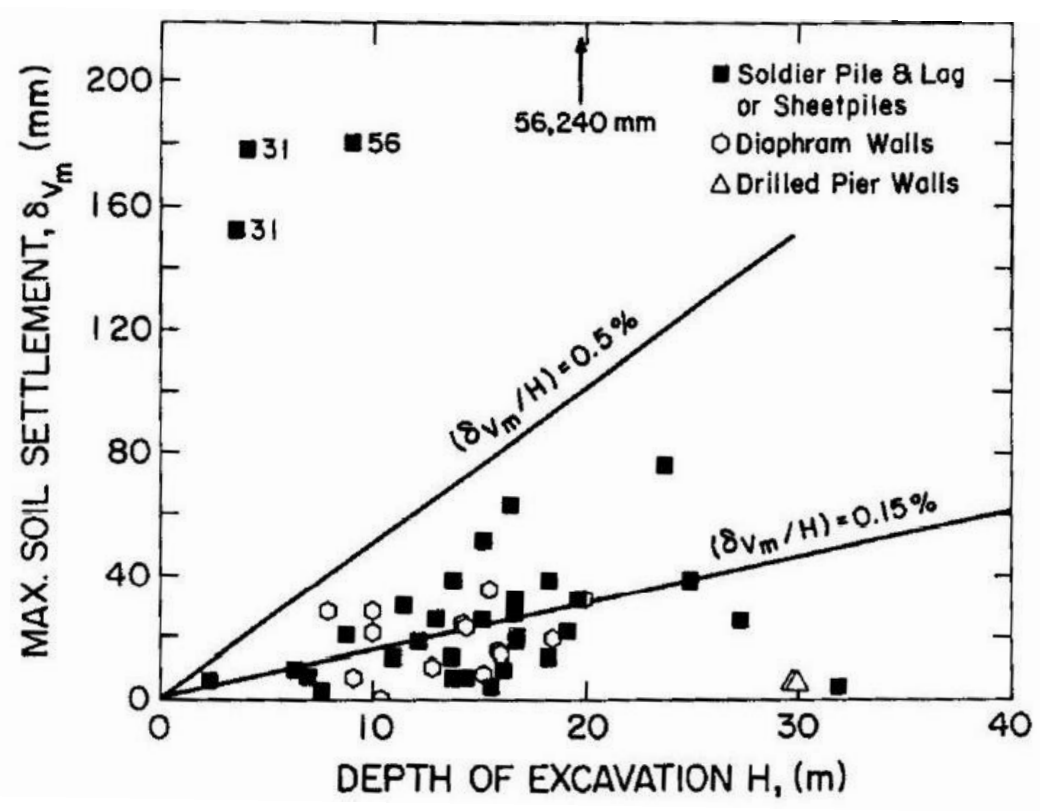

Figure 2.2. Observed Maximum Settlements in Stiff Clays, Sands and Residual Soils (Clough et al. 1990) 


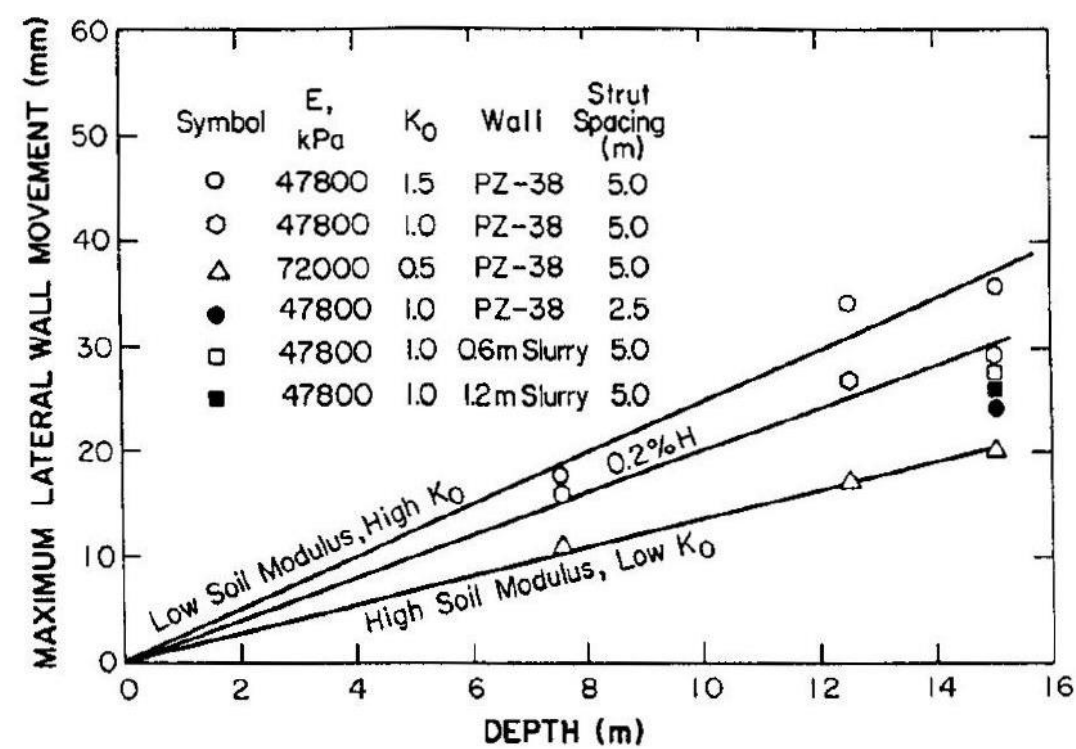

Figure 2.3. Finite Element Analysis Results to Predict Maximum Lateral Wall Displacements (Clough et al. 1990)

Long (2001) presented a database of 300 case histories related to wall and ground movements related to deep excavations. Author found out that for top-down, propped and anchored systems, average values of $\delta_{h, \max }$ come out to be $0.16 \% \mathrm{H}, 0.17 \% \mathrm{H}$ and $0.19 \% \mathrm{H}$, respectively (Figure 2.4 ). It is also stated that these values reduce up to $0.16 \% \mathrm{H}, 0.13 \% \mathrm{H}$ and $0.14 \% \mathrm{H}$ when cases where $\frac{\delta_{h, \max }}{H}>0.3 \%$ (cases involving particular site related problems) are extracted. These values are much lower than Clough et al. (1990) findings which is $0.20 \% \mathrm{H}$. Figure 2.4 and Figure 2.5 shows that propped systems and anchored ones have similar $\delta_{h, \max } / H$ values; however top-down systems show surprisingly poorer values than the others. The reason for this difference is thermal shrinkage of concrete in the supporting slabs.

Long (2001) plotted the $\delta_{h, \max } / H$ data with respect to system stiffness in as defined by Clough et al. (1989) (Figure 2.5) as $E I / \gamma_{w} s^{4}$ where;

It can be seen from Figure 2.5 that the majority of the data points are below the Clough and O'Rourke (1990) line and it is seen that movements decrease with increasing 
system stiffness. However, as mentioned by Long (2001) for the range of data available in the study investigated, lateral wall displacement is independent from system stiffness. Long (2001) presents a much stiffer behaviour of soils than the one assumed by Clough and O' Rourke (1990).

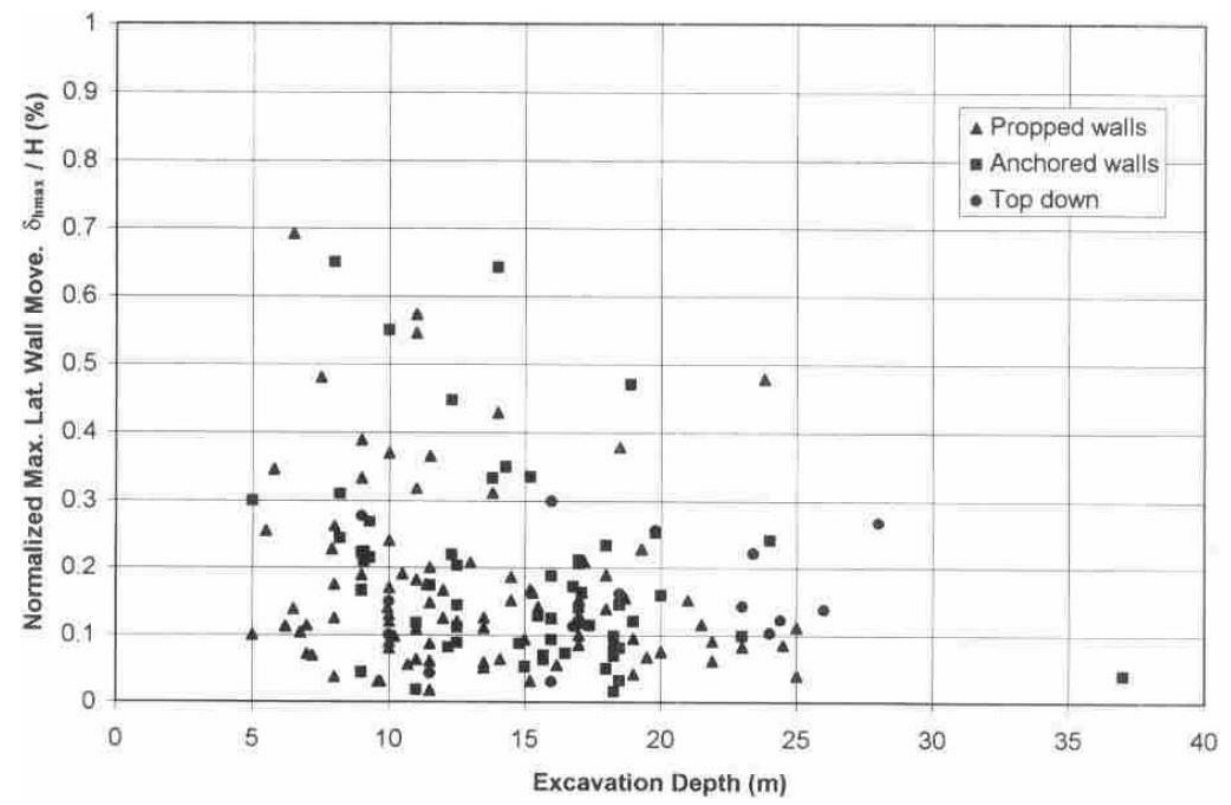

Figure 2.4. Normalized Maximum Horizontal Movement vs. Depth (Long 2001) 


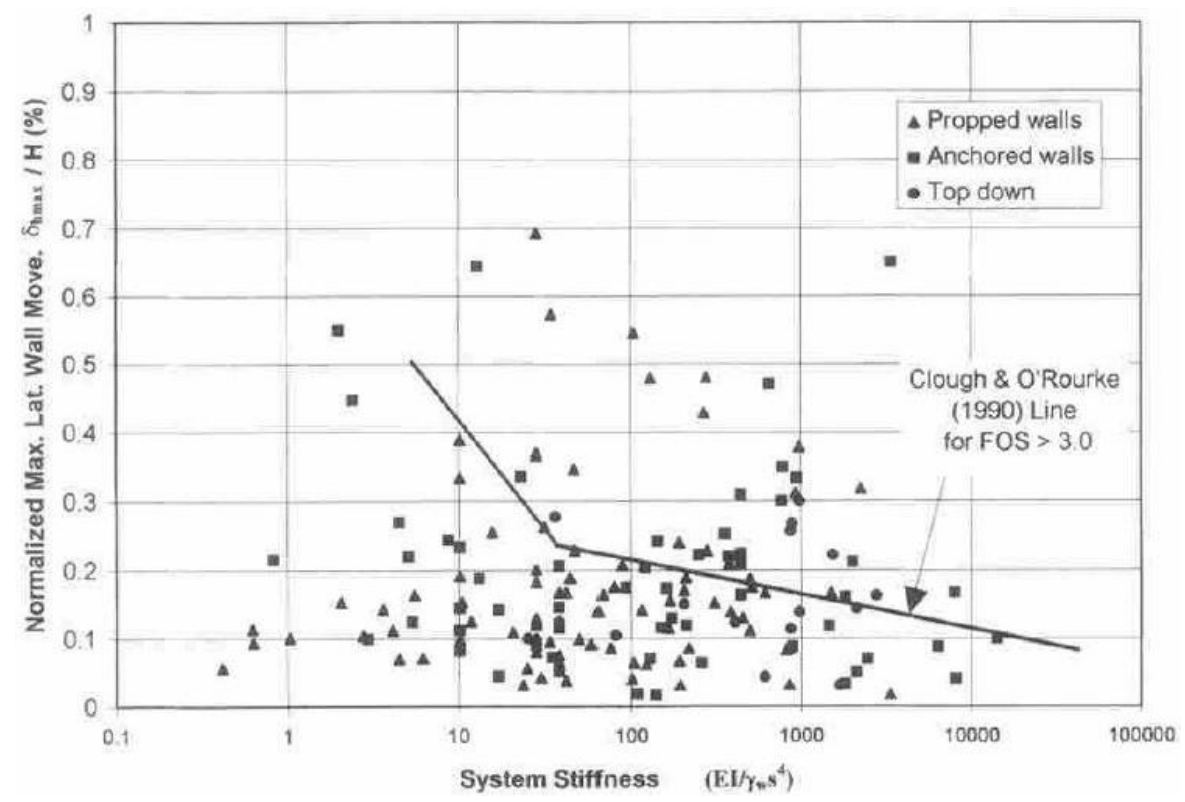

Figure 2.5. Normalized Maximum Lateral Movement vs. Clough et al. (1989) System Stiffness (Long 2001)

\subsubsection{Soft and Medium Stiff Clays}

As opposed to stiff soils, Clough et al. (1990) states that strut spacing and wall stiffness can have a significant effect on movements in soft to medium stiff clays especially when FS is low.

Basal stability is a significant issue in soft and medium stiff clays different from stiff clays. This situation was emphasized by Mana and Clough (1981) and they showed the essential role of the factor of safety against basal heave on the lateral deflections with their study by using both field measurements and finite element analyses. Figure 2.6 shows that displacements show a rapid rise when the factor of safety against basal heave decreases below 1.5. On the other hand, stability of the base is ensured if the FS passes over 2.0 and in such a case maximum displacements decrease below $0.5 \% \mathrm{H}$, which is consistent with the stiff clays' behavior shown in Figure 2.1 and Figure 2.2. However, when the factor of safety approaches to 1.0 , more than $2.0 \% \mathrm{H}$ movement may occur even for a well-constructed wall. 
Mana and Clough (1981) also examined the effect of strut spacing, wall stiffness, excavation width, preloads, depth to an underlying firm level and the modulus of soil on the horizontal movements. They concluded that:

- Movements are reduced when bending stiffness of the wall increases or spacing between struts decreases, or both. This situation is related to factor of safety against basal heave which is more important at lower FS.

- Movements are raised when depth to an underlying firm layer or excavation width are increased.

- Movements decrease with increasing preloads in the struts. However, if higher preloads are used, decrease effect on the movements is decelerated.

- Soil modulus as characterized by the modulus multiplier, M, have a strong effect on movement levels $\left(\mathrm{E}=\mathrm{M} \times \mathrm{c}_{\mathrm{u}}\right)$.

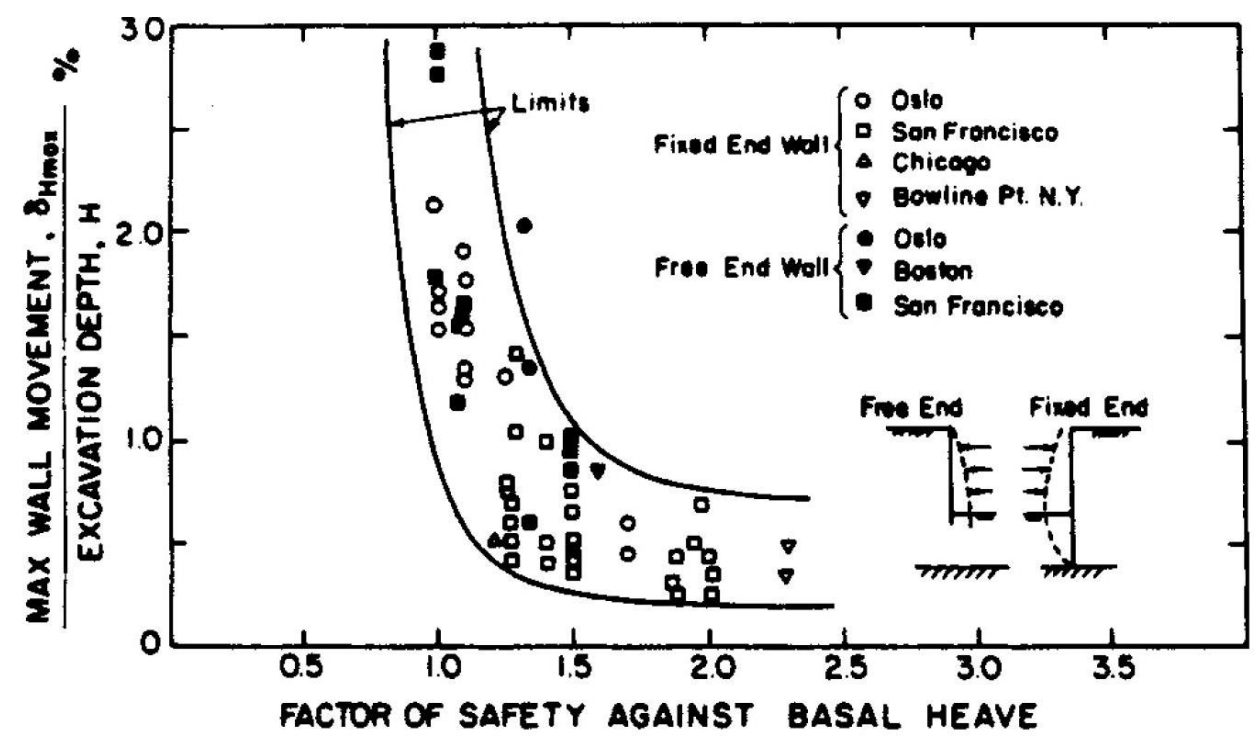

Figure 2.6. Factor of Safety Against Basal Heave vs. Normalized Maximum Wall Movement (Mana and Clough, 1981)

Clough et al. (1990) also presents design curves in order to obtain maximum lateral wall movement for soft to medium stiff clays in their study (Figure 2.7). These design 
curves can be used for circumstances where the main reason of movements are excavation and support process. Figure 2.7 can also be used for predicting maximum soil settlement, because of the fact that the maximum soil settlement is almost equal to maximum lateral wall displacement.

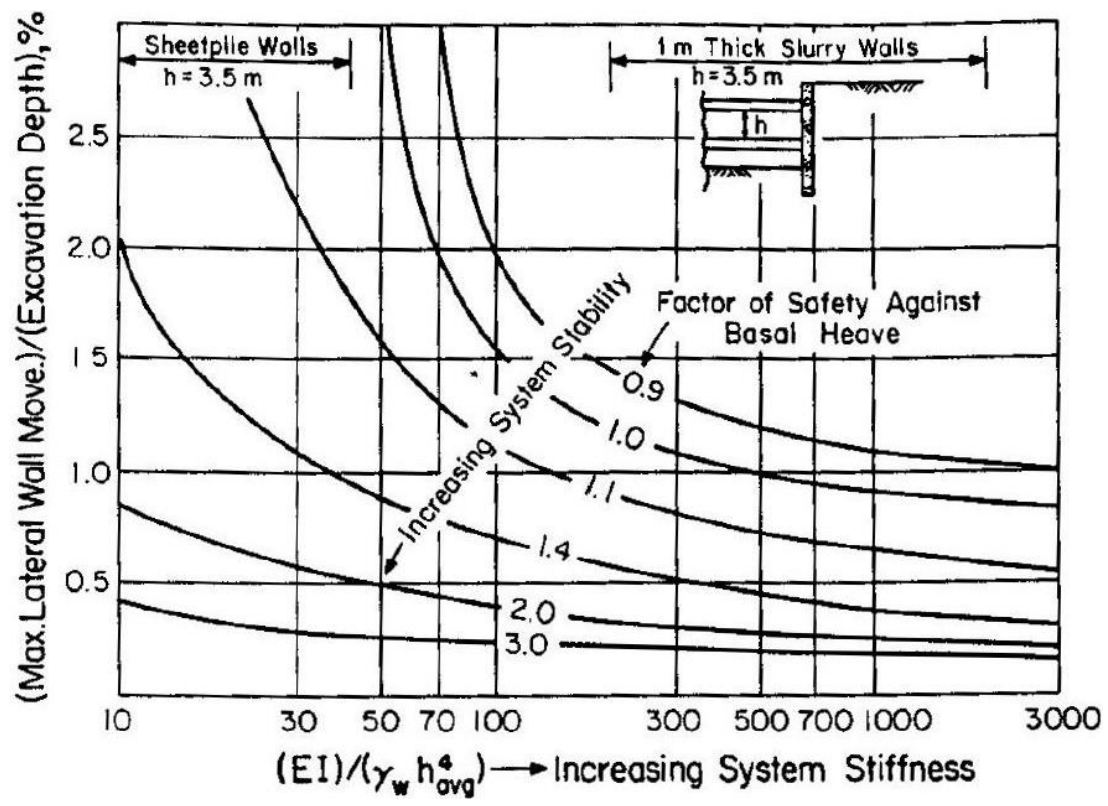

Figure 2.7. Design Curves to Obtain Maximum Horizontal Displacement (Clough et al. 1990)

Long (2001) divide soft to medium stiff clay zones' database into three categories. The first category includes soft soils with a high FS (FS > 3.0) against base heave, which contains stiff soil at the dredge level. The second category includes soft soils with again high FS against base heave, but this time system contains soft soil at the dredge level. The final category contains stiff soil at the dredge level like in the first category but in this case, FS is low.

Long (2001) found that lateral displacements of soft clays in the first category are higher than the displacements obtained from stiff clays. Both the anchored and the propped systems of the first category yield similar average $\delta_{h, \max } / H$ values which are 
$0.21 \%$ when cases where $\delta_{h, \max } / H>0.3 \%$ (cases involving particular site related problems) are extracted. The normalized maximum lateral movement vs system stiffness graph for the first category soft soil can be seen from Figure 2.8. Long (2001) defined a trend line at FS equals 3.0 for approximately representing the average of the data using the system stiffness.

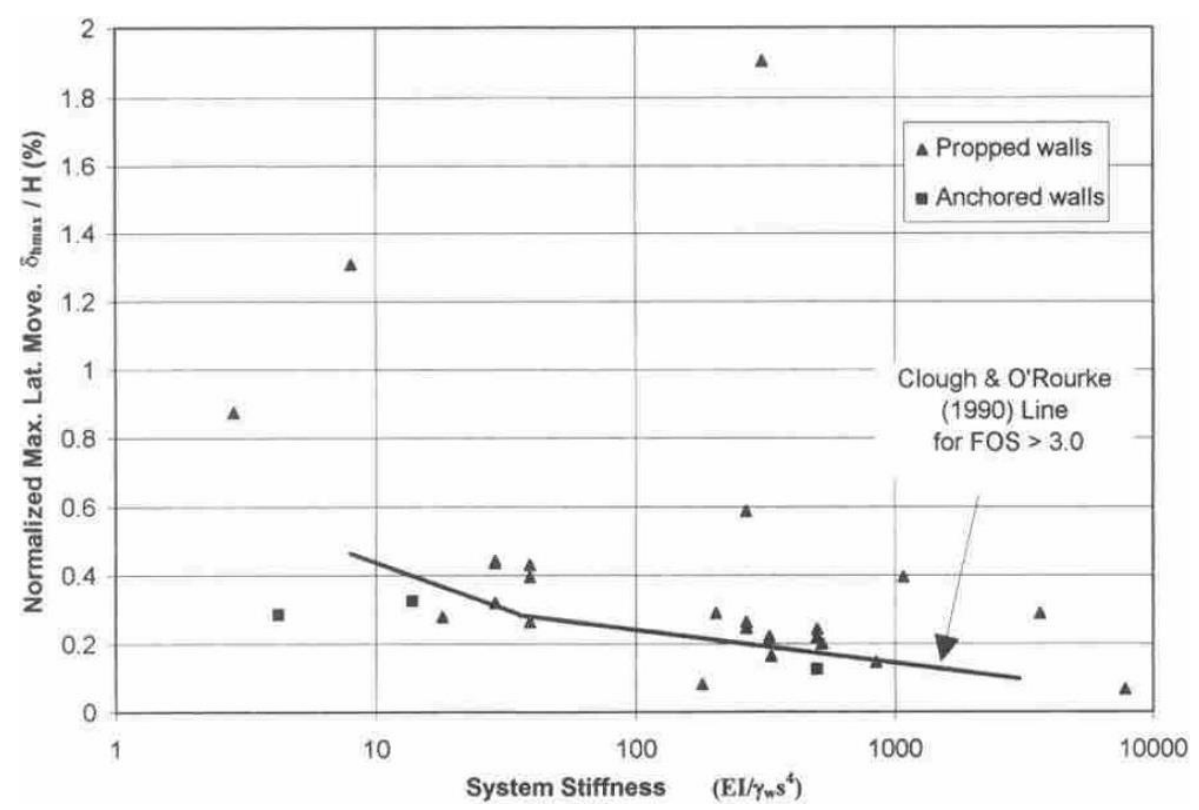

Figure 2.8. Normalized Maximum Lateral Movement vs. Clough et al. (1989) System for Soft Soils with High F.S. against Base Heave and Stiff Soil at the Dredge Level (Long 2001)

Long (2001) found that normalized average lateral movements $\left(\delta_{h, \max } / H\right)$ of soft soils in the second category are $0.84 \%$ and $0.91 \%$ for the propped and anchored system, respectively. These lateral movements are considerably higher than the movements obtained from the first category soft clays. Long (2001) states that the cause of large movements is apparently the inadequacy of lateral support to the retaining wall at dredge level as soft soil conditions are presented at this location. In addition, Long (2001) states that much greater movement values are observed 
compared to the ones predicted. For second category soft soils, the normalized maximum lateral movement vs system stiffness graph is presented in Figure 2.9.

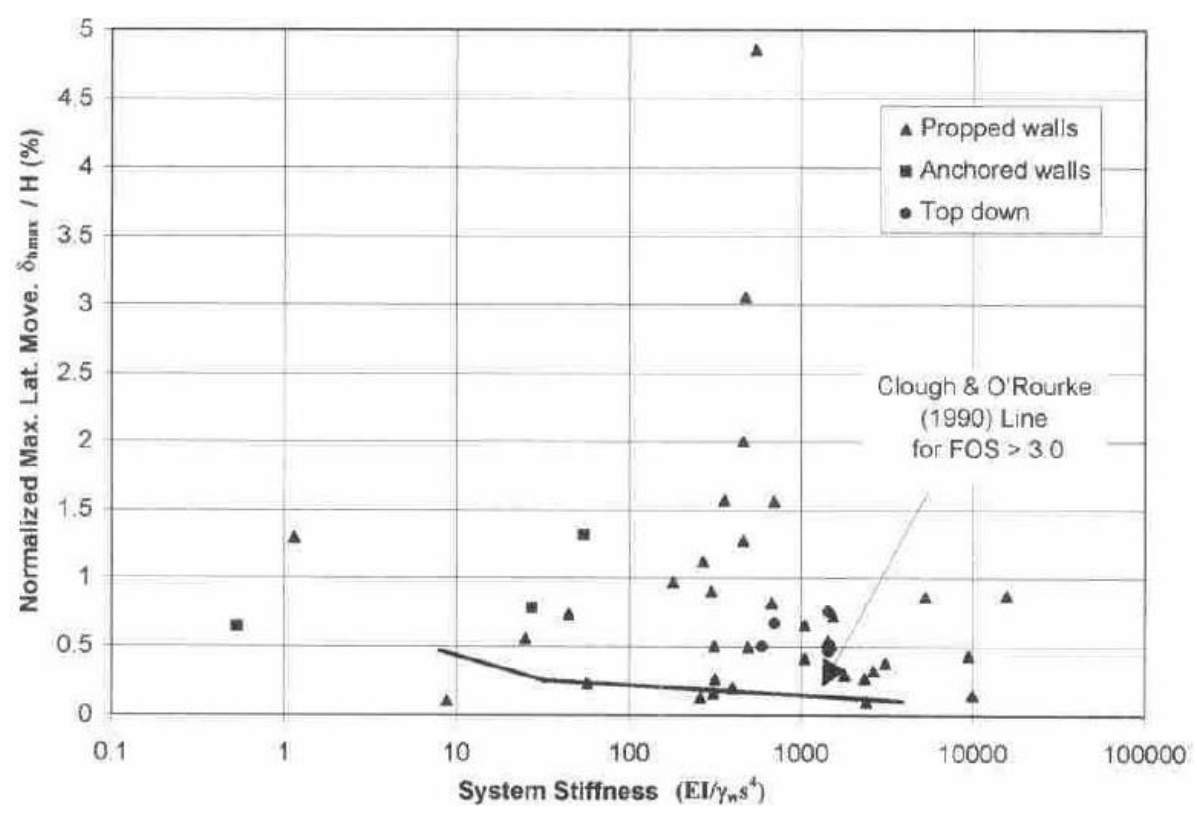

Figure 2.9. Normalized Maximum Lateral Movement vs. Clough et al. (1989) System for Soft Soils with High FS Against Base Heave and Soft Soils at the Dredge Level (Long 2001)

For the third category Long (2001) found out that movements tend to decrease with increasing FS. Long (2001) also states that the dependency of movements to factor of safety decreases for the FS range of 1.0 to 1.5. Furthermore, he claims that for factor of safeties lower than 0.9, movement values up to $3.2 \%$ have been recorded. Based on the data set Long investigated, he concludes that most of the values lie between the limits which are suggested by Mana and Clough (1981) even though their study differs in the way of finding FS. Therefore, Long (2001) proposes the use of Mana and Clough's (1981) design charts for preliminary prediction of movements for this third category. Results obtained by Clough et al. (1990) and Long (2001) are summarized at Figure 2.10. 


\begin{tabular}{|c|c|c|c|c|c|c|}
\hline Reference & \multicolumn{4}{|c|}{ Long, 2001} & \multicolumn{2}{|c|}{ Clough and O'Rourke (1990) } \\
\hline Type of soil & $\begin{array}{r}\text { Max } \\
\text { later: } \\
\text { move } \\
\text { norma } \\
\text { exca } \\
\text { height, } \\
\end{array}$ & $\begin{array}{l}\text { mum } \\
\text { I wall } \\
\text { ments } \\
\text { ized by } \\
\text { ation } \\
\delta_{\text {tmax }} / \mathrm{H} \\
\text { 6) }\end{array}$ & $\begin{array}{r}\text { Maxi } \\
\text { vert } \\
\text { settle } \\
\text { normal } \\
\text { excav } \\
\text { height, } \\
\text { ( }\end{array}$ & $\begin{array}{l}\text { mum } \\
\text { ical } \\
\text { ments } \\
\text { ized by } \\
\text { ation } \\
\delta_{\mathrm{vmax}} / \mathrm{H} \\
\text { o) }\end{array}$ & $\begin{array}{c}\text { Maximum } \\
\text { lateral wall } \\
\text { movements } \\
\text { normalized by } \\
\text { excavation } \\
\text { height, } \delta_{\text {hmax }} / \mathrm{H} \\
(\%)\end{array}$ & $\begin{array}{c}\text { Maximum } \\
\text { vertical } \\
\text { settlements } \\
\text { normalized by } \\
\text { excavation } \\
\text { height, } \delta_{\text {vmax }} / \mathrm{H} \\
(\%)\end{array}$ \\
\hline $\begin{array}{l}\text { Supporting } \\
\text { system }\end{array}$ & $\begin{array}{c}\text { Strut } \\
\text { support }\end{array}$ & $\begin{array}{l}\text { Anchor } \\
\text { support }\end{array}$ & $\begin{array}{c}\begin{array}{c}\text { Strut } \\
\text { support }\end{array} \\
\end{array}$ & $\begin{array}{l}\text { Anchor } \\
\text { support }\end{array}$ & \multicolumn{2}{|c|}{ Not relevant } \\
\hline $\begin{array}{l}\text { Stiff soils, high } \\
\text { factor of safety } \\
\text { of base heave }\end{array}$ & $\begin{array}{l}0.13 \\
(81)^{\circ}\end{array}$ & $\begin{array}{l}0.14 \\
(50)\end{array}$ & $\begin{array}{l}0.11 \\
(35)\end{array}$ & $\begin{array}{l}0.12 \\
\text { (15) }\end{array}$ & 0.20 & 0.15 \\
\hline $\begin{array}{c}\text { Soft soils, high } \\
\text { factor of safety } \\
\text { of base heave, } \\
\text { stiff soil at } \\
\text { dredge level }\end{array}$ & $\begin{array}{l}0.21 \\
(14)\end{array}$ & $\begin{array}{l}0.21 \\
(2)\end{array}$ & $\begin{array}{l}0.39 \\
(7)\end{array}$ & $\begin{array}{c}0.14 \\
\text { (1) }\end{array}$ & \multirow{2}{*}{$<0.5$} & \\
\hline $\begin{array}{l}\text { Soft soils, high } \\
\text { factor of safety } \\
\text { of base heave, } \\
\text { soft soil at } \\
\text { dredge level }\end{array}$ & $\begin{array}{l}0.84 \\
\text { (35) }\end{array}$ & $\begin{array}{r}0.91 \\
\text { (3) }\end{array}$ & $\begin{array}{l}0.80 \\
(13)\end{array}$ & $\begin{array}{c}6.25 \\
(1)\end{array}$ & & \\
\hline $\begin{array}{l}\text { Soft soils, low } \\
\text { factor of safety } \\
\text { of base heave }\end{array}$ & \multicolumn{4}{|c|}{$\begin{array}{l}\text { Values as high as } 3.2 \% \text { have been } \\
\text { recorded for the factor of safety on } \\
\text { the ordet of } 0.9\end{array}$} & $>2.0$ & \\
\hline
\end{tabular}

(81) number of cases studied

Figure 2.10. Maximum Lateral Wall Movements and Vertical Settlements Behind Walls (Ergun, 2008)

\subsection{Studies on Ankara Clay}

Soils in Ankara region can be classified into three main groups. These are residual soils, recent alluvium deposits, and deposits of Pliocene or Ankara clay. Deposits of Pliocene or Ankara clay is the formation which has the largest surface area on the basin. Figure 2.11 shows the geology map of Ankara. 


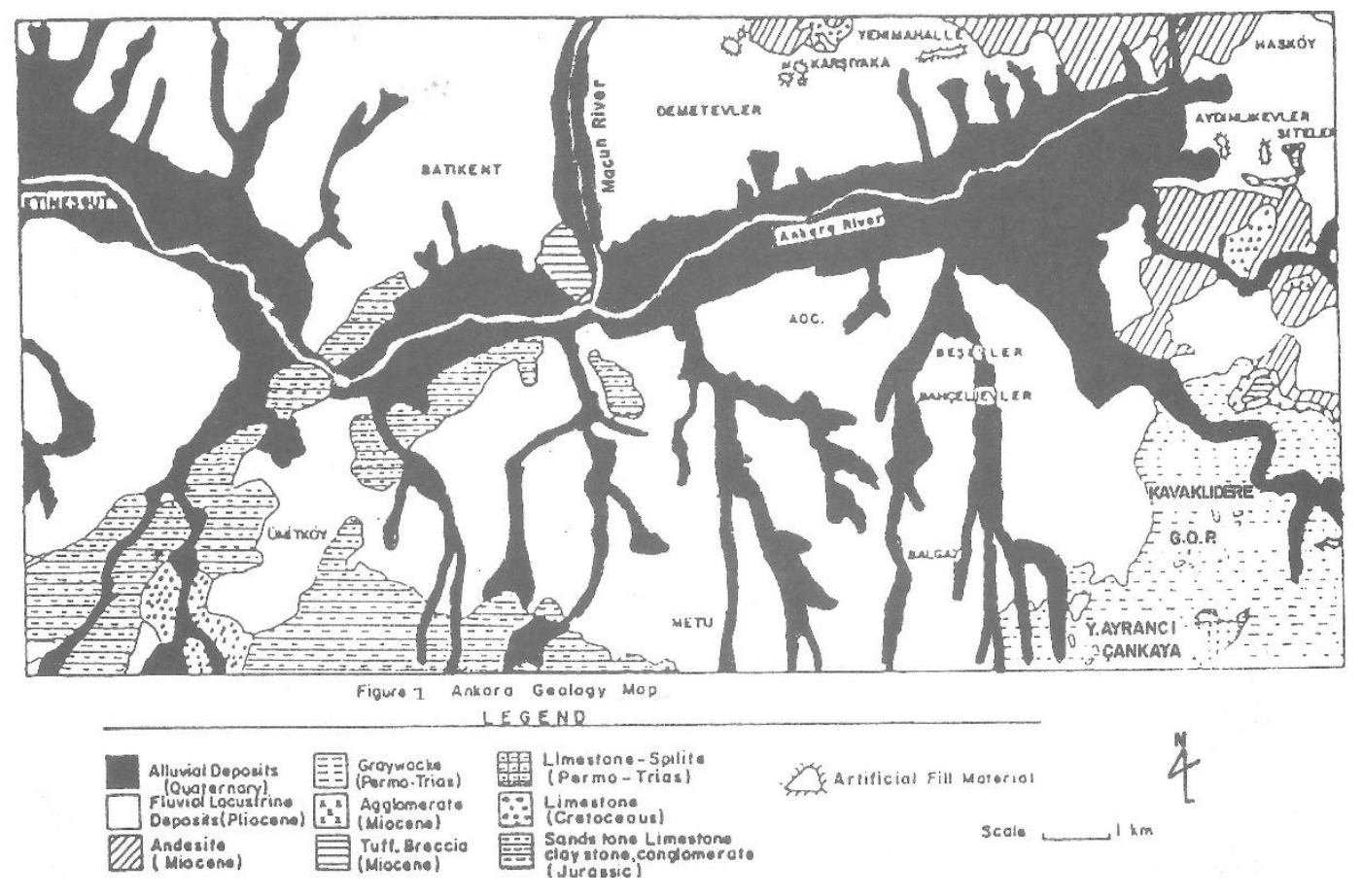

Figure 2.11. Geology Map of Ankara (Cokca, 2000)

Ordemir et al. (1965) and later Birand (1978) described the Ankara clay as reddishbrown and brown in color, stiff, preconsolidated, inorganic, fissured and highly plastic clay. Kiper (1983) divided Pliocene/Ankara clay into two categories. Those are yellow or gray Ankara clay in Etimesgut - Batıkent region and reddish brown Balgat member which are the dominant ones.

The formation predominantly comprises of clay, there are also gravelly and sandy levels within the soil (Ergüler and Ulusay, 2003). Moreover, lime levels, slickensides, and hair cracks network are usually present in the Ankara clay. Ordemir et al. (1965) stated that obtaining undisturbed samples and preparing them for laboratory testing is difficult because of the lime and fissures in the soil. The authors also emphasized that the Ankara clay is a suitable foundation material to support structures safely on individual or continues footings, and to carry heavy loads without an excessive settlement. On the other hand, heaving on the base of the excavation after exposure to 
atmosphere for a long time, and the swelling and creeping of even quite flat slopes after excavation can be a problem for this type of soil.

Several researchers have investigated geotechnical properties of Ankara clay in terms of consistency, shear strength, soil modulus, compressibility and swelling properties (Ordemir et al. [1965], Uçkan [1966], Günece [1968], Topkara [1974], Mirata [1976], Ekmekçioğlu [1975], Surgel [1976] and Çokça [1991]). These properties will be explained in the following sections.

\subsubsection{Consistency}

Ordemir et al. (1965) have performed some laboratory tests on the samples taken from different depths of different locations in Ankara. According to these laboratory test results, the authors concluded that;

- Ankara clay is an inorganic clay with high plasticity.

- The saturated unit weight of the clay varies within $1.75 \mathrm{t} / \mathrm{m}^{3}$ and $1.95 \mathrm{t} / \mathrm{m}^{3}$.

- The specific gravity of particles is between 2.60 and 2.70 .

- The shrinkage limit ranges between $15 \%$ and $20 \%$.

- The plastic limit (PL) and the natural water content (w) of the Ankara clay is in between $20 \%$ and $35 \%$, and the liquid limit (LL) vary within 55\% and 75\% (Figure 2.12).

- The liquid limit vs. plasticity index graph of the Ankara clay (Figure 2.13) was drawn. According to this graph, all points have a higher liquid limit than 50\% and lies above A-line. According to USCS classification system, soil is classified as high plasticity clay $(\mathrm{CH})$. 


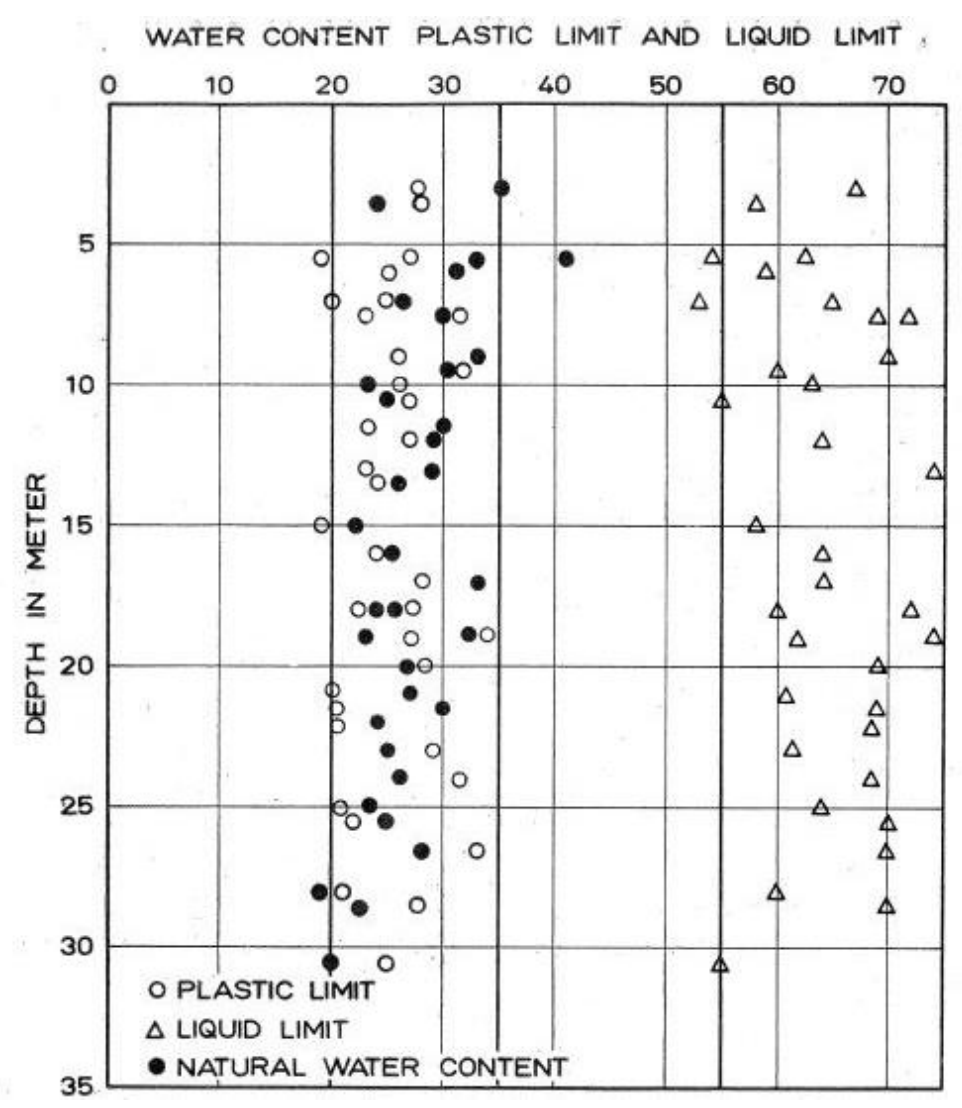

Figure 2.12. Atterberg Limits and Water Content of Ankara Clay (Ordemir et al. 1965)

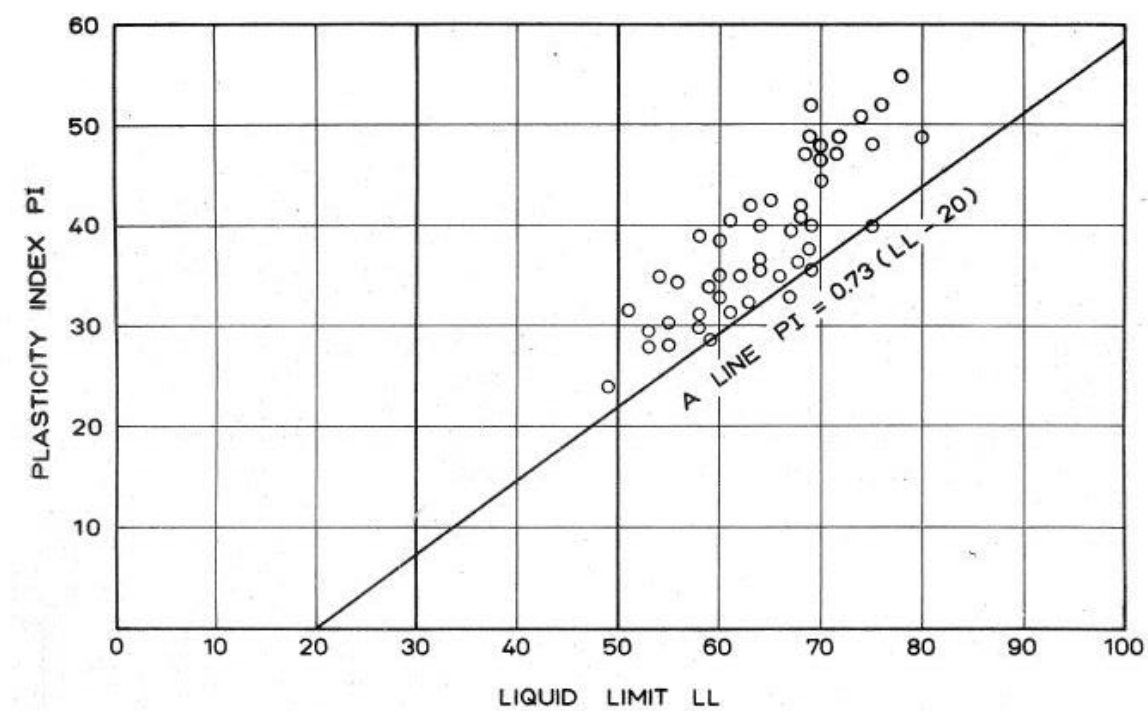

Figure 2.13. Plasticity Chart of Ankara Clay (Ordemir et al. 1965) 
Surgel (1976) collected data from the researches dating between 1963 and 1975 on Ankara soils, and he divided the Ankara soils into three categories, namely Alluvial soils, residual soils and terrace deposits based on Lohnes's Reconnaissance soils map. According to these classifications, the author determined the variation interval of bulk and index properties of the soil. Finally, the author concluded that;

- Plasticity index (PI) of the alluvial soils, residual soils and terrace deposits are in between 10 and 40\%, 21 and $41 \%$, and 20 and 40\%, respectively.

- Almost $75 \%$ to $\% 85$ of the samples of Ankara soils lie above the A-line, which is classified as $\mathrm{CH}$, according to USCS classification system.

- All of the soils seem to be preconsolidated because of the desiccation.

\subsubsection{Shear Strength}

Several researchers have conducted a study to determine shear strength parameters of Ankara clay. Ordemir et al. (1965) determined unconfined compressive strength $\left(\mathrm{q}_{\mathrm{u}}\right)$ values of the samples taken from Middle East Technical University (METU) campus as varying between 2.5 and $3.5 \mathrm{~kg} / \mathrm{cm}^{2}$. Moreover, they found that the friction angle of the samples is in between $20^{\circ}$ and $25^{\circ}$ via consolidated undrained triaxial tests. Also, they concluded that samples tend to fail along fissures both in the unconfined compression test and the triaxial test.

Uçkan (1966), Inal (1967), Günece (1968), Topkara (1974), and Ekmekçioğlu (1975) have carried out some direct shear tests on Ankara clay. Obtained peak strength parameters are in between $0.35 \mathrm{~kg} / \mathrm{cm}^{2}$ and $0.85 \mathrm{~kg} / \mathrm{cm}^{2}$ for cohesion and $23^{\circ}$ and $34^{\circ}$ for friction angle, respectively. The corresponding values for the residual strength alter between $0.25 \mathrm{~kg} / \mathrm{cm}^{2}$ and $0.45 \mathrm{~kg} / \mathrm{cm}^{2}$ and $18^{\circ}$ to $24^{\circ}$.

Mirata (1976) has also performed several consolidated undrained (CU) and unconsolidated undrained (UU) triaxial tests on the samples taken from (METU) campus. The author carried out the experiments in such a slow rate that a minimum of 95\% pore pressure dissipation is acquired. Obtained c' and $\phi$ ' values from the CU triaxial test results can be seen from Table 2.2. 
Table 2.2. Shear Strength Parameters Obtained from Triaxial Test Results (Mirata, 1976)

\begin{tabular}{|l|c|c|}
\hline Location & $\mathbf{c}^{\prime}\left(\mathbf{k g} / \mathbf{c m}^{\mathbf{2}}\right)$ & $\boldsymbol{\phi}^{\prime} \mathbf{( d e g )}$ \\
\hline $\begin{array}{l}\text { Metu Public Administration } \\
\text { Institute }\end{array}$ & 0.27 & 27.1 \\
\cline { 2 - 3 } & 0.13 & 25 \\
\hline \multirow{3}{*}{ Metu Campus Sports Hall } & 0.071 & 22.6 \\
\cline { 2 - 3 } & 0.033 & 30.5 \\
\cline { 2 - 3 } & 0.089 & 23.1 \\
\hline Metu Campus Math Department & 0.218 & 29.6 \\
\hline
\end{tabular}

A set of direct shear tests carried out on the samples, at natural water content, taken from different locations of (METU). The obtained peak strength parameters can be seen in Table 2.3 (Mirata, 1976).

Table 2.3. Shear Strength Parameters Obtained from Direct Shear Test Results (Mirata, 1976)

\begin{tabular}{|l|c|c|}
\hline Location & $* \mathbf{c}_{\mathbf{s}}\left(\mathbf{k g} / \mathbf{c m}^{2}\right)$ & $* \phi_{\mathbf{s}}(\mathbf{d e g})$ \\
\hline \multirow{2}{*}{$\begin{array}{l}\text { Metu Public Administration } \\
\text { Institute }\end{array}$} & 0.748 & 29.2 \\
\cline { 2 - 3 } & 1.028 & 31.8 \\
\hline \multirow{3}{*}{ Metu Campus Sports Hall } & 0.483 & 29.8 \\
\hline & 0.137 & 26 \\
\hline & 0.558 & 22.5 \\
\hline
\end{tabular}

$* \mathrm{c}_{\mathrm{s}}$ and $\phi_{\mathrm{s}}$ are shear strength parameters where "s" denotes slow shearing at which the full drainage could not be ensured

The water content has a significant impact on the shear strength of clays. It is remarkable that overconsolidated clays have a tendency of dilation, particularly after 
the peak resistance, during the shearing process. Increase in water content will result in part of the drop-in shear strength of this soil. Mirata (1976) has performed a direct shear test on the samples taken from (METU) campus clay and he concluded that an increase in water content has led to very low shear strength values.

Stroud (1974) constituted a correlation between the standard penetration resistance (N) and undrained shear strength of cohesive soils. The author used 1200 SPT N values taken from 42 sites around the U.K. from undrained triaxial tests, and he found a relation between SPT N and $c_{u}$ value (Equation 2.1);

$$
c_{u}=f_{1} \times N
$$

where $f_{1}$ is a variable which relies on the plasticity of the soil. The alteration of $f_{1}$ value with plasticity index can be seen in Figure 2.14. The undrained shear strength value proposed by Stroud (1974) was suggested by CIRIA (1995) for fissured overconsolidated clays.

According to Figure 2.14, $c_{u}=4 \sim 5 \times S P T N$ relation can be used for the Ankara clay by considering the PI \% (PI=LL-PL) values determined by various researchers (Ordemir et al., 1965 and Surgel, 1976) as in the range of 20-40. 


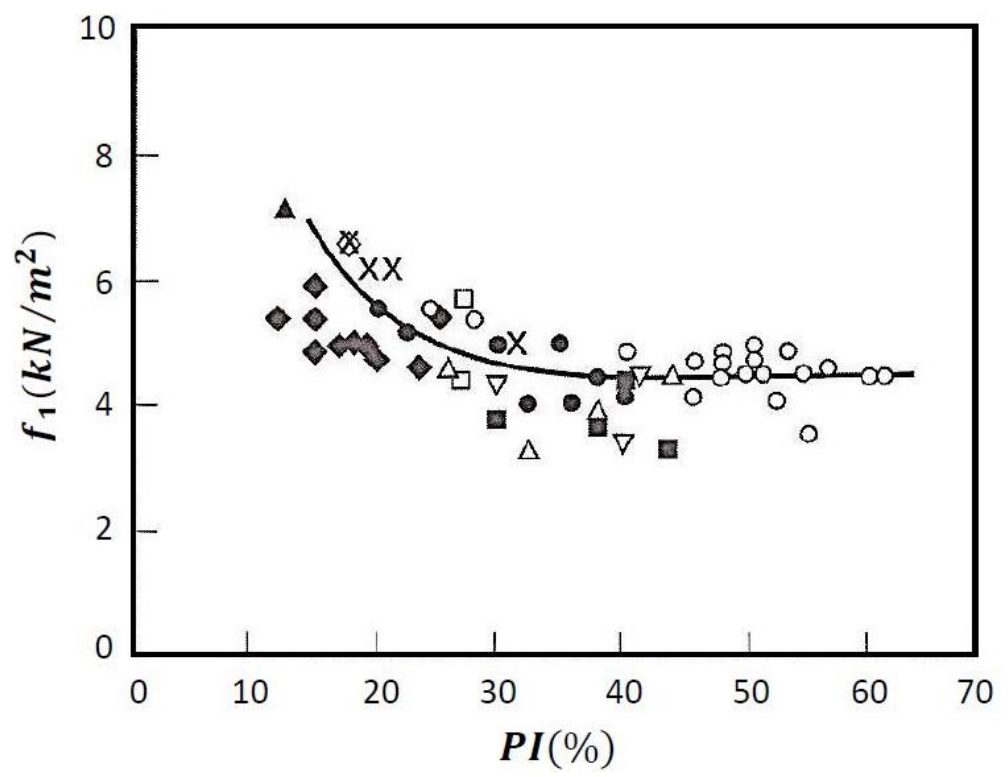

Figure 2.14. Variation of $\mathrm{f}_{1}$ Value with PI (\%) (Stroud, 1974)

Bowles (1996) prepared a graph (Figure 2.15) that represents correlation between effective friction angle $\left(\phi^{\prime}\right)$ and plasticity index $\left(\mathrm{I}_{\mathrm{p}}\right)$ for normally consolidated clays. The author took data from the sources of several researchers, Bjerrum and Simons (1960), Ladd et al. (1977), Kanja and Wolle (1977) and Olsen et al. (1986).

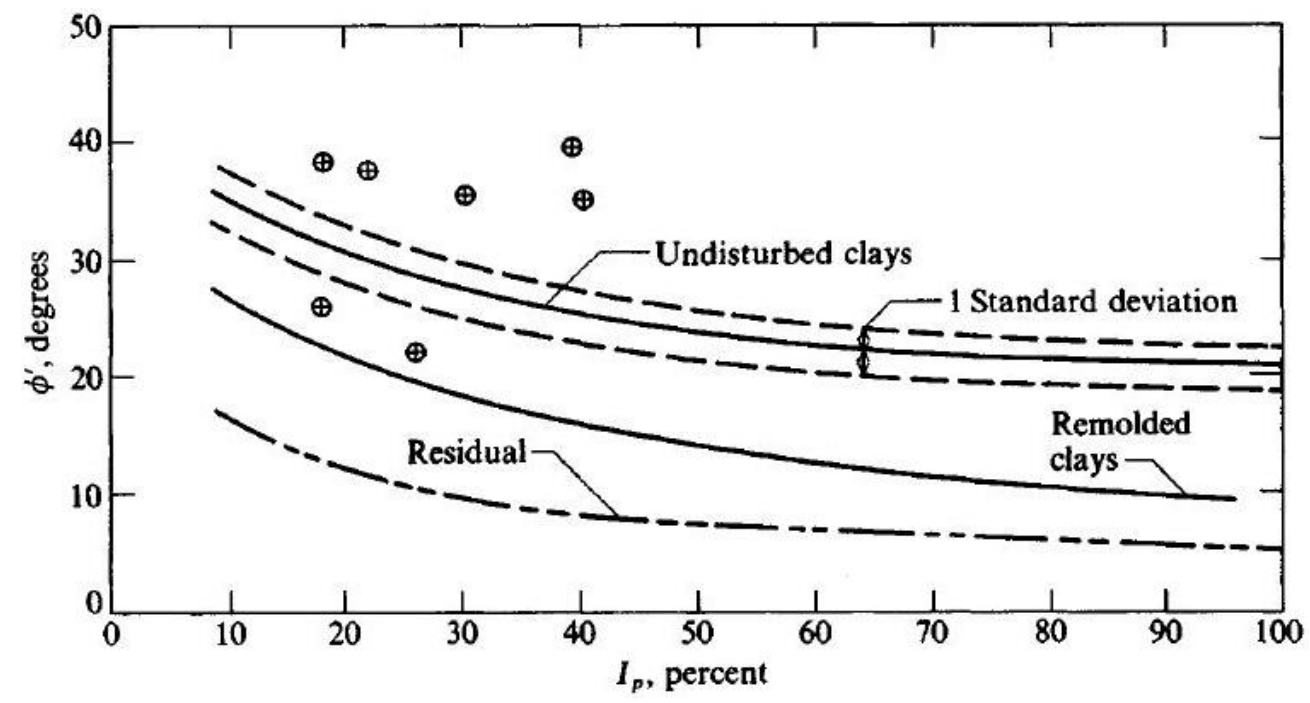

Figure 2.15. Correlation Between $\phi$ ' and $\mathrm{I}_{\mathrm{P}}$ for Normally Consolidated Clays 
Dilatancy angle proposed by Brinkgreve (2008) for cohesive and cohesionless soils are given in Equation 2.2.

$$
\psi=\phi-30
$$

\subsubsection{Soil Modulus}

There are several estimations to determine deformation modulus of the cohesive soils $\left(\mathrm{E}_{\mathrm{s}}\right)$ using SPT $\mathrm{N}$ and $\mathrm{c}_{\mathrm{u}}$ values, although the correlation between SPT $\mathrm{N}$ and $\mathrm{E}_{\mathrm{s}}$ are generally suggested for granular type materials. In order to specify deformation modulus of Ankara clay with respect to SPT N values below correlations can be used. Yoshida and Yoshinaka (1972) recommended a simple equation (Equation 2.3) for the secant modulus $\left(E_{s}\right)$ of the cohesive soils with an average error of $\pm 20 \%$. The $N$ value in Equation 2.3 corresponds to $\mathrm{N}_{70}$ value.

$$
E_{S}(\mathrm{kPa})=650 \times N_{70}
$$

Duncan and Buchignani (1976) back calculated the settlement performance of foundations at various sites and developed a relationship between PI based on $E_{u} / c_{u}$ values and overconsolidation ratio for cohesive soils (Figure 2.16). The correlations developed by the author are obtained from plate load test results and around $0.1 \%$ strain. Therefore, these elastic modulus values represent the initial tangent modulus because of the fact that the low strains produced on the soil at depth (Alexandre, 2014). 


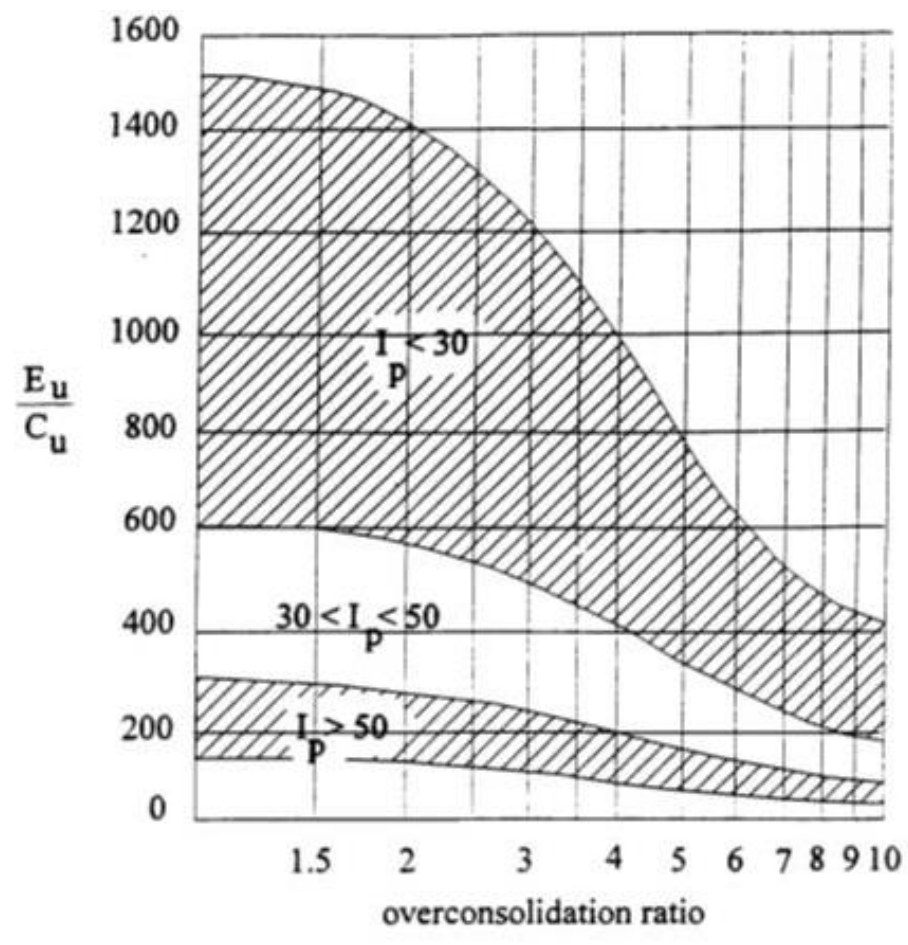

Figure 2.16. Undrained Stiffness of Over-Consolidated Clays (after Duncan \& Buchignani, 1976)

Bowles (1988) proposed a correlation between $\mathrm{E}_{\mathrm{s}}$ and $\mathrm{SPT} \mathrm{N}_{55}$ values for clayey sand or sandy clay mixtures (Equation 2.4). The author also claimed that deformation modulus of cohesive soils depends on the plasticity index value. According to this belief, he found a correlation between $\mathrm{E}_{\mathrm{s}}$ and $\mathrm{c}_{\mathrm{u}}$ value (Table 2.4).

$$
\mathrm{E}_{\mathrm{S}}(\mathrm{kPa})=320 \times\left[\mathrm{N}_{55}+15\right]
$$

Table 2.4. Typical $E_{s}$ and $c_{u}$ Correlation (Bowles, 1988)

\begin{tabular}{|l|l|l|}
\hline \multirow{3}{*}{ CLAY } & PI $>30$ or organic & $E_{\mathrm{s}}=100$ to $500 \mathrm{c}_{\mathrm{u}}$ \\
\cline { 2 - 3 } & $\mathrm{PI}<30$ or stiff & $\mathrm{E}_{\mathrm{s}}=500$ to $1500 \mathrm{c}_{\mathrm{u}}$ \\
\hline
\end{tabular}


CIRIA (1995) suggests Butlers' (1975) correlation (Equation 2.5) for stiff overconsolidated clays. It also suggests that the deformation modulus should be increased when horizontal loading or unloading conditions are considered. Equation 2.6 shows the combination of Equation 2.1 (for $\mathrm{f}_{1}=4 \sim 5 \times \mathrm{N}$ ) and Equation 2.5 for overconsolidated Ankara clay.

$$
\begin{aligned}
& \mathrm{E}^{\prime}=130 \times \mathrm{c}_{\mathrm{u}} \\
& \frac{\mathrm{E}^{\prime}}{N}=0.52-0.65 \mathrm{MPa}
\end{aligned}
$$

Stroud (1987) reworked the Butlers' (1975) data and found higher E' values for overconsolidated clays. The correlation proposed by Stroud (1987) can be seen in Equation 2.7.

$$
\mathrm{E}^{\prime}=(0.7-0.9) \times \mathrm{N}_{60} \mathrm{MPa} \text { (high plastic to less plastic, respectively) }
$$

Clayton (1995) classified the soils whose SPT $\mathrm{N}_{60}$ value is in between 80 and 200 as weak rocks. Stroud (1989) determined a correlation in a wide range for weak rocks and it can be seen in Equation 2.8.

$$
\mathrm{E}^{\prime}=(0.5-2.0) \times \mathrm{N}_{60} \mathrm{MPa}
$$

The relation between drained and undrained Young's modulus of isotropic material can be related to Poisson's ratio with an equation of $\mathrm{E}^{\prime} / \mathrm{Eu}=(1+v) /\left(1+v_{u}\right)$ (CIRIA 1995). Poisson's ratio values for different soil types can be seen in Table 2.5 (Bowles, 1988) and Table 2.6 (Industrial floors and pavements guidelines, 1999). 


\begin{tabular}{lc}
\hline Type of soil & $\boldsymbol{\mu}$ \\
\hline Clay, saturated & $0.4-0.5$ \\
Clay, unsaturated & $0.1-0.3$ \\
Sandy clay & $0.2-0.3$ \\
Silt & $0.3-0.35$ \\
Sand, gravelly sand & $0.1-1.00$ \\
\multicolumn{1}{c}{ commonly used } & $0.3-0.4$ \\
Rock & $0.1-0.4$ \\
Loess & $0.1-0.3$ \\
Ice & 0.36 \\
Concrete & 0.15 \\
Steel & 0.33 \\
\hline
\end{tabular}

Table 2.6. Ranges of Poisson's Ratio (Industrial Floors and Pavements Guidelines, 1999)

\begin{tabular}{lll}
\hline Material & Short term & Long term \\
\hline Sands, gravels and other cohesionless soils & 0.30 & 0.30 \\
Low PI $(<12 \%)$ & 0.35 & 0.25 \\
Medium PI $(12 \%<\mathrm{PI}<22 \%)$ & 0.40 & 0.30 \\
High PI $(22 \%<\mathrm{PI}<32 \%)$ & 0.45 & 0.35 \\
Extremely high PI $(\mathrm{PI}>32 \%)$ & 0.45 & 0.40 \\
\hline
\end{tabular}

Initial deformation modulus is an important soil parameter while interpretation of field data and the ground movements. In soil characterization, damping ratio (D) and small strain shear modulus $\left(\mathrm{G}_{\max }\right)$ are important parameters of soil dynamics. A stiffness degradation curve is generally utilized to explain the shear stiffness for a wide range of shear strain. Atkinson (1991) categorized the strain levels into three groups. These are the very small strain levels $\left(\gamma_{\mathrm{s}} \leq 10^{-6}\right)$, where the stiffness modulus is constant in the elastic range, the small strain levels $\left(\gamma_{\mathrm{s}} \leq 10^{-3}\right)$, where the stiffness modulus 
changes non-linearly with the strain, and the larger strain level, where the soil stiffness is relatively small and the soil is close to failure. This explanation was explained with the normalized stiffness degradation curve as it can be seen in Figure 2.17 (Atkinson, 1991).

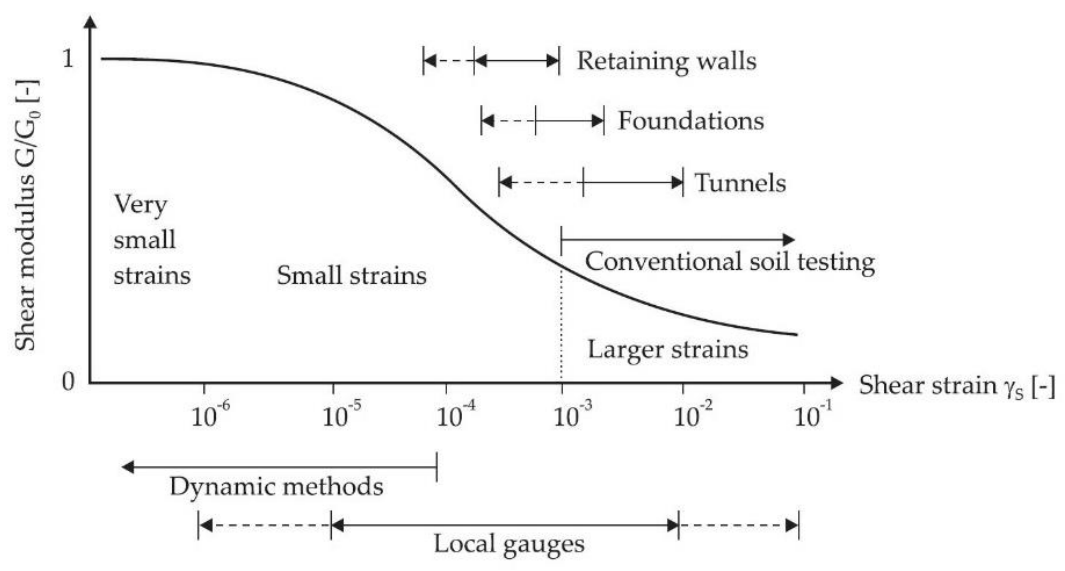

Figure 2.17. Characteristic Strain-Stiffness Behavior in Logarithmic Scale (Atkinson, 1991)

\subsubsection{Compressibility}

Ordemir et al. (1965) reported that the coefficient of volume compressibility $\left(\mathrm{m}_{\mathrm{v}}\right)$ of Ankara clay does not change with depth. The authors stated that $m_{v}$ value alters between 0.005 and $0.010 \mathrm{~cm}^{2} / \mathrm{kg}$ for the pressure range of 1.0 to $10.0 \mathrm{~kg} / \mathrm{cm}^{2}$ according to laboratory consolidation test results. Arda (1966), Gürkök (1970) and Özdikmen (1972) determined that the compression index $\left(\mathrm{C}_{c}\right)$ of Ankara clay varies between 0.10 and 0.24. On the other hand, Ağaoğlu (1974) reported that the compression index value of Ankara clay is as high as 0.30 near to the surface.

Ordemir et al. (1965) emphasized that Ankara clay is preconsolidated because of the closeness of the clay's plastic limit to natural water content, and geological history of the clay. In previous studies of several researchers show that preconsolidation pressure of the samples from the top $4.0 \mathrm{~m}$ of ground surface changes between 2.5 and 10 $\mathrm{kg} / \mathrm{cm}^{2}$. A ğaoğlu (1974) reported that the overconsolidation ratio of the Ankara clay 
is approximately 50 at $1.0 \mathrm{~m}$ depth implying possibly a severe erosion subsequent to deposition as well as desiccation, groundwater table lowering and cementation. As overburden pressure increases with depth, OCR decreases to approximately 5 to 10 around a depth of $7.0 \mathrm{~m}$. Decrease in overconsolidation ratio after a certain depth shows that desiccation has possibly an important impact on the preconsolidation pressure (Kocabayoğlu, 1971).

Birand (1977) specified that the effect of preloading of the soil with a geological load should be seen throughout the depth. Also, the author prepared a graph (Figure 2.18) that represents the alteration of preloading pressure with depth and he concluded that the Ankara clay is normally consolidated after $15.0 \mathrm{~m}$ depth.

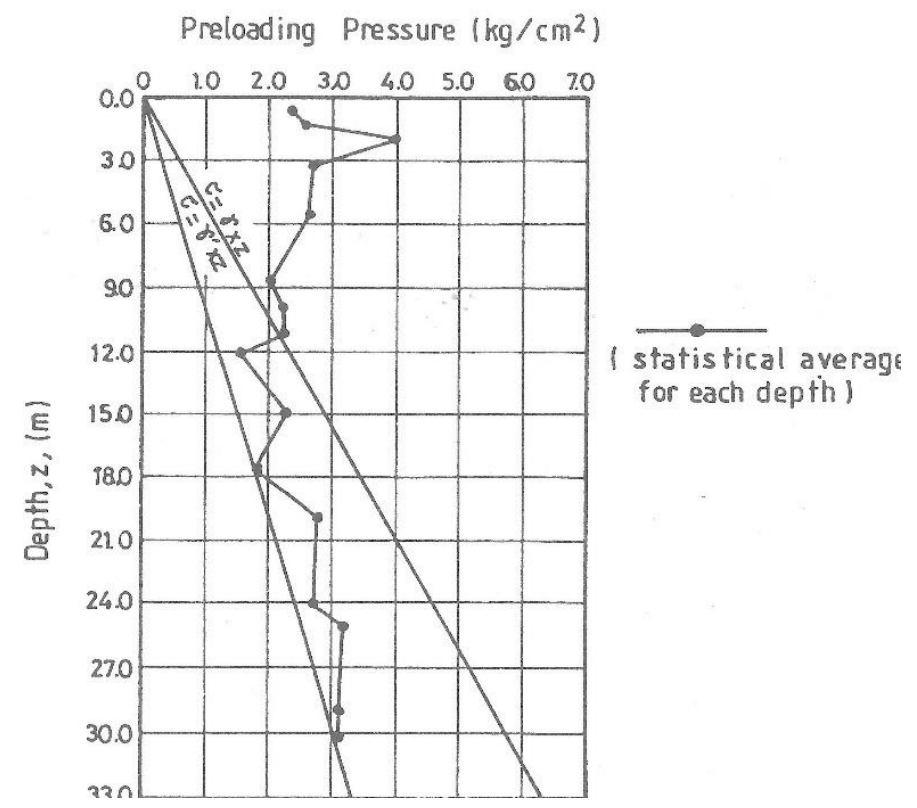

Figure 2.18. Variation of Preloading Pressure with Depth

Means and Parcher (1963) reported that the liquidity index $(L I=(w-P L) / P I)$ value;

- for normally consolidated clays: $\mathrm{LI} \approx 1$

- for overconsolidated clays: $\mathrm{LI} \approx 0$

- for heavily overconsolidated clays: $\mathrm{LI}<0$ 
According to liquidity index vs depth graph prepared by Surgel (1976), LI value is around 0 down to $30.0 \mathrm{~m}$ depth, which means that soil is overconsolidated throughout this depth.

\subsubsection{Swelling Properties}

Ankara clay is rich in two chemical compounds that are Calcium Sulfate $\left(\mathrm{CaSO}_{4}\right)$ and Calcium Carbonate $\left(\mathrm{CaCO}_{3}\right)$. From observations of several samples, Ordemir et al., (1965) have some arguments about the effects of these compounds on soil properties. According to the author, with the increasing $\mathrm{CaCO}_{3}$ content, the swelling potential reduces while the amount of $\mathrm{CaSO}_{4}$ does not alter the swelling potential.

Kaynar (1972) states that there is a relation between plasticity and the ratio of swelling index to compression index as with the increase of plasticity, this ratio increases.

\subsection{Back Analysis of Deep Excavations}

Analysis of a deep excavation can be made by using a direct analysis or a backanalysis method. In direct analysis, soil parameters obtained from soil tests are utilized in computer program and therefore derived results represent the excavation behavior. In direct analysis method reasonable and accurate results can be obtained, in case if the soil parameters and the soil model completely simulate the soil behavior. According to $\mathrm{Ou}$ (2006), behaviors of in-situ soils may not be fully simulated with the existing testing methods or soil behaviors may not appropriately be simulated with available material models because the stress-strain behaviors of soils are in nature anisotropic and influenced by stress paths.

It is possible to obtain more realistic results by using the measurement data obtained from the site. In other words, the parameters of soil model can be changed until the analysis results match the site measurements and then the same soil parameters can be used for the prediction of excavation behavior with similar construction situations, procedures and geological conditions. This method is called back analysis method and it gives satisfactory results [Ou, 1954]. The application of back analysis by using the 
beam on elastic foundation method is quite simple as the only required parameter is coefficient of subgrade reaction $\left(\mathrm{k}_{\mathrm{h}}\right)$. However, when performing back analysis using the finite element method (FEM), there are eight input parameters for each soil layer (c, $\varphi, \mathrm{E}, \mathrm{n}, v, \mathrm{R}_{\mathrm{f}}, \mathrm{E}_{\mathrm{ur}}, \Delta \varphi$ ), so it is very complicated and time-consuming, especially for multilayered soils. Therefore, it is suggested by Ou (2006) that required stiffness parameters which cannot be obtained from soil tests can be derived by back analysis. For instance, for hyperbolic saturated clay models the required parameters like $c, \varphi$ and $\Delta \varphi$ can be obtained from soil tests or correlations obtained from the similar geological areas, while parameters $\mathrm{n}, \mathrm{R}_{\mathrm{f}}$ and $\mathrm{v}$ can be rationally derived separately and only parameters that is to be back analyzed are $\mathrm{E}$ and $\mathrm{E}_{\mathrm{ur}}$.

Several researchers made back analysis on different soil types. In the remaining of this part, two of these studies are summarized.

Çalışan (2009) carried out a back-analysis study to determine the stiffness parameters of overconsolidated Ankara clay. In this study, for obtaining the modulus of elasticity, finite element analysis was performed by utilizing different strength and deformation modulus parameters and results were compared with the displacements obtained by inclinometers. Inclinometer measurements were taken from the highest section of the excavation (Figure 2.19). Properties of this excavation is as follows;

- $65 \mathrm{~cm}$ diameter reinforced concrete piles with a $1.0 \mathrm{~m}$ center to center distance

- $20.0 \mathrm{~m}$ depth of excavation with a $24.0 \mathrm{~m}$ total pile length in an overconsolidated Ankara clay.

- Multilevel anchorages with $2.0 \mathrm{~m}$ horizontal spacing

- 40.0 tons anchorage preloads

According to in-situ and laboratory test results given in the study, there exists a fill layer with a $3.0 \mathrm{~m}$ depth. Beneath this layer, Ankara clay presents down to the end of the borehole. For economical purposes, construction of the piles was started from approximately $3.0 \mathrm{~m}$ below the ground level and up to this level soil was excavated with a slope of $45^{\circ}$. Also, the author divided the overconsolidated Ankara clay into 
two layers, namely clay-1 and clay-2 according to SPT N values. Çalışan (2009) states that due to the majority of the pile length (approximately $17.0 \mathrm{~m}$ ) is located in clay-1, displacements are most affected from this layer. As a result, back analysis was performed only for clay-1 layer.

Çalışan (2009) states that modulus of elasticity and strength parameters obtained from the laboratory test results are not realistic for overconsolidated Ankara clay. Therefore, the author used existing correlations to determine effective friction angle and undrained shear strength of the soil. On the other hand, Çalışan (2009) determined effective cohesion and modulus of elasticity parameters from the back-analysis method. He performed back analyses using hardening soil model (HS) of the Plaxis 2D software. As for the drainage type, drained soil properties were selected for the analysis. The parameters used in the analysis and final parameters obtained from the back-analysis are given below.

The altitude of $863.0 \mathrm{~m}$ is defined as zero elevation $( \pm 0.00)$ in the project.

Fill layer between $+3.5 \mathrm{~m}$ and $0.0 \mathrm{~m}$

$$
\begin{aligned}
& \circ \gamma=18.0 \mathrm{kN} / \mathrm{m}^{3} \\
& \circ \mathrm{c}^{\prime}=3.0 \mathrm{kN} / \mathrm{m}^{2} \\
& \circ \phi^{\prime}=25.0^{\circ} \\
& \circ \mathrm{E}_{50}{ }^{\mathrm{ref}}=\mathrm{E}_{\mathrm{oed}}{ }^{\mathrm{ref}}=12000 \mathrm{kN} / \mathrm{m}^{2} \\
& \circ \mathrm{E}_{\mathrm{ur}}^{\text {ref }}=36000 \mathrm{kN} / \mathrm{m}^{2}
\end{aligned}
$$

Clay-1 layer between $+0.0 \mathrm{~m}$ and $-17.0 \mathrm{~m}$

○ $\gamma=20.0 \mathrm{kN} / \mathrm{m}^{3}$

○ $\quad$ SPT $\mathrm{N}_{\text {avg }}=30$ 
$\circ c^{\prime}=20.0 \mathrm{kN} / \mathrm{m}^{2}$

$\circ \phi^{\prime}=25.0^{\circ}$

$\circ \quad \mathrm{E}_{50}{ }^{\mathrm{ref}}=\mathrm{E}_{\mathrm{oed}}{ }^{\mathrm{ref}}=55000 \mathrm{kN} / \mathrm{m}^{2}$

○ $\mathrm{E}_{\mathrm{ur}}^{\mathrm{ref}}=165500 \mathrm{kN} / \mathrm{m}^{2}$

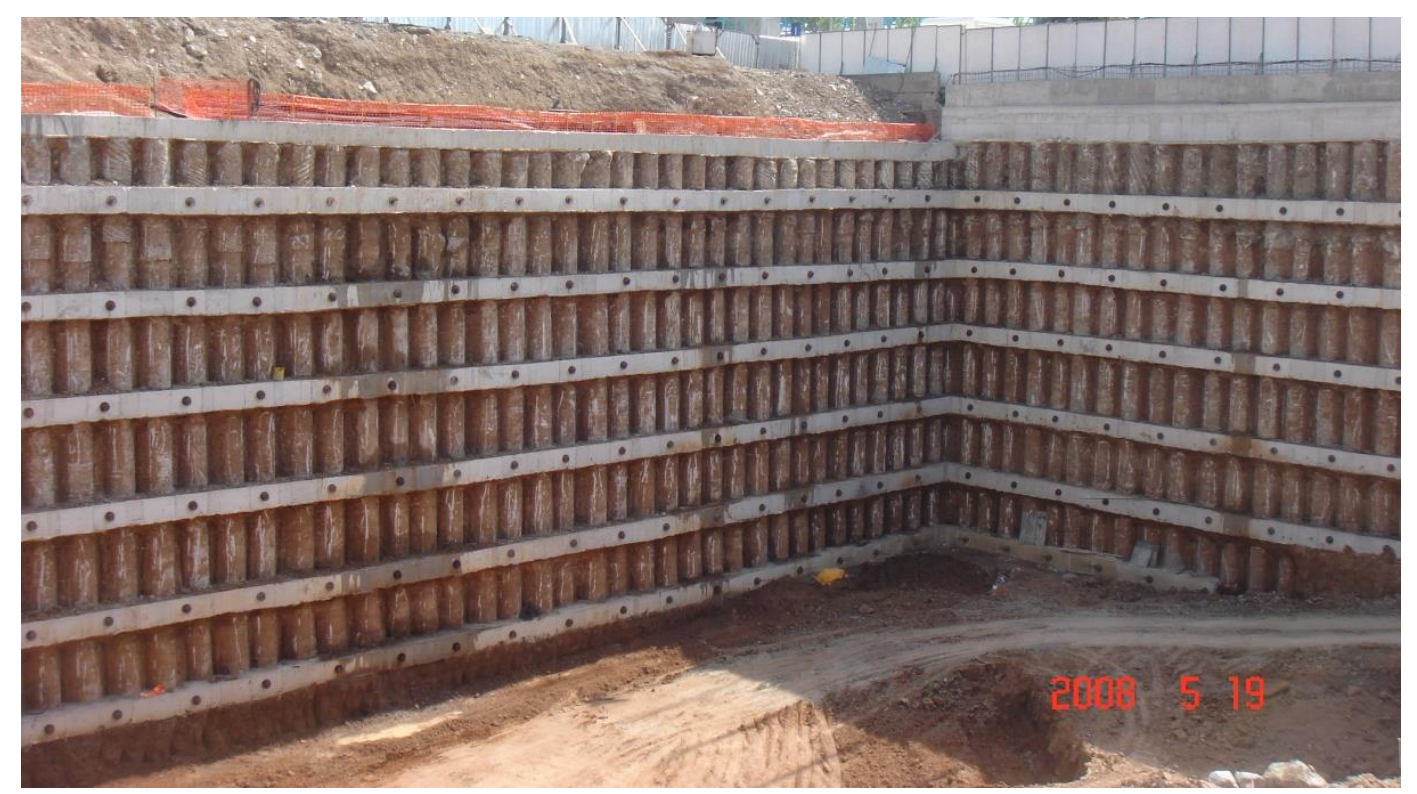

Figure 2.19. Picture from the Deep Excavation Site (Çalışan, 2009)

Based on finite element analyses results and inclinometer measurements, the author deduced significant results:

- Lateral movements measured by inclinometer were approximately $0.13 \% \mathrm{H}$. This value is within the limits recommended by Long (2001) for the anchored walls.

- According to back analysis results, a good match was obtained for the measured displacement profile and the maximum displacement value with the below parameters; 


$$
\begin{aligned}
& \circ \mathrm{c}^{\prime}=20.0 \mathrm{kPa} \\
& \circ \mathrm{E}_{50}{ }^{\text {ref }}=\mathrm{E}_{\text {oed }}{ }^{\text {ref }}=55000 \mathrm{kPa} \\
& \circ \mathrm{E}_{\text {ur }^{\text {ref }}}=165000 \mathrm{kPa}
\end{aligned}
$$

- The ratio of modulus of elasticity to undrained shear strength $\left(\mathrm{E}_{\mathrm{u}} / \mathrm{c}_{\mathrm{u}}\right)$ was found out to be 520 which is in the limits specified by Duncan and Buchignani (1976) for clay layers whose PI value is between 30 and 50 .

Hsiung and Dao (2014) carried out a back-analysis study in order to find out input parameters that cannot be directly obtained from laboratory test results and to assess the performance of three constitutive soil models of Plaxis 2D, Mohr-Coulomb (MC), Hardening Soil Model (HS) and Hardening soil model with small strain stiffness (HSsmall) for the sand layers. The construction site was in the Taiwan and the properties of the deep excavation was as follows;

- $\quad 16.8 \mathrm{~m}$ deep excavation for $70.0 \mathrm{~m}$ in length and $20.0 \mathrm{~m}$ in width construction site

- $0.9 \mathrm{~m}$ thick diaphragm wall with a height of $32.0 \mathrm{~m}$

- Propping by steel struts at four levels with $5.5 \mathrm{~m}$ average strut spacing

- Monitoring of wall deflections and surface settlement by several inclinometers

- Water level of $2.0 \mathrm{~m}$ below the ground level

The authors made series of Plaxis analysis for different constitutive soil models and they performed back analysis by changing only stiffness parameters of the models namely $E^{\prime}, \mathrm{E}_{50}{ }^{\text {ref }}$ and $\gamma_{0.7}$ for MC, HS and HSsmall models respectively. Hsiung and Dao (2014) states that the maximum lateral movement of the wall is approximately $0.39 \% \mathrm{H}$, which is consistent with the study of Ou et al. (1993) (range of $0.2 \% \mathrm{H}$ to $0.5 \% \mathrm{H})$; moreover, the maximum surface settlement ratio $\left(\delta_{\mathrm{vm}} / \mathrm{H}\right)$ is in between $0.12 \%$ and $0.18 \%$. This result supports the findings of Clough and O'Rourke (1990). 
Hsiung and Dao (2014) made analysis by lowering groundwater level with $1.0 \mathrm{~m}$ below the excavation depth in each stage construction. In authors' analysis soil is assumed to be drained. The parameters used in the analysis and final parameters obtained from the back-analysis $\left(\mathrm{E}^{\prime}, \mathrm{E}_{50}{ }^{\mathrm{ref}}\right.$ and $\left.\gamma_{0.7}\right)$ are given in Table 2.7, Table 2.8 and Table 2.9, respectively:

Table 2.7. Input Parameters for the MC Model (Hsiung and Dao, 2014)

\begin{tabular}{|c|c|c|c|c|c|c|c|c|c|}
\hline $\begin{array}{c}\text { Depth } \\
(\mathrm{m})\end{array}$ & $\begin{array}{c}\text { Soil } \\
\text { type }\end{array}$ & $\begin{array}{c}\gamma_{\mathrm{t}} \\
\left(\mathrm{kN} / \mathrm{m}^{3}\right)\end{array}$ & N value & $\begin{array}{c}\phi^{\prime} \\
\left({ }^{\circ}\right)\end{array}$ & $\begin{array}{c}\mathrm{c}^{\prime} \\
(\mathrm{kPa})\end{array}$ & $\begin{array}{c}\mathrm{E}^{\prime} \\
(\mathrm{kPa})\end{array}$ & $v^{\prime}$ & $\begin{array}{c}\Psi \\
\left({ }^{\circ}\right)\end{array}$ & $\mathrm{K}_{0}$ \\
\hline $2.0-6.5$ & $\mathrm{SM}$ & 20.9 & $5-11$ & 32 & 0.5 & 16000 & 0.3 & 2 & 0.47 \\
\hline $8.0-17.0$ & $\mathrm{SM}$ & 20.6 & $5-17$ & 32 & 0.5 & 22000 & 0.3 & 2 & 0.47 \\
\hline $17.0-23.5$ & $\mathrm{SM}$ & 18.6 & $5-17$ & 32 & 0.5 & 22000 & 0.3 & 2 & 0.47 \\
\hline $23.5-28.5$ & $\mathrm{SM}$ & 19.6 & $5-17$ & 33 & 0.5 & 22000 & 0.3 & 3 & 0.46 \\
\hline $30.5-42.0$ & $\mathrm{SM}$ & 19.6 & $18-26$ & 34 & 0.5 & 44000 & 0.3 & 4 & 0.44 \\
\hline $42.0-60.0$ & $\mathrm{SM}$ & 19.9 & $28-42$ & 34 & 0.5 & 70000 & 0.3 & 4 & 0.44 \\
\hline
\end{tabular}

Table 2.8. Input Parameters for the HS Model (Hsiung and Dao, 2014)

\begin{tabular}{|c|c|c|c|c|c|c|c|c|c|c|c|c|}
\hline $\begin{array}{c}\text { Depth } \\
(\mathrm{m})\end{array}$ & $\begin{array}{c}\gamma_{\mathrm{t}} \\
\left(\mathrm{kN} / \mathrm{m}^{3}\right)\end{array}$ & $\begin{array}{c}\mathrm{N} \\
\text { value }\end{array}$ & $\begin{array}{c}\phi^{\prime} \\
\left({ }^{\circ}\right)\end{array}$ & $\begin{array}{c}\mathrm{c}^{\prime} \\
(\mathrm{kPa})\end{array}$ & $\begin{array}{c}\psi \\
\left({ }^{\circ}\right)\end{array}$ & $\begin{array}{c}E_{50}^{\text {ref }} \\
(\mathrm{kPa})\end{array}$ & $\begin{array}{c}E_{o e d}^{r e f} \\
(\mathrm{kPa})\end{array}$ & $\begin{array}{c}E_{u r}^{r e f} \\
(\mathrm{kPa})\end{array}$ & $v_{\mathrm{ur}}^{\prime}$ & $\mathrm{m}$ & $\mathrm{R}_{\mathrm{f}}$ & $\mathrm{K}_{0}$ \\
\hline $2.0-6.5$ & 20.9 & $5-11$ & 32 & 0.5 & 2 & 9600 & 9600 & 28800 & 0.2 & 0.5 & 0.9 & 0.47 \\
\hline $8.0-17.0$ & 20.6 & $5-17$ & 32 & 0.5 & 2 & 13200 & 13200 & 39600 & 0.2 & 0.5 & 0.9 & 0.47 \\
\hline $17.0-23.5$ & 18.6 & $5-17$ & 32 & 0.5 & 2 & 13200 & 13200 & 39600 & 0.2 & 0.5 & 0.9 & 0.47 \\
\hline $23.5-28.5$ & 19.6 & $5-17$ & 33 & 0.5 & 3 & 13200 & 13200 & 39600 & 0.2 & 0.5 & 0.9 & 0.46 \\
\hline $30.5-42.0$ & 19.6 & $18-26$ & 34 & 0.5 & 4 & 26400 & 26400 & 79200 & 0.2 & 0.5 & 0.9 & 0.44 \\
\hline $42.0-60.0$ & 19.9 & $28-42$ & 34 & 0.5 & 4 & 42000 & 42000 & 126000 & 0.2 & 0.5 & 0.9 & 0.44 \\
\hline
\end{tabular}

Table 2.9. Input Parameters for the HSsmall Model (Hsiung and Dao, 2014)

\begin{tabular}{|c|c|c|c|c|c|c|c|}
\hline $\begin{array}{c}\text { Depth } \\
(\mathrm{m})\end{array}$ & $\begin{array}{c}\text { Soil } \\
\text { type }\end{array}$ & N value & $\begin{array}{c}\mathrm{V}_{\mathrm{s}} \\
(\mathrm{m} / \mathrm{s})\end{array}$ & $\begin{array}{c}\sigma_{3}^{\prime} \\
(\mathrm{kPa})\end{array}$ & $\begin{array}{c}\mathrm{G}_{0} \\
(\mathrm{kPa})\end{array}$ & $\begin{array}{c}\mathrm{G}_{0}^{\text {ref }} \\
(\mathrm{kPa})\end{array}$ & $\gamma_{0.7}$ \\
\hline $2.0-6.5$ & $\mathrm{SM}$ & $5-11$ & 161 & 63 & 55343 & 69657 & $10^{-4}$ \\
\hline $8.0-17.0$ & $\mathrm{SM}$ & $5-17$ & 183 & 150 & 69974 & 57153 & $10^{-4}$ \\
\hline $17.0-23.5$ & $\mathrm{SM}$ & $5-17$ & 183 & 226 & 63180 & 42069 & $10^{-4}$ \\
\hline $23.5-28.5$ & $\mathrm{SM}$ & $5-17$ & 183 & 278 & 66577 & 39966 & $10^{-4}$ \\
\hline $30.5-42.0$ & $\mathrm{SM}$ & $18-26$ & 239 & 374 & 114480 & 59204 & $10^{-4}$ \\
\hline $42.0-60.0$ & $\mathrm{SM}$ & $28-42$ & 287 & 518 & 167115 & 73412 & $10^{-4}$ \\
\hline
\end{tabular}


The author concluded that:

- The $\mathrm{E}^{\prime}$ value was found out to be $\mathrm{E}^{\prime}=2000 \times \mathrm{N}$ in MC model; the $\mathrm{E}_{50}{ }^{\text {ref }}$ was found out to be $\mathrm{E}_{50}{ }^{\text {ref }}(\mathrm{kPa})=1200 \mathrm{x} \mathrm{N}$ in $\mathrm{HS}$ and HSsmall models. Furthermore, the $\gamma_{0.7}$ was taken values of $5 \times 10^{-5}, 10^{-4}$ and $5 \times 10^{-4}$. These are the only parameters that are changed during the parametric studies for MC, HS and HSS models.

- Generally, for obtaining better wall deflection and surface settlement predictions more advanced soil models are used in analyses. When the three soil models are compared with each other in terms of their prediction capabilities, it may be deduced that HSsmall is better than HS while HS is better than MC model.

- The MC model overpredicted the wall displacements especially at lower depths. On the other hand, the wall displacements predicted by HS and HSsmall models were close to displacements obtained from the site measurements.

- The input parameters $\mathrm{E}^{\prime}, \mathrm{E}_{50}{ }^{\text {ref }}$ and $\gamma_{0.7}$ of the MC, HS and HSsmall models and their variations have significant influence on the predictions of horizontal and vertical displacements of the wall. 


\subsection{Material Models}

Selection of the material model and soil parameters will have a significant influence on the results of numerical analysis. In recent years, many constitutive soil models have been developed, so there are many options to be used in the simulation of soil behavior in finite element programs such as Plaxis, Midas GTS and Flac. However, each constitutive model has different capabilities and limitations. Therefore, this should be well-known by the user for conducting accurate analysis. In this part of the thesis, three commonly used material models of Plaxis, which are Mohr-Coulomb (MC), Hardening Soil (HS) and Hardening Soil with small strain stiffness (HSsmall), are explained.

\subsubsection{Mohr-Coulomb Model (MC)}

Mohr-Coulomb (MC) is the simplest model investigated in this study and it is a linear elastic-perfectly plastic model. Linear elasticity of the model is ensured by Hooke's law and the elastic region is assumed to be up to failure. Stress state at failure is predicted by Mohr-Coulomb failure criterion and a constant stress level is assumed in the plastic region for which the hardening of soil is ignored. In other words, the nonlinear behavior of the soil is modelled with bilinear lines in MC model (see Figure $2.20 a$ ). One may observe the difference between actual soil behavior, which is obtained from actual tests like consolidation and triaxial, and the stiffness behavior predicted by MC model in Figure 2.20b. The model requires five input parameters to express the stress-strain behavior. Two of these parameters which are Young's modulus (E) and Poisson's ratio (v) come from Hooke's law, other two parameters are related to Coulomb failure criterion and these parameters are friction angle $(\varphi)$ and cohesion (c), the final parameter is dilatancy angle $(\psi)$ which is used for modeling the irreversible change in volume due to shearing.

MC model ensures Coulomb's friction law by the generation of a failure contour which is in the shape of a hexagonal cone in principle stress space (see Figure 2.20d). This failure contour turns out to be quite consistent with true triaxial tests conducted 
on real soil samples (Goldscheider, 1984). Although failure contour is well predicted by MC criterion, stiffness behavior remains unrealistic. This is due to the first order approximation of the model and use of the same elastic modulus for any type of loading. The model underestimates the soil behavior below the $50 \%$ of the ultimate stress level; however, it overestimates the soil behavior above the $50 \%$ of the ultimate stress level (see Figure 2.20c). Therefore, according to Brinkgreeve (2005), not more than $50 \%$ accuracy should be expected in MC model.

Stiffness depends on the stress path in real soils, however; in Mohr-Coulomb model, there is only one stiffness parameter $(\mathrm{E})$ in order to simulate both primary loading and unloading/reloading behavior of soils. In other words, the model takes the same stiffness parameter for primary loading and reloading/unloading ( $\left.\mathrm{E}_{50}=\mathrm{E}_{\mathrm{ur}}\right)$. However, unloading-reloading stiffness modulus $\left(\mathrm{E}_{\mathrm{ur}}\right)$ can be much higher than the loading stiffness by a factor of 2.0 to 5.0 (Gouw, 2014). This means that the MC model will generally overpredict the soil heave in excavation problems. In order to overcome this insufficiency of the model, Gouw (2014) suggests the use of a stiffness parameter (E) between $\mathrm{E}_{50}$ and $\mathrm{E}_{\mathrm{ur}}$. 
(a)

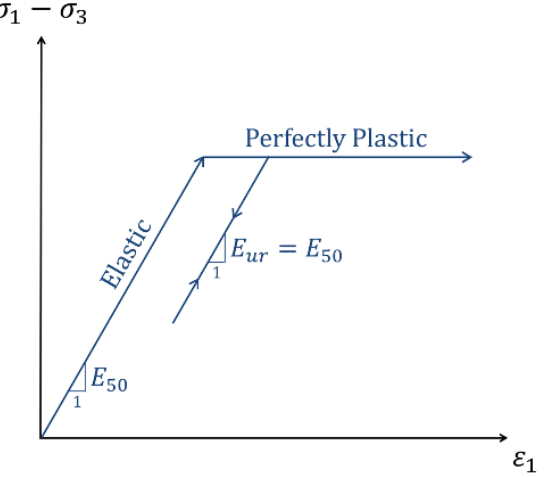

(c)

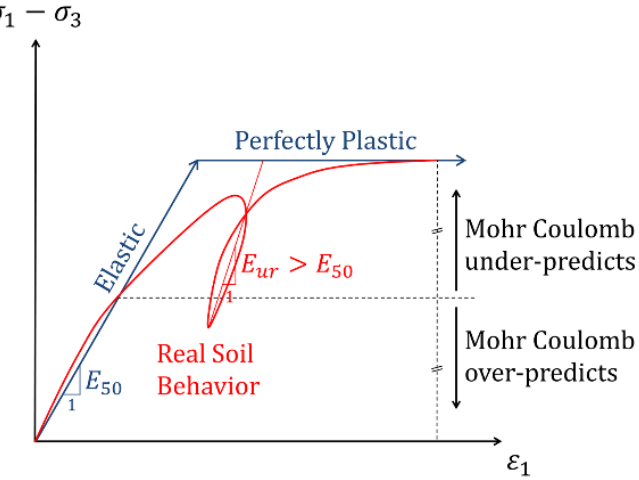

(b) $\sigma_{1}-\sigma_{3}$

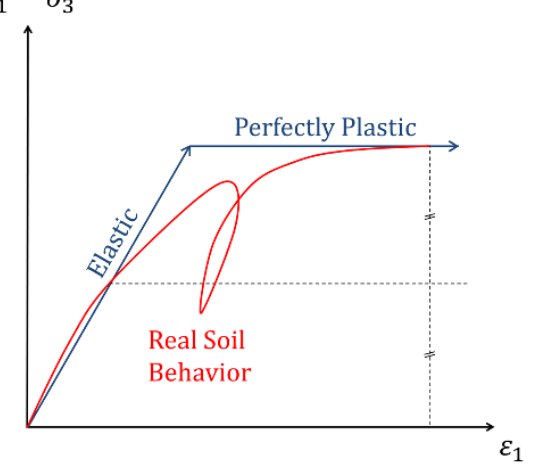

(d)

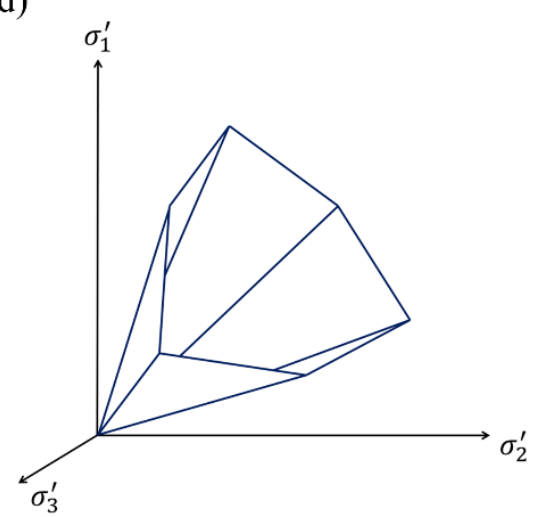

Figure 2.20. (a) Mohr-Coulomb Model Soil Behavior (b) Comparison of Mohr-Coulomb Soil Behavior with Real Soil Behavior, (c) Unrealistic Aspects of Mohr-Coulomb Model, (d) MohrCoulomb Model Yield Surface in Principal Stress Space

\subsubsection{The Hardening Soil Model}

Hardening soil (HS) is a more sophisticated model compared to Mohr-Coulomb in the way of simulating the soil behavior. Model is developed by Schanz (1998) and Shanz et al. (1999). The hyperbolic stress-strain relationship of the model is formulated by Kondner (1963) which is also used in Duncan and Chang model (1970). However, the main difference of the hardening soil model is the use of plasticity rather than elasticity and the two types of hardening (isotropic), which are formulated by Vermeer (1978). The model also includes the unloading/reloading relation, which is controlled by $\mathrm{E}_{\mathrm{ur}}$ stiffness parameter and assumes this behavior to be fully elastic. 
Hyperbolic part of HS is modelled by using two stiffness parameters, i.e. $\mathrm{E}_{50}{ }^{\mathrm{ref}}$ and $\mathrm{E}_{\text {oed }}{ }^{\text {ref }}$ that are stress dependent with a power law formulation. In plastic part, two types of hardening (Figure 2.22) and yield surface are introduced that may extend up to failure surfaces which are based on Mohr-Coulomb failure theory. These distinct hardening types are shear hardening (cone hardening) and compression hardening (cap hardening) that include the plastic strains developed due to primary deviatoric loading and primary compression loading (oedometer or isotropic loading) respectively (Figure 2.22). Shear hardening is controlled by $E_{50}$ stiffness parameter while compression hardening is controlled by $\mathrm{E}_{\mathrm{oed}}$ stiffness parameter. The model uses ten (10) input parameters which are;

- Three reference stiffness moduli at reference pressure of $100 \mathrm{kPa}$; $E_{50}^{r e f}, E_{u r}^{r e f}$ and $E_{o e d}^{r e f}$

- Power $\mathrm{m}$ for formulation of hyperbolic stress-strain relation.

- Poisson's ratio for unloading/reloading $\left(v_{u r}\right)$.

- Mohr Coulomb strength parameters; $\varphi, c$ and $\psi$.

- $K_{0}^{n c}\left(K_{0}\right.$ value for normally consolidation)

- Failure ratio $\left(R_{f}\right)$.

Stress-strain behavior in primary loading is highly non-linear and it is assumed to be hyperbolic in HS model. Initial stiffness $\left(E_{i}\right)$ of the stress-strain graph can be written in terms of triaxial stiffness $\left(E_{50}\right)$ and it can be shown as,

$$
E_{i}=\frac{2 . E_{50}}{2-R_{f}}
$$

$R_{f}$ introduced in Equation 2.9 is called the failure ratio which is a ratio of deviatoric stress at failure $\left(q_{f}\right)$ to asymptotic deviatoric stress $\left(q_{a}\right)$. This value is proposed to be 0.9 by PLAXIS (Plaxis, 2019). Deviatoric stress at failure can be calculated as follows,

$$
q_{f}=\left(\sigma_{3}+c \cdot \cot (\varphi)\right) \frac{2 \cdot \sin (\varphi)}{1-\sin (\varphi)}
$$


Formulations of three stress dependent stiffness moduli that define the soil behavior are given between equation 2.11 and 2.13 .

$$
\begin{aligned}
& E_{50}=E_{50}^{r e f}\left(\frac{\sigma_{3}+c \cdot \cot (\varphi)}{p_{\text {ref }}+c \cdot \cot (\varphi)}\right)^{m} \\
& E_{\text {oed }}=E_{\text {oed }}^{r e f}\left(\frac{\sigma_{1}+c \cdot \cot (\varphi)}{p_{\text {ref }}+c \cdot \cot (\varphi)}\right)^{m} \\
& E_{\text {ur }}=E_{u r}^{r e f}\left(\frac{\sigma_{3}+c \cdot \cot (\varphi)}{p_{\text {ref }}+c \cdot \cot (\varphi)}\right)^{m}
\end{aligned}
$$

Where;

- $E_{50}$ is the stiffness related with shear deformations

- $E_{\text {oed }}$ is the stiffness related with axial deformations

- $E_{\text {ur }}$ is the unloading-reloading modulus

- $\sigma_{1}$ can be expressed as $\sigma_{3} / K_{0}^{n c}$ and $K_{0}^{n c}=1-\sin \varphi$

All stiffness parameters explained above are stress dependent and they are formulated with a power law which uses m parameter. According to Brinkgreeve (2005), power $\mathrm{m}$ should be taken as 0.5 for sands, and 1.0 for normally consolidated clays and silts. For the Ankara clay, Karatağ (2012) made consolidation tests and from the obtained deformation modulus and stress values, author concluded that power $\mathrm{m}$ value can be taken between 0.55 and 0.60 .

Hyperbolic soil behavior approximated by HS model is shown in Figure 2.21. In Figure 2.21a, deviatoric stress is plotted with respect to axial strain in which unloading/reloading part is also presented. In Figure 2.21 b, axial strength, behavior of which is dominated by $E_{\text {oed }}$ stiffness parameter, is plotted with respect to axial strain. 
(a)

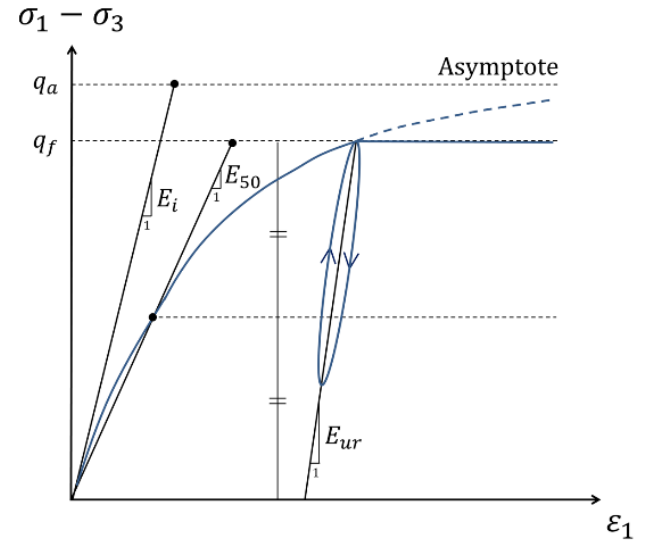

(b) $\sigma_{1}$

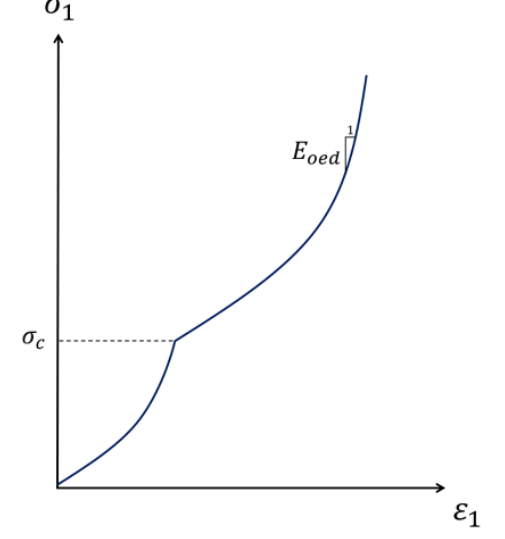

Figure 2.21. (a) Deviatoric Stress-Axial Strain Graph (b) Axial Stress-Strain Graph of HS Model

Strains at unloading/reloading part are assumed to be fully elastic in HS model. Elastic strains at this region can be calculated by using Hooke's law and related formulations for loading/unloading part are given below,

$$
\begin{aligned}
& G_{u r}=\frac{1}{2 \cdot\left(1+v_{u r}\right)} E_{u r} \\
& \varepsilon_{1}^{e}=\frac{q}{E_{u r}} ; \quad \varepsilon_{2}^{e}=\varepsilon_{3}^{e}=v_{u r} \cdot \frac{q}{E_{u r}}
\end{aligned}
$$

Moreover, unloading/reloading behavior of soil is assumed to be non-linear elastic as the stiffness parameter $E_{u r}$ is stress dependent with the power law.

In HS model except for unloading/reloading part, plastic strains develop and as mentioned above triaxial and oedometer stiffness parameters control the hardening behavior of soil. Hardening of soil, which are cone and cap hardening, continue until the yield functions defined for HS model come out to be zero. At this point, yield surfaces are called Mohr Coulomb cone and cap and soil behaves perfectly plastic after reaching the stress state at these boundaries. For cone and cap hardening, yield functions can be seen in Equation 2.16 and 2.17, respectively. 


$$
\begin{aligned}
& f=\frac{2-R_{f}}{E_{50}} \cdot\left(\frac{q}{1-\frac{q}{q_{a}}}\right)-\frac{2 \cdot q}{E_{u r}}-\gamma^{p}=0 \\
& f_{c}=\frac{\tilde{q}^{2}}{M^{2}}+{p^{\prime}}^{2}-p_{p}^{2}=0
\end{aligned}
$$

where

$$
\begin{aligned}
& p^{\prime}=\left(\sigma_{1}^{\prime}+\sigma_{2}^{\prime}+\sigma_{3}^{\prime}\right) \\
& \tilde{q}=\sigma_{1}+(\alpha-1) \cdot \sigma_{2}-\alpha \cdot \sigma_{3} \\
& \alpha=\frac{3+\sin (\varphi)}{3-\sin (\varphi)}
\end{aligned}
$$

$\mathrm{p}_{\mathrm{p}}$ is the isotropic pre-consolidation stress

Hardening behavior simulated in HS model is shown in Figure 2.22a for $q-p^{\prime}$ plane and in Figure 2.22b for principal stress space. As shown in figure, both yield surfaces expand up to Mohr-Coulomb (MC) failure surfaces (cone and cap). Material exhibits cone hardening in the direction of $q$ and cap hardening in the direction of $p^{\prime}$.

(a)

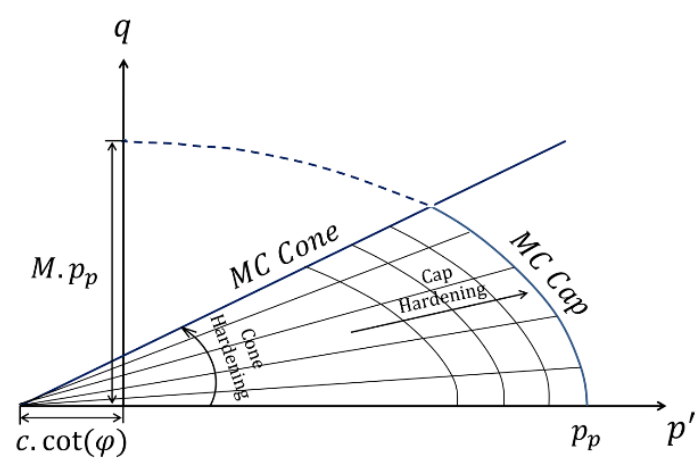

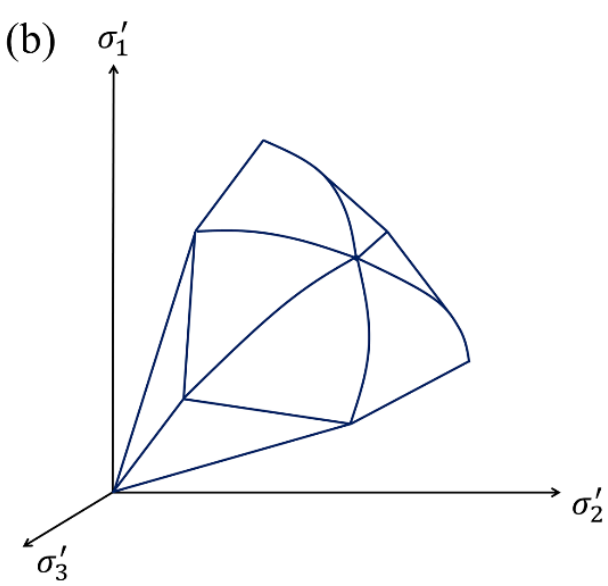

Figure 2.22. (a) Cone and Cap Hardening Behavior in HS Model (b) Failure Surfaces of HS Model in Principle Stress Space 


\subsubsection{The Hardening Soil Model with Small Strain Stiffness}

Stiffness of soils at small shear strains are called small strain stiffness. At this level, soils exhibit almost fully recoverable behavior and soil stiffness decreases nonlinearly with increasing strain amplitude (see Figure 2.17). The very small strain stiffness $(\varepsilon<$ $10^{-6}$ ) associated with this strain range is believed to be a fundamental property of all types of geotechnical materials comprising silts, clays, sands, gravels, and rocks under even different loading and drainage conditions. In order to consider small strain behavior of soil, an extended version of the hardening soil model is developed by Benz (2006) and it is called Hardening soil model with small strain stiffness (HSsmall).

Small strain stiffness plays an important role in excavation problems to predict surface settlement or heave behavior of the soil behind the wall. H.F. Schweiger et al. (2009) and B.B Hsiung \& S. Dao (2014) compare MC, HS and HSsmall models according to several aspects. Results of both studies show that HSsmall model gives more realistic surface settlement, while excessive heave is observed in MC model. When results of HSsmall and HS model are compared, it is observed that both methods yield similar results. However, HSsmall model which considers small strain stiffness gives more accurate results.

Compared to the HS model, Matsuoka-Nakai (1982) failure criterion is added to the HSsmall model to be used optionally. However, this feature has been discarded by Plaxis in 2017 and now the model uses only Mohr-Coulomb failure criterion like MC and HS model.

HSsmall model uses 12 input parameters, most of which are the same as HS model except two additional parameters, which are the reference shear modulus at very small strains e.g. $\varepsilon<10^{-6}\left(\mathrm{G}_{0}{ }^{\text {ref }}\right)$ and threshold shear strain $\left(\gamma_{0.7}\right)$ at which the secant shear modulus $\mathrm{G}_{\mathrm{s}}$ is reduced to $70 \%$ of $\mathrm{G}_{0}{ }^{\text {ref }}$.

Initial shear modulus at very small strains $\left(\mathrm{G}_{0}\right)$ and very small strain modulus $\left(\mathrm{E}_{0}\right)$ formulations are shown in equation 2.21 and 2.22, respectively. Also, soil stiffness 
behavior of HSsmall model for triaxial test is presented in Figure 2.23 which also shows the stiffness moduli $\left(\mathrm{E}_{0}, \mathrm{E}_{50}, \mathrm{E}_{\mathrm{ur}}\right)$.

$$
\begin{aligned}
& \mathrm{G}_{0}=\mathrm{G}_{0}^{r e f} \cdot\left(\frac{\sigma_{3}+c \cdot \cot (\varphi)}{p_{r e f}+c \cdot \cot (\varphi)}\right)^{2} \\
& E_{0}=2 \cdot G_{0} \cdot\left(1+v_{u r}\right)
\end{aligned}
$$

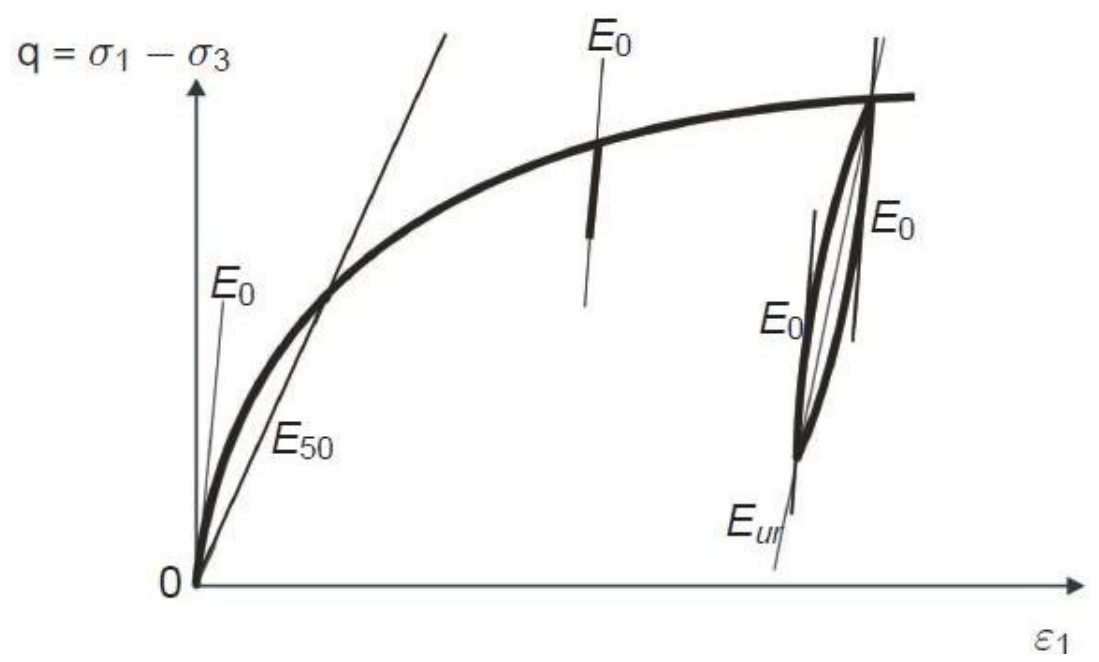

Figure 2.23. Stiffness Parameters of HSsmall Model [PLAXIS]

In addition to initial shear modulus $\left(\mathrm{G}_{0}\right)$, unloading-reloading shear modulus $\left(\mathrm{G}_{\mathrm{ur}}\right)$ is also defined for simulating the behaviour of soil in cyclic shear test. This behaviour is shown in Figure 2.24.

$$
G_{u r}=\frac{E_{u r}}{2 \cdot\left(1+v_{u r}\right)}
$$




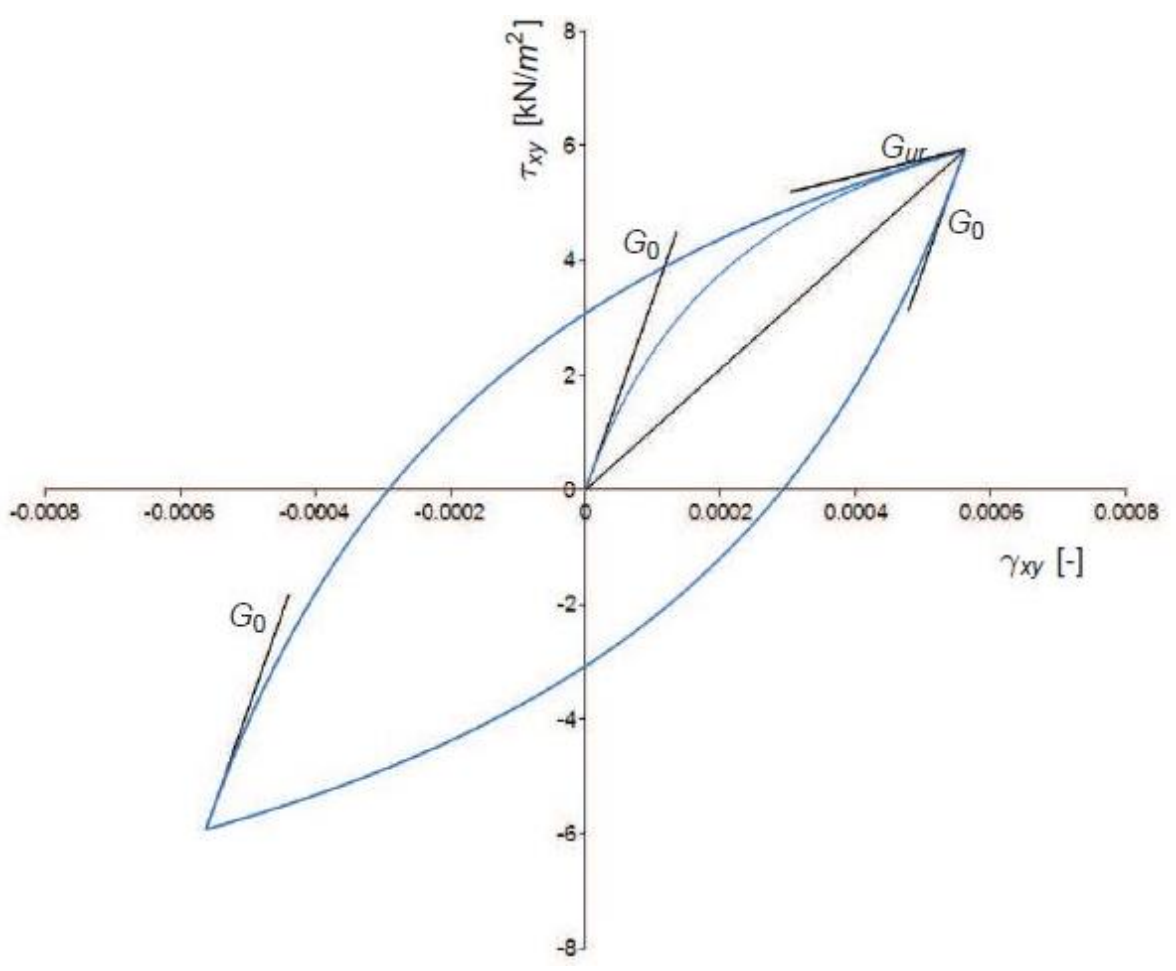

Figure 2.24. Soil Stiffness Behavior in Cyclic Shear Test (Plaxis, 2017)

The shear strain $\gamma_{0.7}$ can be related to damping: the larger the value of $\gamma_{0.7}$, the less damping. The specific threshold value of $70 \%$ percent is selected by Benz (2006) according to the recommendation of Santos \& Correia (2001). According to Seed and Idris (1970), void ratio, strain amplitude, confining stress, and the amount of in-situ interparticle bonding turn out to be the most important parameters that affect the stiffness of soils at small strains.

\subsubsection{Comparison of the models: Simple Benchmark Problem}

Schweiger et al. (2009) investigated a study to determine the effect of the selection of the constitutive model for a simple benchmark problem. The authors have worked in four (homogenous) different types of soil, which are dense sand, a loose to medium dense sand, an overconsolidated clay and a soft soil, with the purpose of evaluating 
the influence of different constitutive models of Plaxis 2D for several ground conditions. However, only the results obtained from dense sand and soft clay were mentioned in their study. 6.0m excavation was performed for both dense sand and soft clay layers by using sheet pile wall and a single row strut (Figure 2.5), but only drainage conditions and height of the wall were changed according to the type of the soil.

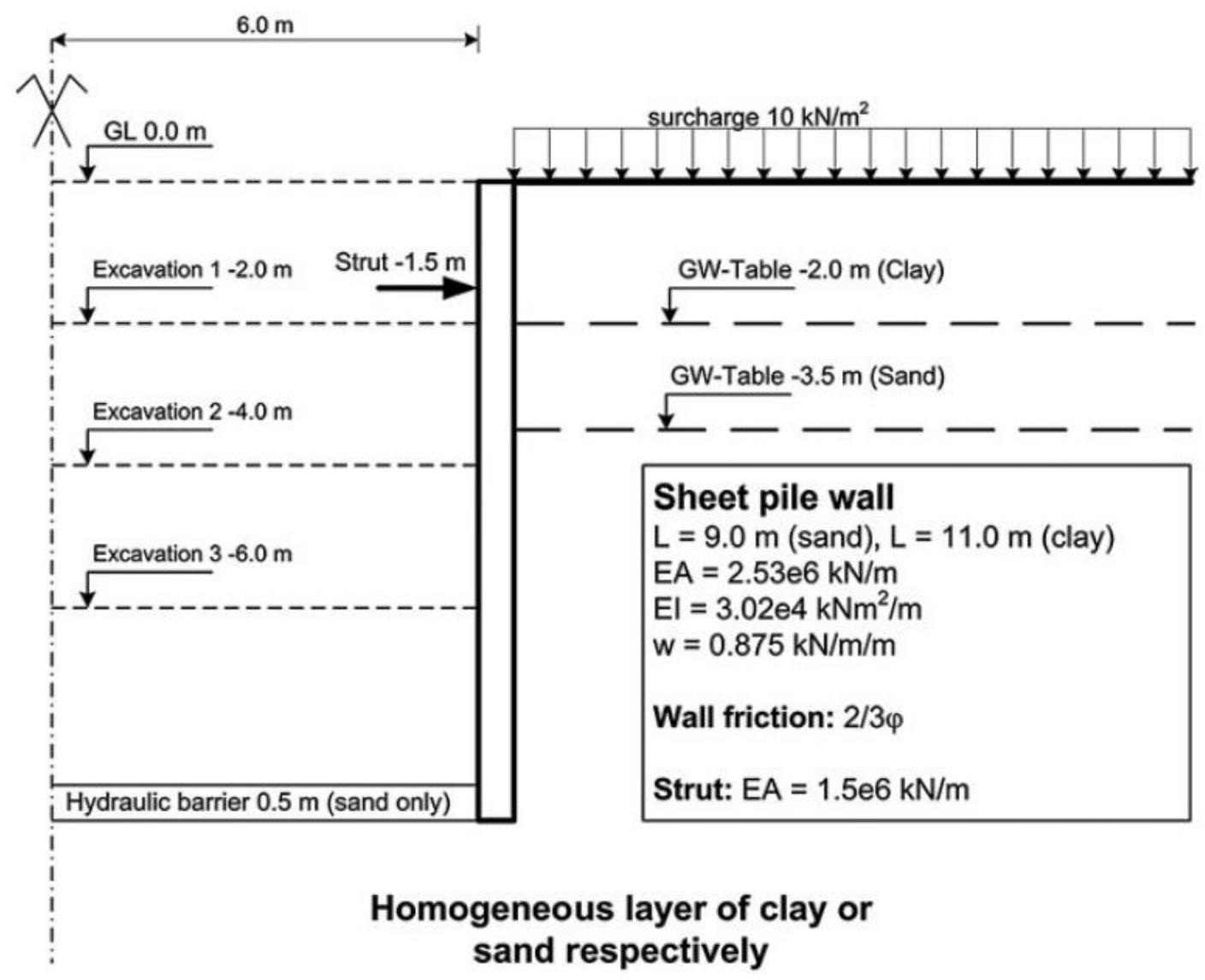

Figure 2.25. Geometry of the Benchmark Problem

In their study, Schweiger (2009) used the soil parameters obtained from laboratory test results during analyses. Step calculation procedure was performed during analyses as it is listed below; 
Phase 0: Initial phase K0 procedure is used $\left(\sigma_{\mathrm{v}}=\gamma \cdot \mathrm{h} ; \sigma_{\mathrm{h}}=\mathrm{K}_{0} \cdot \sigma_{\mathrm{v}} ; \mathrm{K}_{0}=1-\sin \phi\right)$

Phase 1: Surcharge load is applied

Phase 2: Wall is activated, and displacements are reset to zero

Phase 3: Excavation to the $-2.0 \mathrm{~m}$ level is modelled

Phase 4: Strut is activated at level $-1.5 \mathrm{~m}$

Phase 5: Groundwater table is lowered to $-6.0 \mathrm{~m}$ level inside the excavation. (This step is used for sand layers)

Phase 6: Excavation to the bottom excavation level is performed.

Assumptions made by Schweiger (2009) are listed below.

- Seepage flow was neglected in the sand layer by an assumption of a deep hydraulic barrier at the bottom excavation level. On the other hand, in the soft clay layer, the author assumed that groundwater was also taken when the soil layer were excavated, so groundwater conditions was not modified in the analysis.

- The groundwater level was assumed at $-3.5 \mathrm{~m}$ for the sand layer.

- Drained analyses were performed for both soils.

- In sand layer three constitutive soil model of the Plaxis 2D software were used, Mohr Coulomb (MC), hardening soil model (HS) and hardening soil model with small strain stiffness (HSsmall). In clay layer in addition to these models Plaxis soft soil model (SS) was used.

- Strength parameters were taken the same for all the models of the same soil; however, stiffness parameters were changed. Parameters used in the analyses are listed for sand and clay layers in Table 2.10 and Table 2.11, respectively. 
Table 2.10. Sand Parameters of the Simple Benchmark Problem

\begin{tabular}{llll}
\hline Parameter & & Model & Value \\
\hline$\gamma$ & {$\left[\mathrm{kN} / \mathrm{m}^{3}\right]$} & MC, HS, HSsmall & 18 \\
$\gamma_{\text {sat }}$ & {$\left[\mathrm{kN} / \mathrm{m}^{3}\right]$} & MC, HS, HSsmall & 20 \\
$\varphi^{\prime}$ & {$\left[{ }^{\circ}\right]$} & MC, HS, HSsmall & 41 \\
$c^{\prime}$ & {$[\mathrm{kPa}]$} & MC, HS, HSsmall & 0 \\
$\psi$ & {$\left[{ }^{\circ}\right]$} & MC, HS, HSsmall & 15 \\
$v^{\prime}$ & {$[-]$} & MC & 0.25 \\
$\mathrm{E}$ & {$[\mathrm{kPa}]$} & MC & 60,000 \\
$\mathrm{E}_{50}{ }^{\text {ref }}$ & {$[\mathrm{kPa}]$} & HS, HSsmall & 30,000 \\
$\mathrm{E}_{\text {oed }}{ }^{\text {ref }}$ & {$[\mathrm{kPa}]$} & HS, HSsmall & 30,000 \\
$\mathrm{E}_{\text {ur }}{ }^{\text {ref }}$ & {$[\mathrm{kPa}]$} & HS, HSsmall & 90,000 \\
$\mathrm{G}_{0}{ }^{\text {ref }}$ & {$[\mathrm{kPa}]$} & HSsmall & 270,000 \\
$\gamma_{0.7}$ & {$[-]$} & HSsmall & 0.0002 \\
\hline
\end{tabular}

Table 2.11. Clay Parameters of the Simple Benchmark Problem

\begin{tabular}{llll}
\hline Parameter & & Model & Value \\
\hline$\nu$ & {$\left[\mathrm{kN} / \mathrm{m}^{3}\right]$} & MC, HS, HSsmall & 15 \\
$\gamma_{\text {sat }}$ & {$\left[\mathrm{kN} / \mathrm{m}^{3}\right]$} & MC, HS, HSsmall & 16 \\
$\varphi^{\prime}$ & {$\left[{ }^{\circ}\right]$} & MC, HS, HSsmall & 27 \\
$\mathrm{c}^{\prime}$ & {$[\mathrm{kPa}]$} & MC, HS, HSsmall & 15 \\
$\psi$ & {$\left[{ }^{\circ}\right]$} & MC, HS, HSsmall & 0 \\
$v$ & {$[-]$} & MC & 0.3 \\
$\mathrm{E}$ & {$[\mathrm{kPa}]$} & MC & 9,350 \\
$\mathrm{E}_{50}{ }^{\text {ref }}$ & {$[\mathrm{kPa}]$} & HS, HSsmall & 4,300 \\
$\mathrm{E}_{\text {oed }}{ }^{\text {ref }}$ & {$[\mathrm{kPa}]$} & HS, HSsmall & 1,800 \\
$\mathrm{E}_{\mathrm{ur}}{ }^{\text {ref }}$ & {$[\mathrm{kPa}]$} & HS, HSsmall & 14,400 \\
$\mathrm{G}_{0}{ }^{\text {ref }}$ & {$[\mathrm{kPa}]$} & HSsmall & 100,000 \\
$\gamma_{0.7}$ & {$[-]$} & HSsmall & 0.0003 \\
\hline
\end{tabular}


According to analyses results, the author concluded that;

- In sand layer; above the excavation level horizontal displacements obtained from the MC model is smaller than the displacements of the HS and HSsmall model; on the other hand, below the excavation level, displacements of the MC model are higher than these two models. The reason behind this situation is related to the constant elastic modulus parameter of the MC model. Horizontal displacements obtained from HS and HSsmall model analyses are near to each other, but small strain stiffness reduces the maximum displacement to a certain extent. The author emphasized that the HSsmall model is quite sensitive to $\gamma_{0.7}$ parameter; therefore, appropriate parameter selection is needed.

- In the clay layer; similar results are obtained except from the shape of the displacements. In MC model, horizontal displacement shape below the excavation level is almost parallel to the wall, which is different from the HS and HSsmall models. 



\section{CHAPTER 3}

\section{GEOLOGICAL ASSESMENT OF THE STUDY AREA}

A new residence and business center have been built in Çukurambar district of Ankara. Area of the construction site is approximately $19400 \mathrm{~m}^{2}$ and it is surrounded by roads and buildings. The topographic view of the construction site is given in Figure 3.1. The structure consists of 2 blocks namely A and B. Block A is composed of 32 floors with seven (7) basements and one (1) ground floor, on the other hand, Block B consists of thirty (30) floors with five (5) basements and one (1) ground floor. For the construction of basements and a ground floor, an excavation ranging from $20.0 \mathrm{~m}$ to $32.0 \mathrm{~m}$ depth was performed on the construction site. The excavation was supported by bored piles and multilayered anchorages.

In order to define the soil stratigraphy and determine the engineering properties of the soil, a ground investigation was performed. A total of 20 boreholes, whose plan view is shown in Figure 3.3, were drilled and some laboratory and field tests were conducted. According to these test results, there exists a fill layer whose depth ranges between $0.5 \mathrm{~m}$ and $8.0 \mathrm{~m}$, and just below the fill layer there exists an Ankara clay along the borehole. Also, some inclinometer and load cell measurements were taken in the construction site. The construction of the building continues; however, construction of basements was finished in June 2018.

In this study, back analysis of the deep excavation will be performed according to inclinometer measurement obtained from Block B excavation. SK-10 is the closest borehole to the related inclinometer among the boreholes. Therefore, back analysis study will be performed according to data obtained from this borehole. 


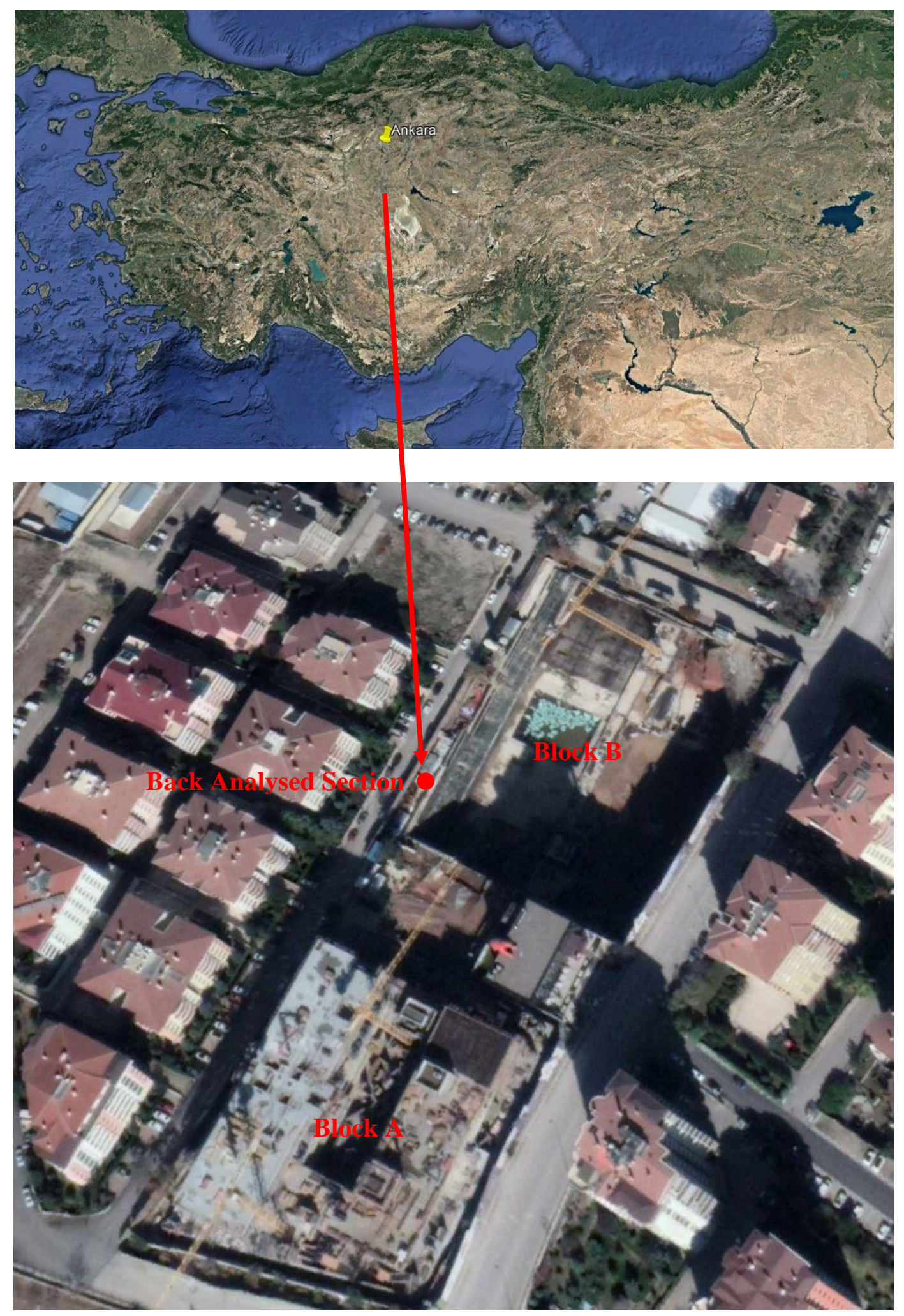

Figure 3.1. Satellite View of the Study Area 


\subsection{General Properties of the Back Analyzed Section}

Natural ground levels of the site where B block construction would take place are between $886.0 \mathrm{~m}$ and $882.5 \mathrm{~m}$. Bottom excavation level of the project is $861.0 \mathrm{~m}$. Since the topography of the construction area is inclined, depth of excavations varies along the shoring line. Excavation system is supported by $80.0 \mathrm{~cm}$ diameter piles with $1.0 \mathrm{~m}$ center to center distances and a multilayered anchor system. A cross-sectional view of the deepest excavation from which back analysis is performed is shown in Figure 3.2. Also, properties of this section are given below:

- There is a six-storey existing building 12 meters away from the shoring system.

- Depth of the excavation is $25.0 \mathrm{~m}$ and 12 rows of anchorages are used along the depth.

- Except for the first row, vertical anchorage distances are $2.0 \mathrm{~m}$.

- Horizontal anchorage distances for the first four rows are $2.0 \mathrm{~m}$ while it is $1.0 \sim 2.0 \mathrm{~m}$ for other rows.

- The concrete and steel class are specified by the design engineer as S420 and C25, respectively.

- 4 x 0.6 inches temporary anchorages are utilized for the whole shoring system. First three rows of anchorages were preloaded with 30.0 tons, the next six rows were preloaded with 40.0 tons and the others were preloaded with 50.0 tons.

- The length of the pile below the bottom excavation level is about 7.0 meters.

- Bond length of the anchorages is 8.0 meters.

- All anchorages are designed to have an angle of $15^{\circ}$ with horizontal axis. 


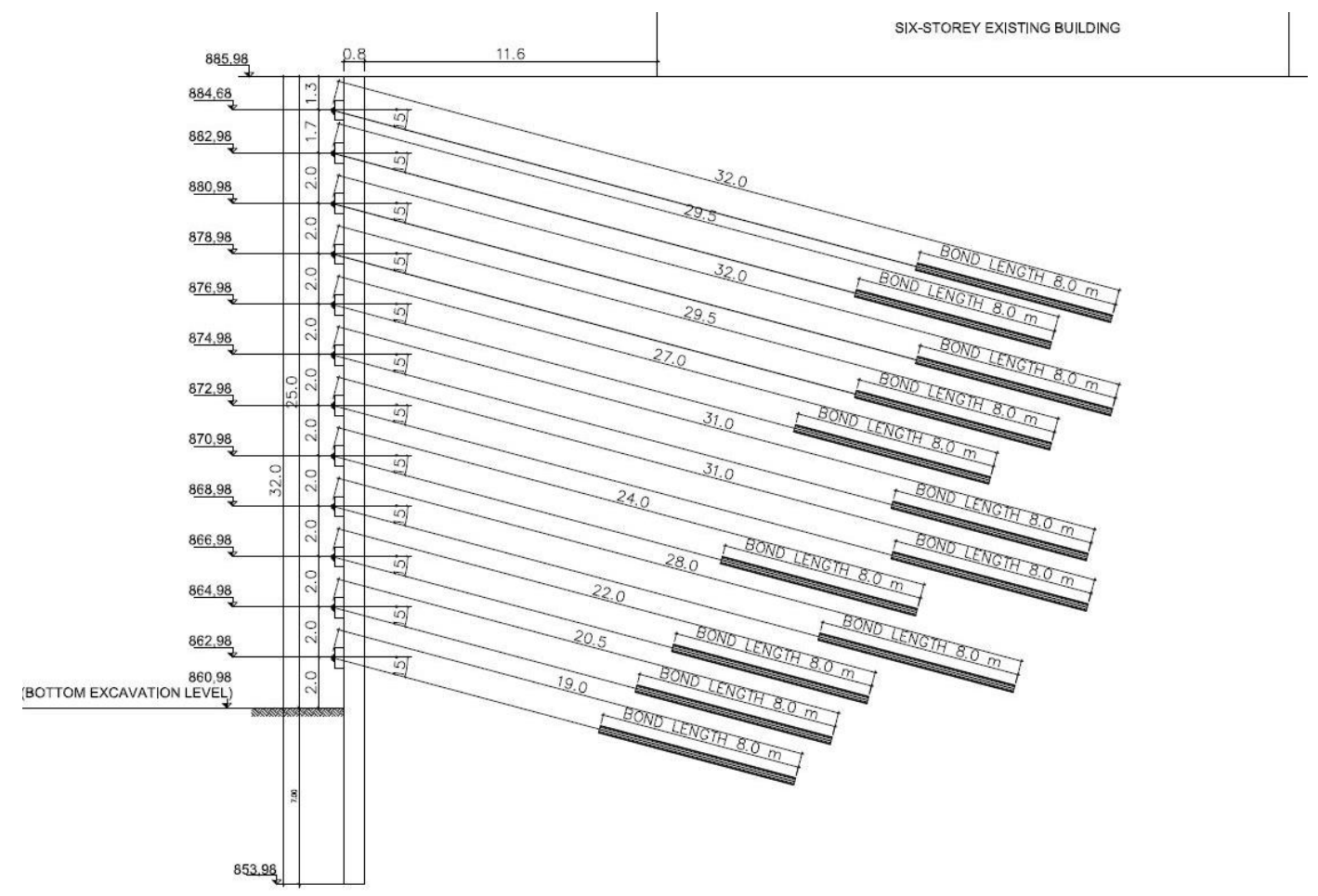

Figure 3.2. Cross Sectional View of the Shoring System

\subsection{Soil Properties}

In order to determine the soil properties and soil parameters, a ground investigation was performed using 20 boreholes at different locations of the construction site, each borehole has different depth and their total depth is about $1205.0 \mathrm{~m}$. The borehole layout plan is given in Figure 3.3. In each borehole, standard penetration tests (SPT) were carried out with $1.5 \mathrm{~m}$ intervals during drilling. Also, disturbed and undisturbed samples were taken from the appropriate levels of these boreholes and standard laboratory tests were performed to determine strength parameters (undrained shear strength) and index properties (water content, liquid limit, plastic limit, natural water content, unit weight and grain size distribution) of the soil. The soil samples were classified according to Unified Soil Classification System (USCS). 


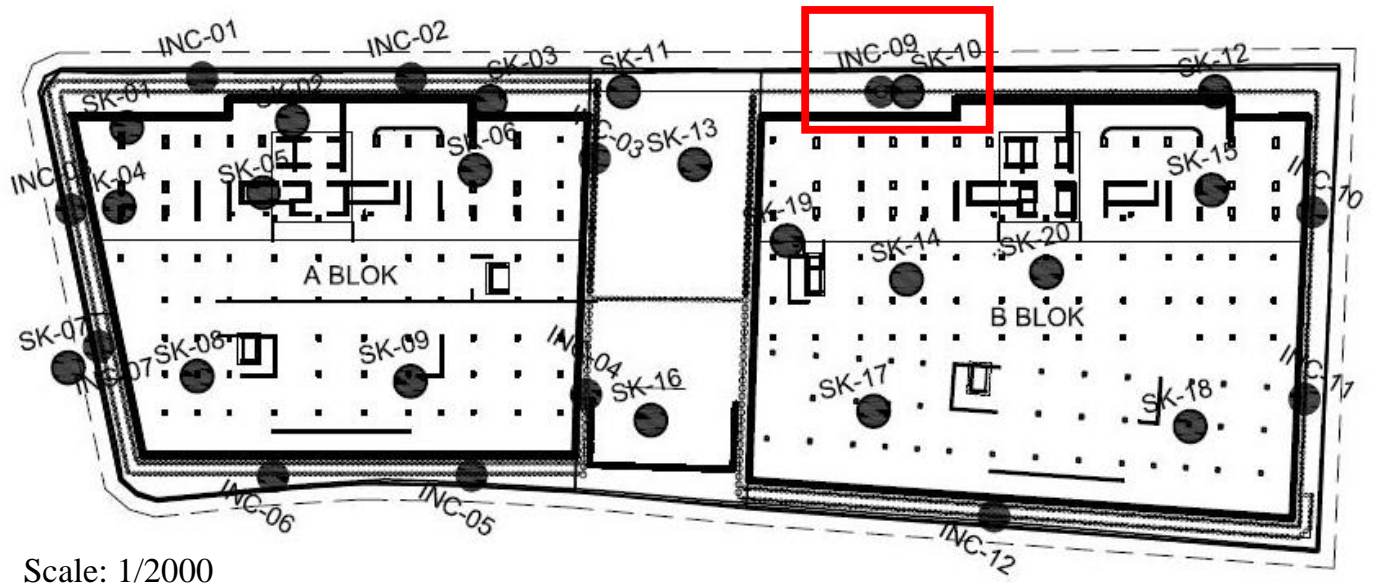

Figure 3.3. Borehole Layout Plan

In the ground investigation report, it is emphasized that there was a rubble fill in the site whose depth ranges from $1.0 \mathrm{~m}$ to $3.0 \mathrm{~m}$ and the site was cleared from the rubble fill before the ground investigation process.

According to the ground investigation report, there exists a fill layer whose depth ranges from $0.5 \mathrm{~m}$ to $8.0 \mathrm{~m}$ in all boreholes. Also, below the fill layer there exists an Ankara clay along the drilling hole and it is defined as medium to high plasticity clay in a reddish-brown color. Also, it is stated that Ankara clay in the site contains thin sandy-gravelly levels which have no continuity in horizontal and vertical directions. Soil tests were conducted to determine strength parameters and index properties of the Ankara clay.

In ground investigation report, 30 undrained shear strength $\left(c_{u}\right)$ parameters were obtained from unconsolidated undrained (UU) triaxial test. According to these test results, $c_{u}$ values are found between $41.0 \mathrm{kPa}$ and $95.0 \mathrm{kPa}$. However, these values are so low that it is unrealistic for stiff clays. The reason behind this is based on sand/gravel bands in the soil and the sample disturbance during transportation and sample taking process. SPT N test results were also available to correlate strength parameters of the soil. Graph that shows variation of SPT N values with depth is given in Figure 3.4. It seems that the $\mathrm{N}$ values of the Ankara clay increases with depth and 
it ranges from 12 to 100 . The corrected SPT N values $\left(\mathrm{N}_{60}\right)$ are calculated according to Equation 3.1.

$$
\mathrm{N}_{60}=\mathrm{N} \times \frac{\mathrm{ER}}{0.6} \times \mathrm{C}_{\mathrm{B}} \times C_{S} \times C_{R}
$$

Where:

$\mathrm{N}_{60}=\mathrm{SPT} \mathrm{N}$ values corrected for $60 \%$ energy efficiency and field procedures

$\mathrm{ER}=$ Hammer energy ratio $(\mathrm{ER}=0.45)$

$C_{B}=$ borehole diameter factor $\left(C_{B}=1.05\right.$; for $120 \mathrm{~mm}$ drill diameter $)$

$\mathrm{C}_{\mathrm{S}}=$ sampling method factor $\left(\mathrm{C}_{\mathrm{S}}=1.0\right.$; for standard sampler $)$

$C_{R}=$ correction factor for rod length $\left(C_{R}=0.75\right.$; for $3.0 \mathrm{~m}$ rod length $)$

A total of 136 sieve analysis and Atterberg limit test results are available for the construction site. According to these test results;

- According to USCS soil classification system, soil type is designated as CL in 121 of the 136 laboratory test results and for the remaining test results soil type is designated as $\mathrm{CH}$.

- PI values of the samples ranges from 18.1 to $35.6 \%$.

- Water content and liquid limit of the samples are in between $16.5 \%$ and $49.7 \%$, and $37 \%$ and $61 \%$, respectively.

- Unit weight of the samples ranges from $18 \mathrm{kN} / \mathrm{m}^{3}$ to $21 \mathrm{kN} / \mathrm{m}^{3}$.

- The percentage of soil samples passing through No 200 sieve and remaining above the No 4 sieve ranges between $67 \%$ and $98 \%$, and $0 \%$ and $39.4 \%$, respectively. All laboratory test results are given in Appendix A. 


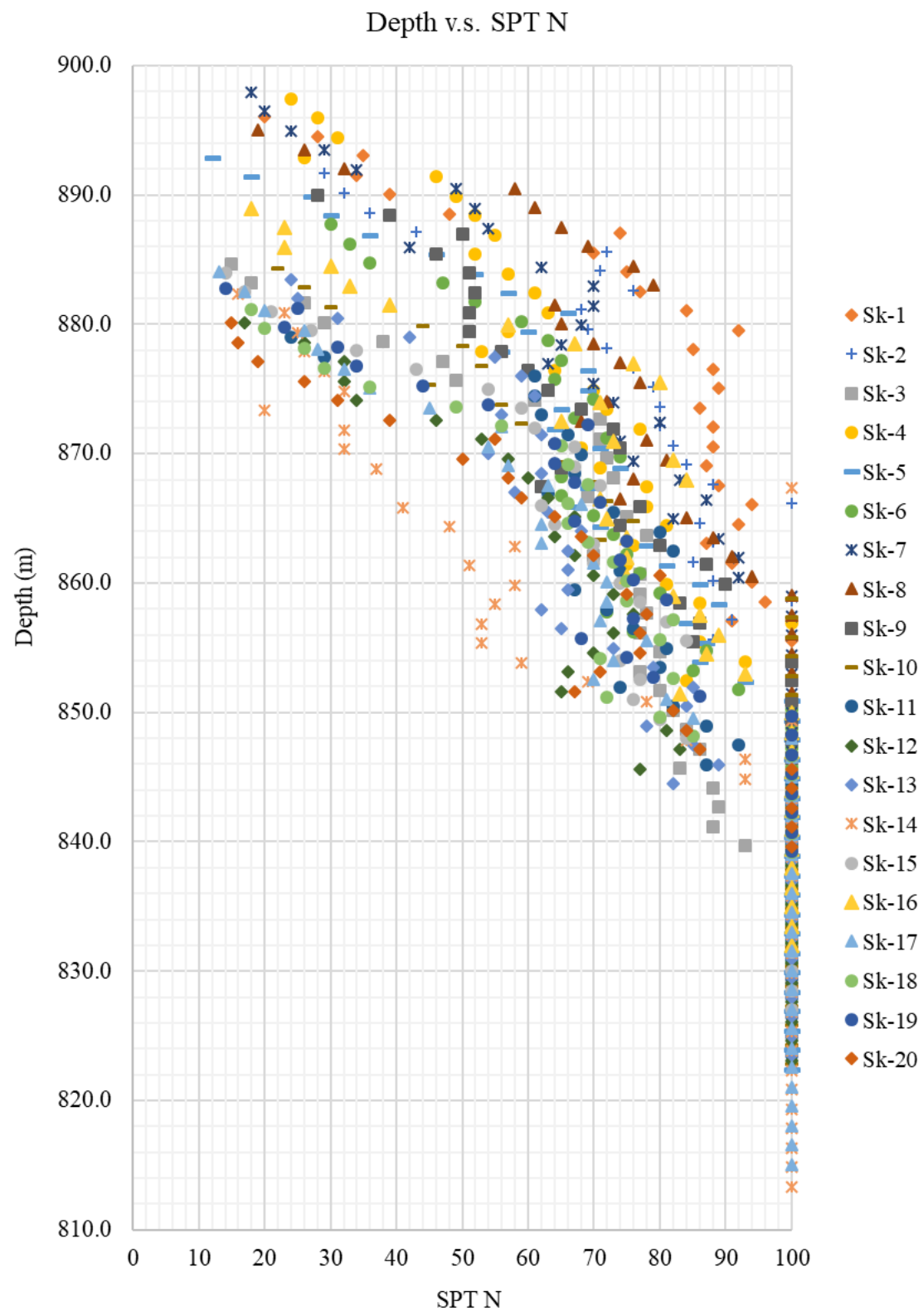

Figure 3.4. Variation of SPT N Values with Depth

Groundwater measurement was performed on all boreholes. In the ground investigation report, it is stated that there observed a water in the depths between $6.0 \mathrm{~m}$ to $12.0 \mathrm{~m}$. However, it was reported that these waters are perched water and it came from thin sandy gravelly levels which have no continuity in horizontal and vertical directions. Also, field observations support this information. 
Among the 20 boreholes, SK-10 is the closest borehole to the section for which back analysis will be performed. Boring depth of the SK-10 is $65.0 \mathrm{~m}$ and boring elevation is reported as $886.0 \mathrm{~m}$. According to this borehole, there exists a fill layer whose depth is approximately $1.5 \mathrm{~m}$ and below this layer there exists an Ankara clay along the borehole. Sieve analyses and Atterberg limit test results are available for the samples taken from this borehole. Also, an oedometer test was carried out at $3.5 \mathrm{~m}$ depth below the natural ground surface near the back analysed section (Figure 3.5), and it was found out that preconsolidation pressure of the sample is approximately $200.0 \mathrm{kPa}$. Considering preconsolidation pressure, overconsolidation ratio was calculated as 3.2 $(\mathrm{OCR}=200 /(3.5 \times 18))$ in the soil sample. A diagram that shows variation of SPT N, sand percent (> \#4), clay percent (<\#200), plasticity index (PI), liquid limit (LL) and water content values with depth are given in Figure 3.6.
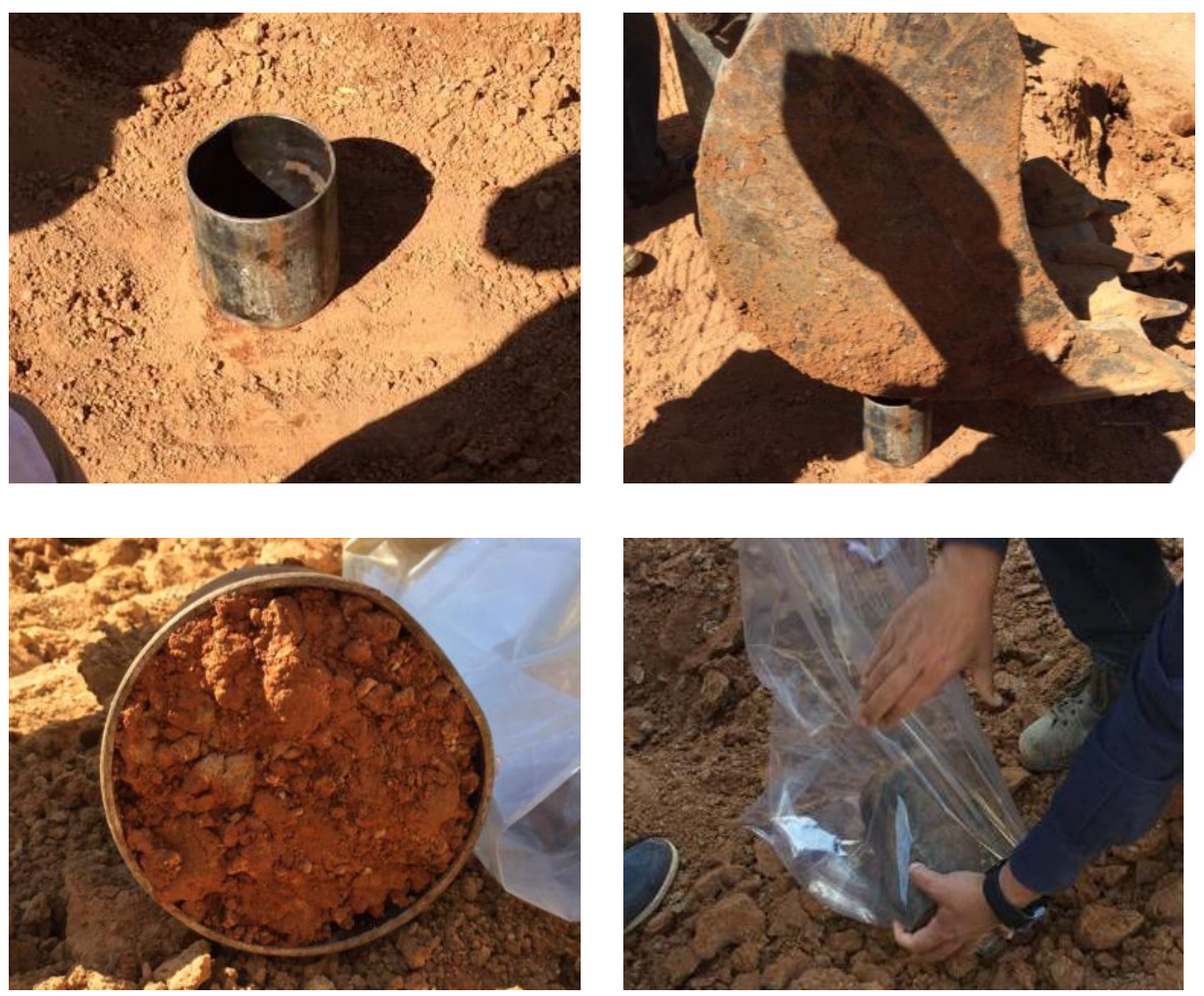

Figure 3.5. Receiving Undisturbed Sample from the Site for Oedometer Test 

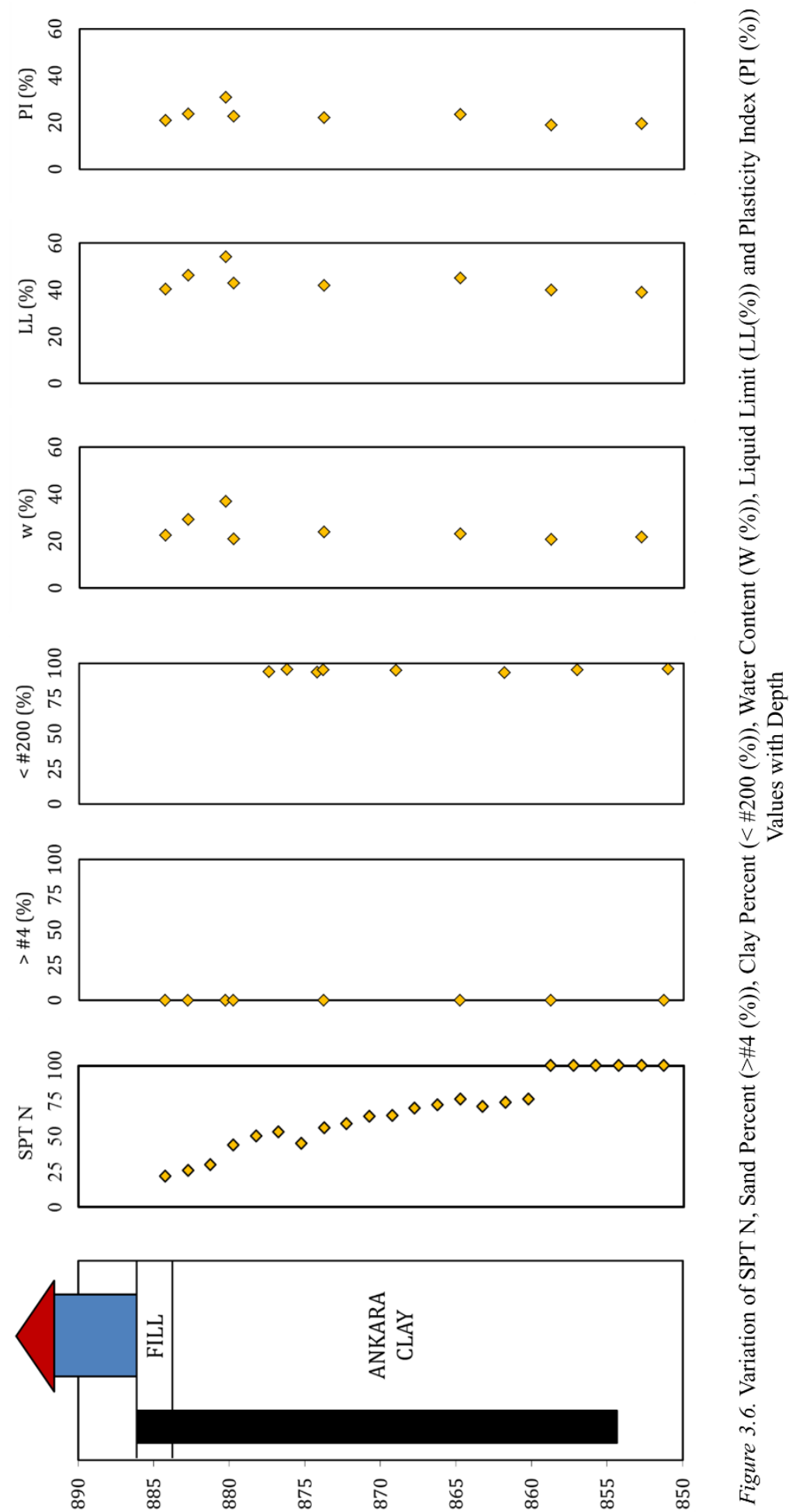


\subsection{Instrumentation and Monitoring}

The horizontal movements of the soil layers are measured by 12 inclinometers, whose layout plan are given in Figure 3.3, in the site. 8 of these inclinometers belong to shoring system where A Block excavation was performed and 3 of them are in the site where B Block excavation was carried out. Some inclinometer measurement errors have been detected in measurement results of the A Block; therefore, calibration of the inclinometer device was ensured before the B Block measurements started. For the comparison of horizontal displacements with finite element models, data obtained from the inclinometer 9, which belongs to B Block are used. There are two (2) reasons for selecting this inclinometer. First of all, some errors are determined for the A Block inclinometer measurement results (inclinometers between 1 and 8); therefore, A Block inclinometers are disregarded. Secondly, among the inclinometer measurements performed on the B Block excavation, inclinometer 9 is the closest inclinometer to a borehole, which is SK-10. Considering the purpose of the study, this inclinometer measurements are found to be appropriate for correlating SPT N values with the deformation modulus parameter $(\mathrm{E})$, which ensures the displacements obtained from the site measurements. Measurements for inclinometer 9 were taken for $34.0 \mathrm{~m}$ depth starting from the pile top elevation. The measurement results are given in Figure 3.7.

The load cell was also placed to the $4^{\text {th }}$ anchor level $(878.98 \mathrm{~m})$ of the pile where the inclinometer 9 was located. 


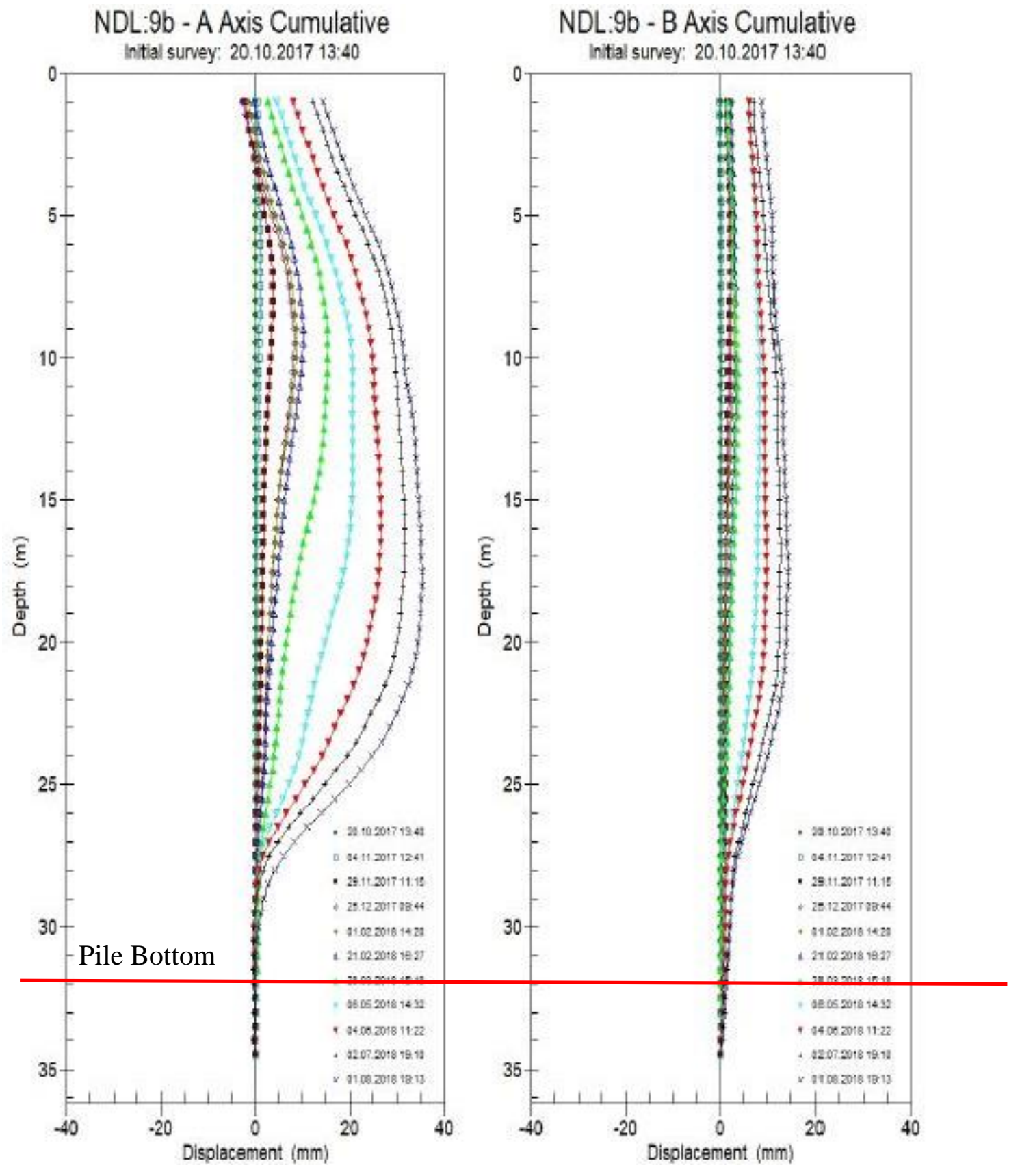

Figure 3.7. Inclinometer 9 Measurements 



\section{CHAPTER 4}

\section{METHODOLOGY}

Plaxis $2 \mathrm{D}$ is a finite element software which is mainly used to analyze stabilities and deformations of soils. It gives opportunity to users to model the soil with different soil models like Mohr-Coulomb model, hardening soil model (HS) and hardening soil model with small strain stiffness (HSsmall). Assumptions and basic principles of these models are mentioned in Chapter 2 in detail. For the purpose of the thesis, parametric back analysis study is performed with a Python code interacted with Plaxis 2D software. Although by using Plaxis 3D more accurate results would probably be obtained, Plaxis 2D was preferred for parametric back analysis study since the plain strain assumption used in Plaxis 2D is an accepted theory for most of the soil problems and the increase of accuracy of the model may not worth the time cost of $3 \mathrm{D}$ analysis from the point of iterative analysis.

Information about the site for which back analysis study is performed, support system and field-laboratory test results are given in Chapter 3. In this part of the thesis, modeling of the back analyzed system will be discussed. First of all, some background information will be given about the software and modeling principles of Plaxis 2D will be explained. Secondly, background information about Plaxis remote scripting with python will be given and Python code details about back analysis study will be discussed.

\subsection{Finite Element Modelling with Plaxis 2D}

Plaxis 2D is mainly composed of two programs which are input and output. Input program consists of 5 subsections. These are soil, structures, mesh, flow conditions and staged construction. Type of model (plane strain or axisymmetry), type of elements (6-noded or 15-noded) and units can be determined from the project 
properties section. To model the soil geometry, boreholes can be used or soil layer boundaries can be imported from the soil subsection, or it can be modelled by creating soil polygons from the structures part. Model geometry, soil and material parameters and load properties can be created; in addition, soil and material parameters can be assigned from the structure subsection of the input program. From the material sets toolbar; material model, drainage type, soil parameters and groundwater conditions can be characterized. Before creating a mesh, all geometry must be modelled and properties of the materials must be assigned, otherwise, computational errors may be encountered. After creation of the geometry, generation of mesh process starts in order to perform finite element calculations. In the mesh subsection, the geometry is separated into finite elements with a desired level of fineness. Five (5) automatic mesh options are available in the software; also, Plaxis offers users to choose mesh dimensions and mesh size from the expert settings. Water levels can be added from the flow conditions subsection. After this part, one may start calculations. According to the purpose of the study, the model can be divided into calculation steps in stage construction part. Stage construction starts with the initial phase. Calculation type of the initial phase can be selected from several options such as $\mathrm{K}_{0}$ procedure, gravity loading and field stress. Stages after the initial phase can be constituted according to construction phases on the site. For these stages, one of the calculation methods which are plastic, consolidation, safety, dynamic and dynamic with consolidation can be selected. In deep excavation problems, plastic analysis is recommended. The plastic analysis considers elastoplastic drained and undrained behavior of soils; on the other hand, consolidation is not considered in this analysis type. After calculations are completed, analysis results can be obtained from the output program. The main outputs of this program are the displacements and the stresses. Moreover, if the finite element program contains structural elements and forces applied to these elements, additional outputs related to these structural elements like deformations, axial shear forces, bending moments, etc. may be obtained. 
Plaxis is a useful geotechnical tool which provides many options to users for simulating the soil behavior with its' advance soil models, stage construction option and different calculation methods. However, it does not have an option for modeling actions that have a repetitive nature; therefore, the software gives opportunity to users having VIP license for the automation of the problem with using Python scripting. Automation is needed for the following cases;

- Parameter or design optimization

- Running multiple calculations in a short time

- Doing same actions in input program (e.g. calculation, changing parameter)

- Reusing data from databases

In this thesis, parametric study is performed by using Python scripting. Input and output backgrounds of the code in Plaxis 2D are given in the following sections.

\subsubsection{Input}

In this part of the thesis, detailed information will be given how the geometry of the model is created, what parameters of soil and material are taken and how mesh sizes and calculation stages are created.

\subsubsection{Geometry}

Creating geometry starts with determining the size of the model. Plaxis 2018 fixes the boundaries of the model in all directions automatically. Boundaries of the model are selected large enough so that soil zone of interest will not be affected from these fixities. On the other hand, enlarging the soil boundaries also increases computation time. Therefore, an optimal boundary size should be determined. After several trials, half of the width of the site is found to be appropriate for the boundary length of the model.

Geometry of the deep excavation problem is modelled in the structure subsection of the input program by using points, lines, plates, node to node anchors, geogrids and 
clusters. Bored pile is modelled with plate element in Plaxis 2D analysis. Also, the interfaces are included to the plate element to simulate the soil structure interaction. Free length and bond length of the anchors are modelled as node to node anchor and geogrid, respectively. The parameters assigned to these materials are described in detail in the next section.

As mentioned in previous section, there is Ankara clay on the construction site. In order to perform parametric analysis and correlate soil stiffness with SPT $\mathrm{N}_{60}$ values, soil is divided into layers in accordance with the vertical distances between SPT N test measurements $(1.5 \mathrm{~m})$. Soil clusters are used in order to create soil polygons. Figure 4.1 shows soil layers (20), pile, free length and bond length of anchors, and road $(20 \mathrm{kPa})$ and building loads $(90 \mathrm{kPa})$.

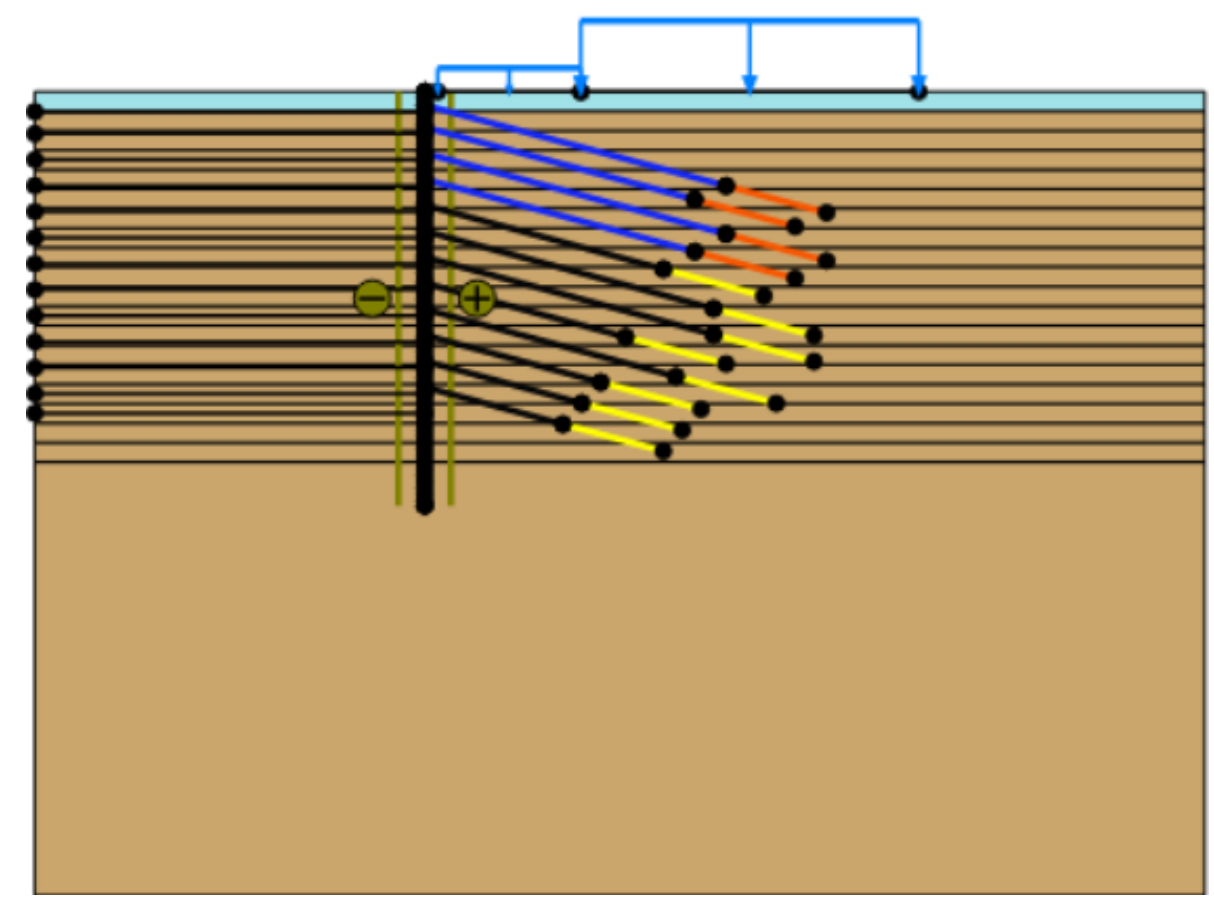

Figure 4.1. Geometry of the Model (Scale: 1/750) 


\subsubsection{Material Parameters Used in Plaxis}

The choice of material properties in finite element analysis is important in order to reflect the system precisely. In this study, three different constitutive soil models, namely Mohr Coulomb model, hardening soil model and hardening soil model with small strain stiffness, are used to simulate the soil behavior. For all these soil models; drained, undrained and non-porous drainage types are available to represent the pore pressure behavior of soils in Plaxis 2D. Since long term stability is more critical in excavations for overconsolidated clays like Ankara clay, it is decided to use drained parameters in the analysis.

A parametric study is performed for different elastic modulus values of the Ankara clay whose SPT N values are less than 100. While the deformation modulus of Ankara clay is changed, other geo-mechanical properties of soil like friction angle, unit weight, dilatancy angle, cohesion and Poisson's ratio are kept constant. Among these parameters; $\varphi^{\prime}, c^{\prime}, \psi$ (strength parameters) take the same values for MC, HS and HSsmall models because stress state at failure is predicted by Mohr-Coulomb failure criteria for these models. Furthermore, parameters c' and $\varphi^{\prime}$ are varied through the depth of Ankara clay and their values are in the range of $12-17 \mathrm{kPa}$ and $22^{\circ}-24^{\circ}$ respectively. Ranges of these parameters are determined with respect to the studies of several researchers (Mirata [1976] and Çalışan [2009]) and optimum values of these parameters for each Ankara clay layer is obtained by iteratively changing the parameters in the specified range.

Ankara clay whose SPT N value equals to 100 are considered as weathered claystone (soft rock) according to classification made by Clayton (1995) and its' parameters are determined from the literature research. Since SPT N values are not exactly known for this layer (measurements are taken until $\mathrm{N}=100$ ), correlation of stiffness modulus with SPT $\mathrm{N}_{60}$ values was not made. Instead, range of the correlation proposed by Stroud (1989) is used to obtain stiffness modulus parameter. In addition, strength parameters c' and $\phi$ ' are determined with respect to the ranges specified by Hoek et 
al. (1981). Iterations are made in such a way that for one selected parameter set $\left(\mathrm{E}_{50}{ }^{\mathrm{ref}}\right.$, c' and $\phi$ ') of weathered claystone (soft rock), displacement curve is compared with measured displacements and this process is repeated for each parameter set in the specified ranges up until the set that minimize total error is found. As a result, the upper bound of the correlation of Stroud (1981) is found to be appropriate for $\mathrm{E}_{50}{ }^{\mathrm{ref}}$. Parameters of the fill layer are obtained from similar sites reported by Çalışan (2009). Parameters of fill and weathered claystone (soft rock) are given in Table 4.1. During parametric analysis, stiffness of fill and weathered claystone (soft rock) are also kept constant for each model. In MC model, deformation modulus parameter (E') of fill and weathered claystone (soft rock) are taken as 1.5 times the $\mathrm{E}_{50}{ }^{\text {ref }}$ value of the HS/HSsmall model, as suggested by Gouw (2014), because MC model uses only one deformation modulus parameter to simulate primary loading, reloading and unloading behavior of soils.

According to the research of Karatağ (2012), power m value is taken as 0.55 for all layers of Ankara clay. Also, $K_{0}$ value is taken as the default value $\left(K_{0}=1-\sin (\varphi)\right)$ since there is no consolidation test result to determine OCR ratio of Ankara clay for all of its' soil layers.

The altitude of $886.0 \mathrm{~m}$ is defined as zero elevation $( \pm 0.00)$ in the project 


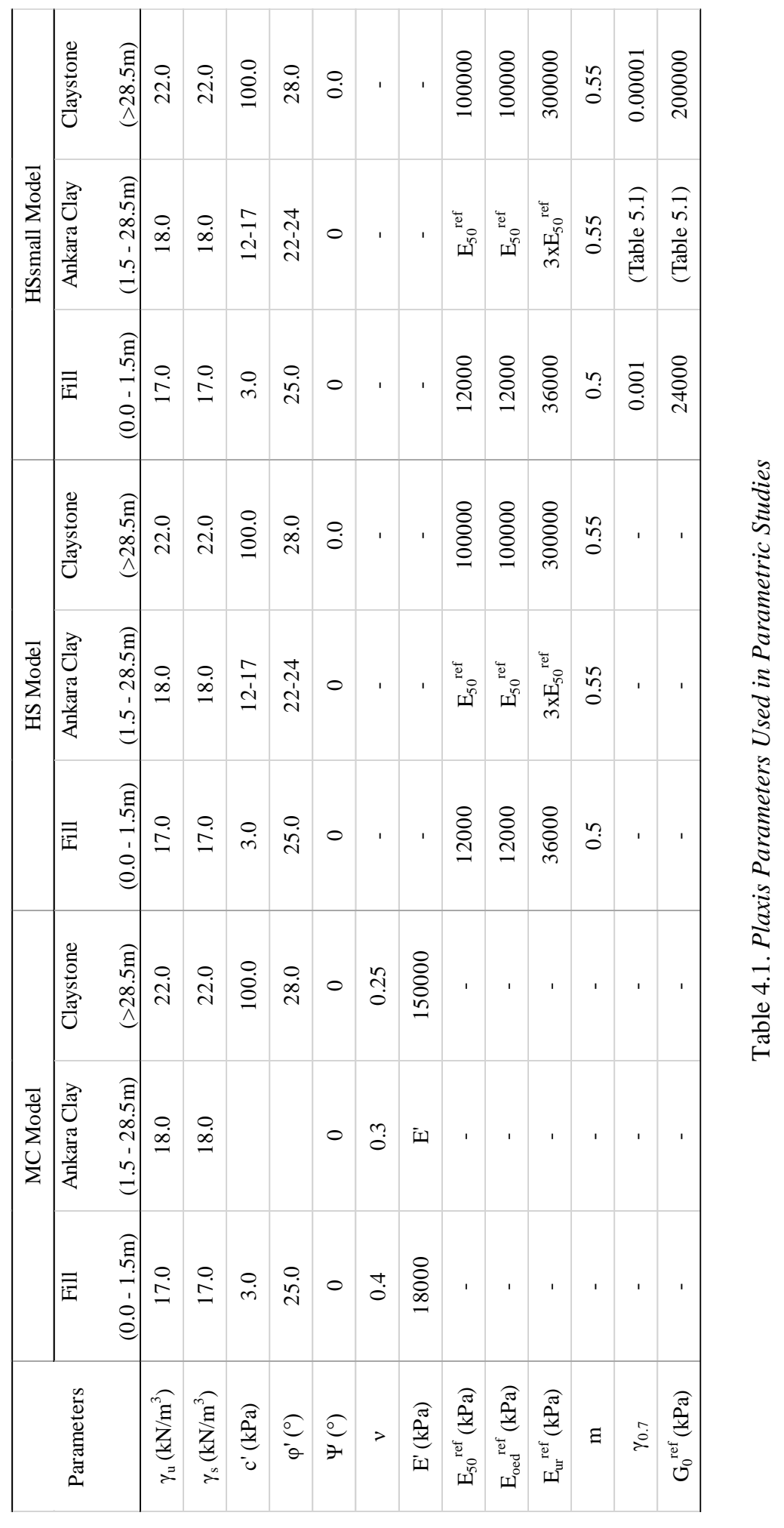


$80 \mathrm{~cm}$ diameter piles with $1.0 \mathrm{~m}$ center to center distance are used in the construction site. Bored piles are modelled with plate element in Plaxis 2D analysis and elastic material properties are selected. The parameters used for bored piles are shown in Table 4.2 .

$\mathrm{E}=285 \times 10^{5} \mathrm{kPa}(\mathrm{C} 25$ concrete class $)$

$\mathrm{A}=\pi \times \mathrm{d}^{2} / 4=\pi \times 0.8^{2} / 4=0.5 \mathrm{~m}^{2}$

$\mathrm{I}=\pi \times \mathrm{d}^{4} / 64=\pi \times 0.8^{4} / 64=0.02 \mathrm{~m}^{4}$

4 x 0.6 inches temporary anchorages are utilized in the construction site and prestress anchorages consists of 7-wire strands. Specific characteristic strength of 7 wire strand is given in Table 4.3. Strands, whose nominal diameter are $15.2 \mathrm{~mm}$, are used for prestressing anchorages in the construction site.

Table 4.2. Input Data of the Structural Element (Plate Element)

\begin{tabular}{cccc}
\hline \hline Parameter & Symbol & Value & Unit \\
\hline Material Type & Elastic & - & - \\
Axial stiffness & EA & 14325663 & $\mathrm{kN} / \mathrm{m}$ \\
Bending stiffness & EI & 573027 & $\mathrm{kN} . \mathrm{m}^{2} / \mathrm{m}$ \\
Weight & w & 5 & $\mathrm{kN} / \mathrm{m} / \mathrm{m}$ \\
Poisson's ratio & $v$ & 0.2 & - \\
\hline
\end{tabular}

Table 4.3. Specific Characteristic Strengths of 7 Wire Strands (BS8081)

\begin{tabular}{cccc}
\hline \hline \multirow{2}{*}{ Type of steel } & $\begin{array}{c}\text { Nominal } \\
\text { diameter } \\
\mathrm{mm}\end{array}$ & $\begin{array}{c}\text { Characteristic } \\
\text { strength } \\
\mathrm{kN}\end{array}$ & $\begin{array}{c}\text { Nominal steel } \\
\text { area } \\
\mathrm{mm}^{2}\end{array}$ \\
\hline \multirow{3}{*}{ 7-wire strand } & 12.9 & 186 & 100 \\
& 15.2 & 232 & 139 \\
& 15.7 & 265 & 150 \\
\hline
\end{tabular}


Anchor parameters defined in Python code for Plaxis analysis are given below;

$\mathrm{E}_{\text {anchor }}=195 \mathrm{kN} / \mathrm{mm}^{2} \quad($ BS8081 Figure 12)

$\mathrm{A}_{\text {anchor }}=139 \times 4=556.0 \mathrm{~mm}^{2} \quad($ Table 4.3$)$

$\mathrm{EA}=108420.0 / 2.0=54210 \mathrm{kN} / \mathrm{m} \quad$ For $2.0 \mathrm{~m}$ anchor spacing

$\mathrm{EA}=108420.0 / 1.5=72280 \mathrm{kN} / \mathrm{m} \quad$ For $1.5 \mathrm{~m}$ anchor spacing

Bond length of the anchorages are modelled as geogrid in Plaxis 2D using Python code. Geogrids are slender structures having only axial stiffness, no bending stiffness. The only parameter of geogrid is EA per unit length. Considering $15.0 \mathrm{~cm}$ bond diameter of anchorages in the project, axial stiffness values per unit length are calculated as;

$\mathrm{E}=285 \times 10^{5} \mathrm{kPa}$

$\mathrm{A}=\pi \times 0.15^{2} / 4=0.017 \mathrm{~m}^{2}$

$\mathrm{EA}=285 \times 10^{5} \times 0.017 / 2.0=251818.0 \quad$ For $2.0 \mathrm{~m}$ anchor spacing

$E A=285 \times 10^{5} \times 0.017 / 1.5=335758.0$ For $1.5 \mathrm{~m}$ anchor spacing

\subsubsection{Mesh}

The geometry of the excavation is in rectangular shape. Therefore, the plane strain model is used for the analysis with considering uniform cross section of the excavation. The plane strain models assume uniform cross section and no deformation in $\mathrm{z}$ direction during analysis. Also, 15 node triangular elements, which is the default element, are selected for modelling of soil layers and volume clusters.

Mesh size is important in terms of accuracy and calculation time. When the size of the mesh decreases, complexity of the model and the accuracy of the analysis increases. However, mesh refinement non-linearly increase the calculation time. Considering 
this property of finite elements, regions that require less accuracy are modelled with coarse mesh. For regions where high accuracy is needed like the surrounding of pile and anchors are modelled with fine mesh. In order to reduce the mesh size some geometric alterations are made in those regions. For example, on pile, extra points are created with $0.5 \mathrm{~m}$ spacing, which is the spacing between inclinometer measurements, so that mesh distribution will follow the geometry and decrease the mesh size.

In Plaxis, default mesh size is "Medium"; however, for the analysis "Coarse" mesh size is selected with g_i.mesh() command as with the default selection mesh convergence issues are encountered. Applied mesh is given in Figure 4.2.

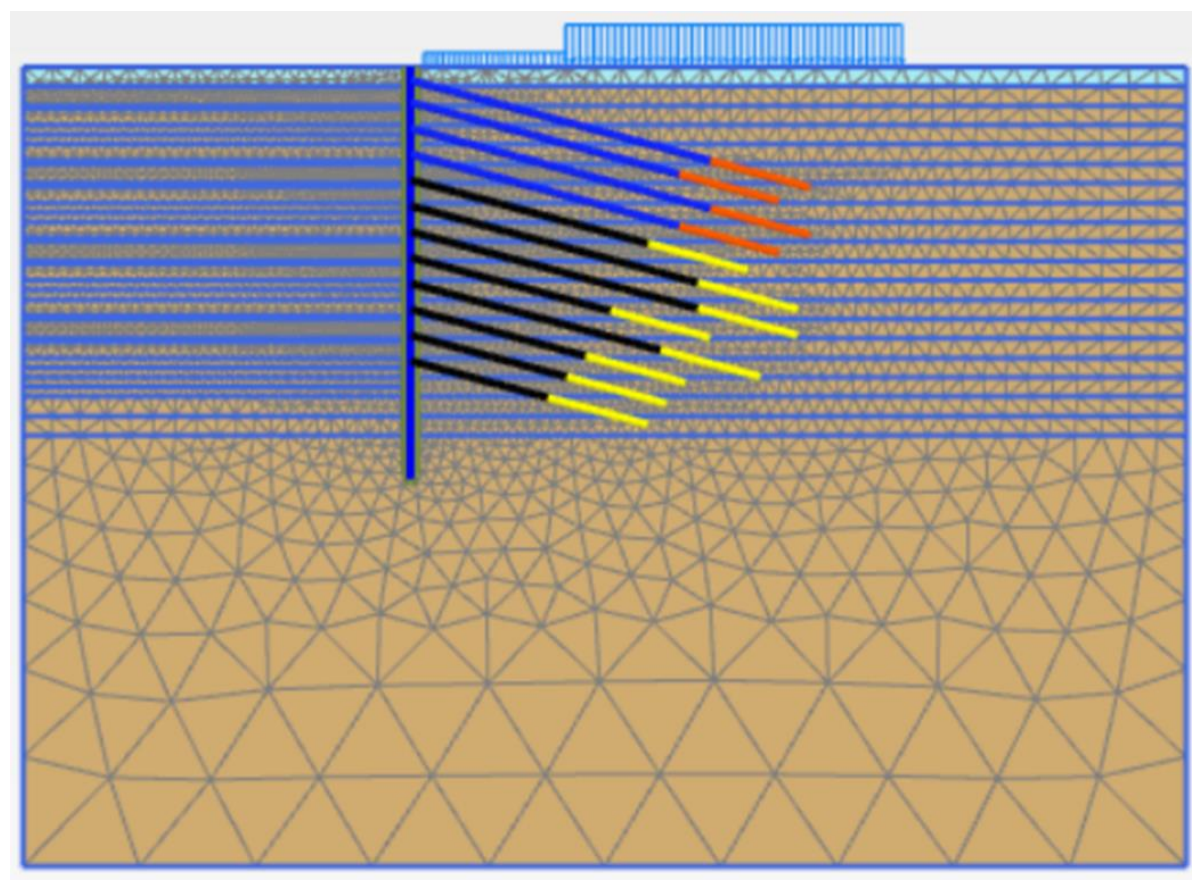

Figure 4.2. Applied Mesh to the System (Scale:1/750)

\subsubsection{Calculations}

The full height of the excavation cannot be performed in a single stage; therefore, stage construction is needed to reflect the real situation. Each analysis of the anchor 
supported system consists of 25 consecutive stages. Analysis starts with initial phase. In this phase, surcharge load of the building and the road are implemented to the finite element model and $\mathrm{K}_{0}$ procedure is selected for initial stress state. The calculation procedure is continued with activation of the pile and its interfaces. Furthermore, excavation is performed up to a level which is $0.5 \mathrm{~m}$ below the first -row anchor level. This stage is followed by the activation of the first-row anchor and application of prestress. Other construction stages continue with the subsequent excavation phase and anchor activation phase, these come one after another. In excavation stages, excavation is performed up until $0.5 \mathrm{~m}$ below the following anchor level and in anchor stages, anchorage is activated and prestressed. After final anchorage level is activated, stage construction is finalized with the excavation up to the bottom excavation level. Each stage construction (except the initial phase) is automized by using Python scripting and the algorithm is presented in Section 4.2.

\subsubsection{Output}

Calculation results in the form of plots and tables can be obtained for the full model or selected structures from the output program. Outputs of the analysis are created and stored by using Python scripting. Outputs of the study are given in Chapter 5.

\subsection{Python Scripting of Plaxis}

Plaxis enables user to utilize Python codes to alter the flow of calculations and to make automation studies. Scripts may be written in any text editor; however, the one provided by Plaxis is named SciTE. In this part of the thesis, details of the Python code written for back analysis are explained.

Hashash et al (2006) states that optimization techniques provide a powerful tool for model calibration using field measurement though they have important limitations:

- The techniques are unable to overcome inherent limitations in the selected material constitutive model such as the inability to capture small strain 
nonlinearity essential to representing the distribution of deformations around an excavation;

- It is possible that several combinations of material model properties may lead to similar estimates of deformations, leading to nonconvergence or nonuniqueness in the solution

\subsubsection{Remote Scripting Server}

Before running a script in Plaxis, one should activate the Remote Scripting Server from the Expert menu and also an internet connection is required along with a VIP license for utilizing Python scripts. Activation of the Remote Scripting Server has the following steps:

- Starting the Plaxis Input application.

- Starting a new project.

- Going to Expert menu and selecting Configure remote scripting server. Figure 4.3 shows the window that will open.

- Configuring the port which is 10000 as default.

- Defining the password which is provided by Plaxis for VIP license.

- Starting the server.

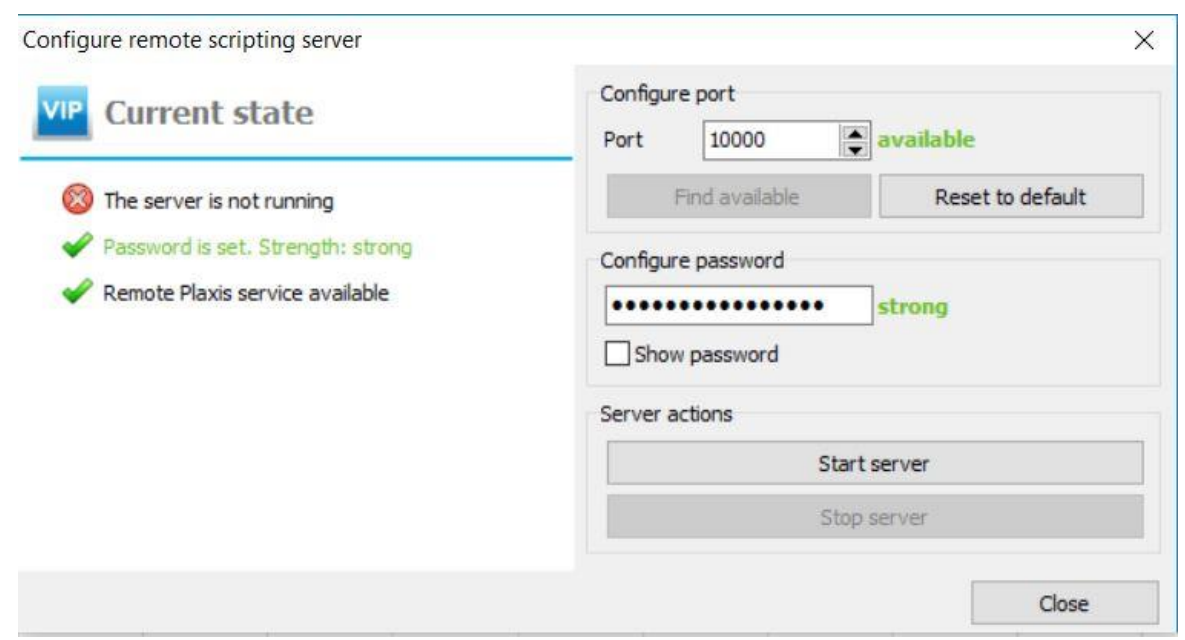

Figure 4.3. Configure Remote Scripting Server of Plaxis 2D 
After following these steps, if the tick mark on the left side of "The server is not running" activates, then it means server is ready and scripts can be run. This procedure is demonstrated for Plaxis Input while for Plaxis Output a different port number shall be used.

\subsubsection{SciTE Editor}

SciTE Editor unlike other text editors eases the interaction of Python scripts and Plaxis as SciTE has a direct connection to Plaxis and there is no need to use user interface of Plaxis anymore after remote scripting server is activated.

For utilizing Python scripts some adjustments should be made in SciTE. First, the programming language should be selected as "Python" from the Language menu, and then scripts should be saved with “.py” extension. In order to run the scripts, one shall only need to press the F5 button.

\subsubsection{Boilerplate Code}

In any Python code, the first step is to import the libraries and to set up the connection to Plaxis. This task can be achieved by so called "boilerplate code" and it is as follows:

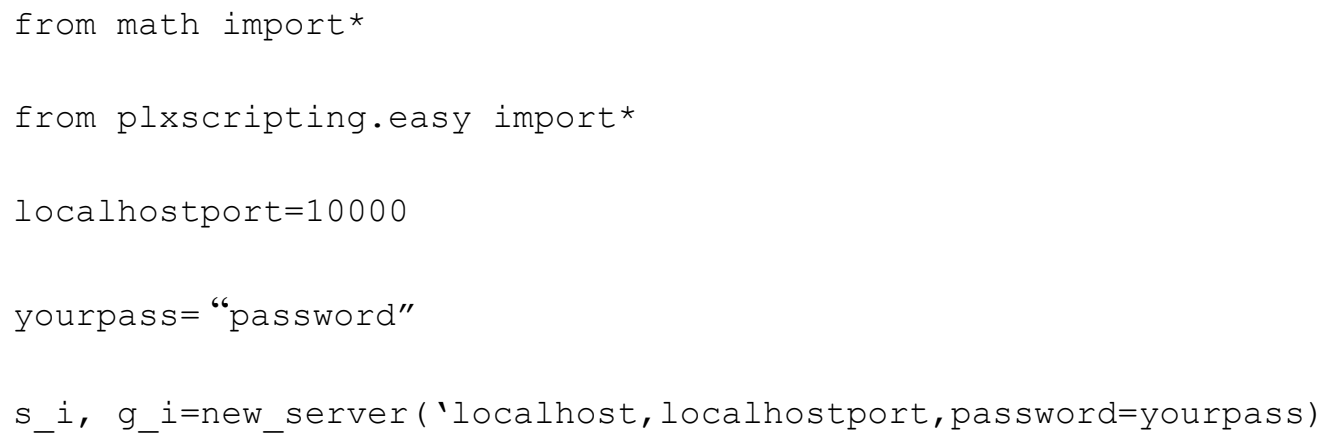

In this boilerplate code localhostport is defined to be 10000 which is the value entered in the remote scripting server. Likewise, password (yourpass in the boilerplate code) should be the same that entered in the remote scripting server.

The variable $\mathrm{s}$ _i bounds to objects that represent Plaxis to allow the users to control project files like opening projects while variable g_i relates to objects that allow the 
users to manipulate the current model. It is worth to mention that s_i and g_i are both related to Plaxis Input objects.

\subsubsection{Start of Iterations}

Since the purpose of this study is to correlate stiffness of soil layers to SPT $\mathrm{N}_{60}$ values with a linear formulation, Python code starts with a for loop with respect to correlation constant of SPT $\mathrm{N}_{60}$. Maximum and minimum values of this constant with incrementation is defined in the code for the for loop.

For estimating the time required for analysis a time counter is included in the program. Furthermore, date and time data are used as a prefix in file names for identification of the files. Following code is utilized for obtaining date and time in desired format:

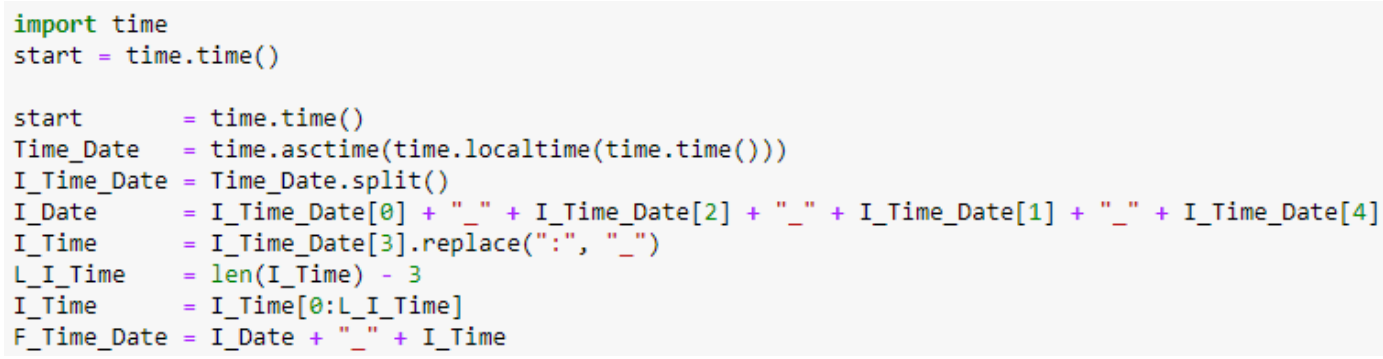

As seen in above code "time" should be imported first and start of timer is set with "time.time()" function. Date and time data is stored in the variable Time_Date. However, default value stored in Time_Date is not in desired format. For example for a run in Saturday 21 April 2019 at 10:15 Time_Date will give 'Sat Apr 21 10:15:00 2019'. Therefore, at the rest of the code Time_Date is arranged in order to seperate the date and time data. Final parameter F_Time_Date will give day, date, month, year and time in order. For the specified example F_Time_Date will give 'Sat_21_Apr_2019_10_15'. 


\subsubsection{Inputs}

Python code requires input values related to the geometry of the shoring system, soil properties and support system. All inputs are gathered in 'Inputs' section of the code which makes the code more user friendly. Detailed information is given in this section about these inputs and how they are implemented into the code.

Inputs of the code are as follows:

- Project path

- Material model name (MC, HS or HSsmall)

- Shoring system geometry

- Soil properties

- Support system properties

- Loads (Preloads; road and building loads)

First input to the code is the path to be used for data transfer. Path is defined with a string in the following format;

Project_path $=$ 'D $: \backslash$ ProjectPath'

Next, material model name is defined. Model name is used in result files for identification purposes along with the F_Time_Date parameter. In addition, it is used to adjust the soil properties.

Code is continued with defining boundaries of the system. Boundary size of the shoring system is defined in the code according to reasons described in section 4.1.1.1. After this part, properties of the support system are defined. These include anchor angles, vertical distance between anchors, anchor lengths, pile location in x-direction and pile start and end coordinates. Since anchor lengths are not the same, they are stored in an array. Preload of anchors are stored in an array as well.

Constant soil parameters which will be used in material models are also defined in this section. As mentioned previously, soil is separated into three regions according to its 
properties, namely fill, Ankara clay and claystone. Then soil parameters of each layer are defined. Definition of soil parameters are made in such a way that parameter names include soil layer names as prefixes like Fill_nu parameter. Because Ankara Clay is divided into layers with $1.5 \mathrm{~m}$ thicknesses, parameters of each layer like friction angle, cohesion, etc. are defined with arrays.

Soil stiffness parameter is adjusted in the code with if and elif commands using Model name so that the input stiffness value of HS and HSsmall material models will be $\mathrm{E}_{\mathrm{ur}}{ }^{\text {ref }}$ while it is E' for MC model. $\mathrm{E}_{50}{ }^{\text {ref }}$ values of HS and HSsmall models are calculated to be one-third of $\mathrm{E}_{\mathrm{ur}}^{\mathrm{ref}}$ in the same if-elif block.

Finally, lineload values are defined in the code that simulate road and building loads on the shoring system. Lineloads are used in Plaxis to create uniformly distributed pressure loadings. Two lineload values with their lengths of impact are utilized in the Python code as loading magnitude for road and building are assumed to be different.

\subsubsection{Storing Inputs}

Input parameters which are significant with regards to parametric analysis are stored in text files. Therefore, user may check parameters of each analysis and decide which parameter should be modified to obtain the optimal solution. Input file name has the format of "Inputs_for_ModelName_at_F_Time_Date". For example, for HS analysis made in 18.05.2019 20:18 input file name will be "Inputs_for_HS_at_18_May_2019_20_18". Input files contain parameters given below:

- Model Name

- Analysis Name

- Fill Input Parameters
- Fill depth
- $E_{\text {ur }}{ }^{\text {ref }}$
○ $\mathrm{E}_{50}{ }^{\text {ref }}$ or $\mathrm{E}^{\prime}$
○ $\gamma_{0.7}$ and $\mathrm{G}_{0}{ }^{\text {ref }}$ (for HSsmall) 
- Ankara Clay Input Parameters

- SPT N60 constant values

○ Cohesion (c')

○ Friction Angle $\left(\varphi^{\prime}\right)$

○ $\gamma_{0.7}$ and $\mathrm{G}_{0}{ }^{\text {ref }}$ (for HSsmall)

- Claystone Input Parameters

- $\mathrm{E}_{\mathrm{ur}}{ }^{\text {ref }}$

○ $\mathrm{E}_{50}{ }^{\text {ref }}$ or E'

- Cohesion (c')

○ Friction Angle ( $\left.\varphi^{\prime}\right)$

- Dilatancy Angle ( $\psi$ )

○ $\gamma_{0.7}$ and $\mathrm{G}_{0}{ }^{\text {ref }}$ (for HSsmall)

- Force Input Parameters

- Anchor Preloads

○ Lineload-1 and impact length

○ Lineload-2 and impact length

In python code, input parameters for fill, Ankara clay, claystone and surcharge load are stored in lists in the order given above. Moreover, only the required parameters for the selected model are stored. For example, for fill input parameters following code is used for this operation:

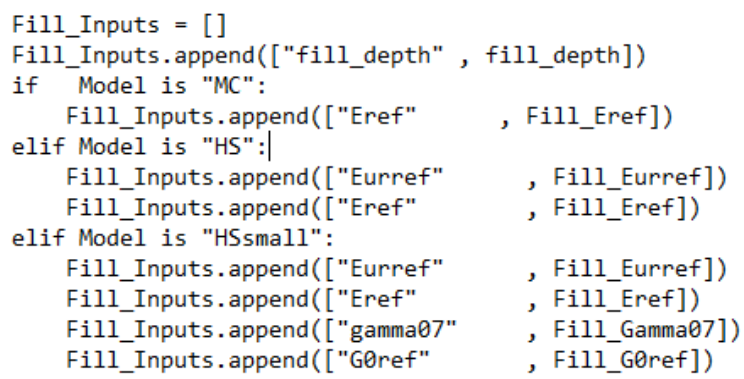

In above code, first an empty list is created and assigned to Fill_Inputs. Then, first element of the list is added which is related to fill depth. This process is achieved by the append command of Python and as can be seen from the code, parameters are 
coupled with their definitions as strings in another list and added to the main list (Fill_Inputs). Thus, one may reach the definition of the first element of Fill_Inputs by Fill_Inputs [0][0] which will give "fill_depth". For the value of the first element one may use Fill_Inputs [0][1] which will give fill_depth. Since each material model uses different stiffness values, if-elif block is utilized for storing the parameters required for the analysis. For instance, if the model selected is HSsmall, five parameters will be stored in the input file.

After these lists are created, input file may be opened with open function of Python. This function requires the file name with its path and the type of operation that will be made to the text file. For writing, the operation type is "w" and format of the file path should be "D:IProjectPath|FileName". Here, it is important that FileName should also contain the suffix ".txt". After text file is opened, data may be written with the write command. For writing the data stored in Fill, Ankara Clay, Claystone and Force lists, for loops are created. In for loop all elements in list are scanned and the parameter values are written below their definitions. Since some parameters are stored in arrays (parameters in Ankara Clay), if-elif block is used to identify those elements and to write those parameter values in desired format. Following code is utilized for Ankara Clay and shown as an illustration:

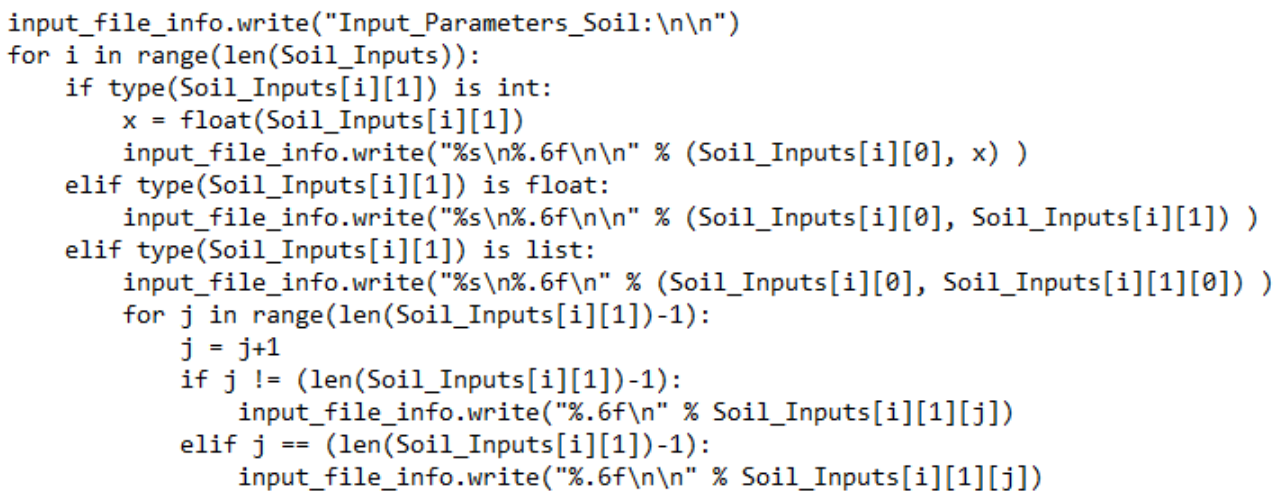

In the above code input_file_info is the text file opened with open function. Then, by using write function a heading is created that named "Input_Parameters_Soil:". Next, for loop for Ankara Clay is started and all the elements in list are scanned. Scanning 
is done according to the type of parameter which may be integer, double or list. If type of the parameter is list (array) another for loop activates to write the elements in that list.

After input parameters are written to the text file, it should be closed. This operation can be done with close function. For the given example above, input_file_info.close() will close the text file.

\subsubsection{Start of the Project}

After inputs are gathered, Python-Plaxis interaction is started by opening a new project. This operation can be achieved with new function applied on s_i object. For Plaxis model default values are taken which is plane stress solution with 15-noded triangular elements. Then, soil contours are created with boundaries defined in inputs section. For creating soil contours, initializerectangular function is applied to $\mathrm{g} \_\mathrm{i}$ object. Following code does the operations explained above:

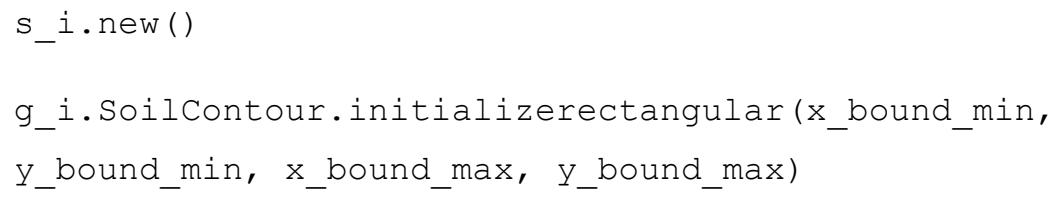

\subsubsection{Geometry of the Model}

In this part of the Python code, all geometric elements of the shoring system are defined to Plaxis. These geometric elements include soil layers, anchors, geogrids and pile geometry. Moreover, soil to be extracted during phase construction and points from which displacement data will be taken are identified by geometric modifications in the model. For all these operations, first thing to do is passing to Structure subsection which can be performed with the following line:

\section{g_i.gotostructures()}

Modelling of the geometry starts with creating soil boundaries from the top elevation. Soil layers are created by using polygon function of Plaxis. This function takes four 
list inputs which contain $\mathrm{x}$ and $\mathrm{y}$ coordinates of corners of the polygon. For creating the fill boundary, following line of the code is utilized:

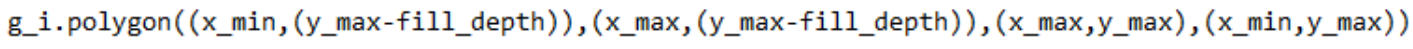

In this line; $x \_m i n, x \_m a x, y \_m i n$ and y_max defines the boundaries of the system and fill_depth is the depth of fill which gives the height of the polygon.

Geometry of Ankara clay requires an iterative process as soil will be divided into layers according to the number of SPT N measurement points. Therefore, a for loop is written for which again polygon function is used but y coordinate is iteratively changed. Since the maximum y coordinate will be (y_max - fill_depth) for Ankara clay this definition is named y_i and it is replaced with y_max in the above code line. Iteration is made as much as the number of SPT N measurement points and in each measurement y coordinate is decreased by $1.5 \mathrm{~m}$ which is the measurement depth of SPT N values. After Ankara Clay layer is created, weathered claystone (soft rock) layer whose SPT N values are specified as 100 in borehole logs is formed. The boundary of the weathered claystone (soft rock) is started from the bottom height of the Ankara Clay and it continues till the bottom of the soil boundary.

Modelling of the geometry continues with creation of support systems (anchors, geogrids and pile). Anchors are formed with the function $n n a$ which is the acronym of node-node anchor. This function requires 4 inputs which are $\mathrm{x}$ and $\mathrm{y}$ coordinates of the start of anchor, anchor angle and anchor length. Format of function nna is as follows:

g_i.nna (x, y, "angles", angle, L)

Anchors are formed by using a for loop as vertical distance between anchors are constant except for the first two anchors which are created manually. This for loop is based on anchor lengths since anchor lengths are different. Anchor lengths are stored in a list and in python it is possible to loop over any list. Following lines are used for creation of anchors other than first two anchors: 


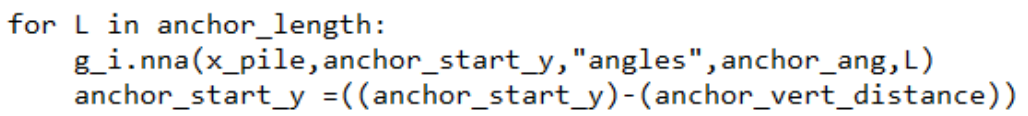

In above lines, anchor_length is the list that contains anchor lengths while $\mathrm{L}$ is the value of the list for each iteration. The parameter $\mathrm{x} \_$pile is the $\mathrm{x}$ coordinate of pile axis while anchor_start_y is the starting y coordinate of the first anchor in the loop. Another parameter anchor_ang is the anchor angle which is $15^{\circ}$ as mentioned before in section 3.1 .

Geogrids are created in a similar manner like anchors, but the function used is geogrid. Geogrid function takes the same inputs of nna function. Coordinates of geogrids are found by using trigonometric equations as starting point of anchors and their angles are known.

Creation of pile is achieved by plate function of Plaxis and this function only requires the coordinates of the pile. After pile is formed, interfaces of the pile should be defined which is ensured by nif and pif functions. Functions nif and pif are the acronyms of negative and positive interface and their inputs are the same with plate function. Format of the plate function is as follows:

g_i.plate((x_pile, y_pile_top), (x_pile, y_pile_bottom))

After geometry of the shoring system is created, boundaries of stage constructions should be introduced to the system. In order to achieve this goal lines are formed which show the end of each construction. Creation of lines is achieved with line function (g_i.line()) of Plaxis which takes two list inputs namely starting coordinates of the line (x_start, y_start) and ending coordinates of the line (x_end, y_end). Excavations are up to $0.5 \mathrm{~m}$ below anchor starting depths as mentioned in section 4.1.1.4. Therefore, same number of lines with anchors will be formed as they have relation with anchors. Thus, similar procedure is performed to form lines while their y coordinates are stored in a list to be used in identification of polygons which will be removed during phase construction stages (see Section 4.2.12). 
In order to extract displacement data from the pile and to increase the mesh number along the pile, points are created with $0.5 \mathrm{~m}$ distance. This process is achieved by using point function (g_i.point()) of Plaxis and with a for loop.

Finally, loading is applied to the model by using lineload function. This function takes the coordinates of the line (start and end points) on which loading will be applied and loading value is assigned to the line with set function. For set function to be used line number of the line created by lineload function should be known. Following code lines give an example to the process for line_n on which line load is applied:

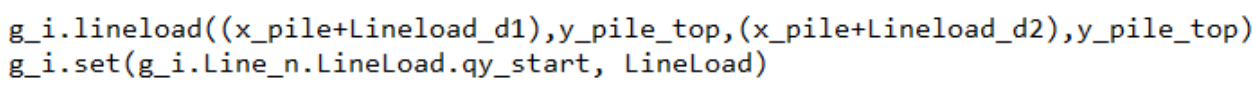

In above code, (x_pile + Lineload_d1) and (x_pile + Lineload_d2) are the start and end coordinates of the Lineload in $\mathrm{x}$ direction respectively. LineLoad in second code line is the value of lineload. This code lines are utilized for the two lineloads defined in the system, which are surcharge load and load of the existing six storey building.

\subsubsection{Defining and Assigning Material Properties}

In this part of the Python code, properties of soil layers and support systems are first specified and then attributed to Plaxis.

In order to ease the assignment of soil properties, properties defined in inputs section are stored in lists with their definitions. Material model-based properties such as "SoilModel" and "E50ref" are appended with if-elif blocks. This procedure is exemplified for the fill layer below:

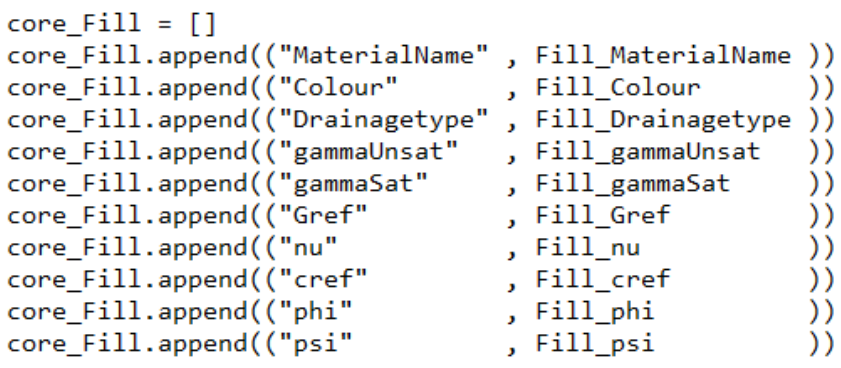




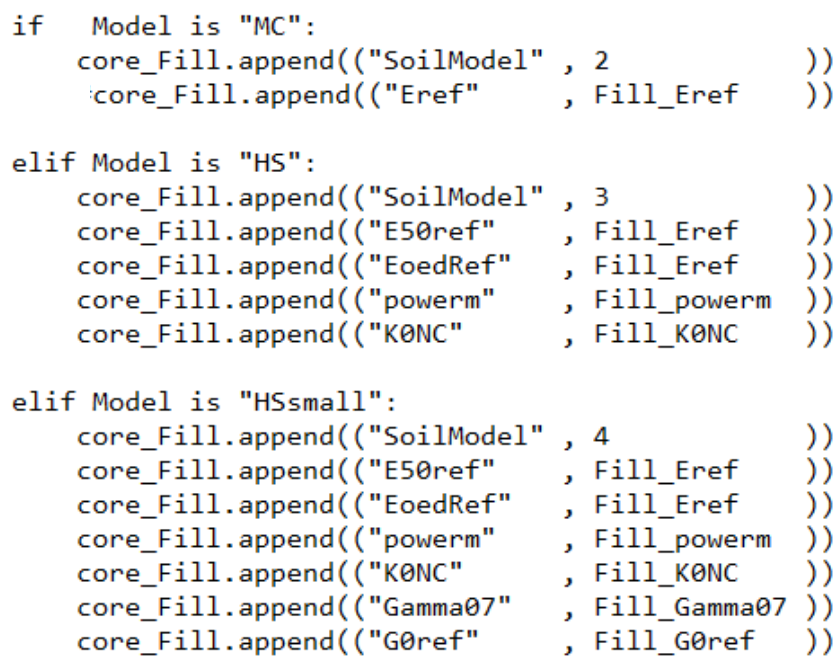

In above example; after list core_Fill is filled, soil properties can be created by using soilmat function of Plaxis. Then, this property set can be assigned to soil objects in Plaxis by equality. Following code shows how this procedure is achieved:

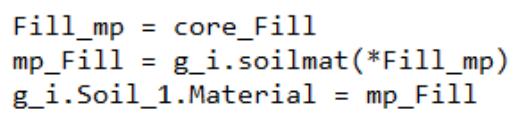

In these three lines, the list core_Fill is assigned to parameter Fill_mp in the first line. Then, soil property set which is now represented with parameter Fill_mp is used to create soil material in Plaxis with soilmat function and the created soil material is assigned to mp_Fill object. It is important to mention that "*" symbol is used for identifying the set of lists that contain soil properties to Plaxis. Finally, property set is assigned to Soil_1's material with the third line. This procedure is performed for other soil layers also, but for Ankara clay it is done iteratively as this soil layer has several regions.

Similar procedure is applied for anchors, geogrids and pile material property assignment. Plaxis requires four parameters for anchors which are "MaterialName", "Colour", "Lspacing" and "EAPerLength". Values of these parameters are stored in lists with their definitions like in soil properties and creation of the material parameters is performed by anchormat function of Plaxis. Geogrids require seven parameters which are "MaterialName”, "Colour", "Elasticity”, "IsIsotropic", "EA1”, "EA2” and 
"GA". For geogrids creation of properties is performed with geogridmat function. Since first four anchor/geogrid has different properties than the rest of anchor/geogrids two different property sets are created, and they are assigned with a for loop which is shown below:

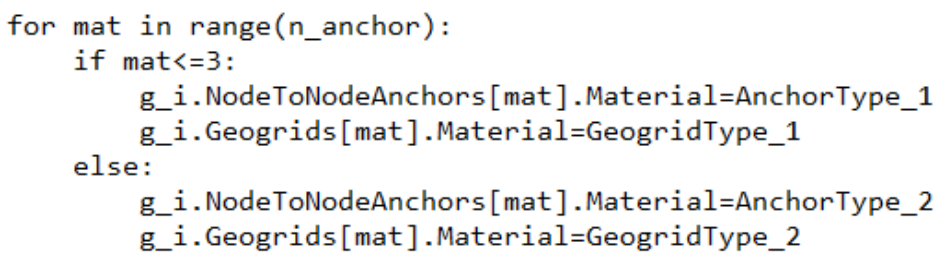

Pile requires much more properties compared to anchor and geogrids which are defined according to the system investigated. After property list is formed, creation of pile material is performed with platemat function as pile is defined with plate in Plaxis. Finally, created pile property is assigned to Plaxis plate material object.

\subsubsection{Mesh of the Model}

After geometry of the system is created and properties are assigned, mesh will be generated. As explained in section 4.1.1.3 to generate finer mesh in local areas some geometric alterations are made in the model and to avoid convergence issues coarse mesh is utilized. Plaxis generates medium size mesh in default. For generating coarse mesh following code is used:

g_i.gotomesh ()

g_i.mesh $(0.07998)$

As seen above, program first passes to Mesh subsection than generation of the mesh is achieved by using mesh function with a factor defining coarseness of the mesh.

\subsubsection{Back Analysis}

After mesh is generated, soil properties of Ankara clay and weathered claystone (soft rock) may be attributed. Different from fill layer, soil stiffness properties of Ankara clay are related to SPT N values, thus a for loop is written. Weathered claystone (Soft rock) layer is also assigned according to SPT N values (SPT N=100 is assumed to be 
weathered claystone layer) as mentioned before in this for loop. Moreover, program is passed to Stage subsection and polygons (soil layers) are activated at the initial phase so that after property assignment, phase construction will be started. Following code lines perform this operation:

$$
\begin{aligned}
& \text { g_i.gotostages() } \\
& \text { g_i.Polygons.activate(g_i.InitialPhase) }
\end{aligned}
$$

Before for loop is started $\mathrm{E}_{\mathrm{ur}}{ }^{\text {ref }}$ and $\mathrm{E}_{50}{ }^{\text {ref }}$ values are formed in terms of SPT $\mathrm{N}_{60}$ values. Since a linear formulation is assumed between stiffness parameter and SPT N60 values, constant of this formulation is named SPT N60 constant and shown with sptn_c. Code lines presented below are used for implementing this relationship:

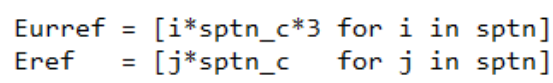

In above lines, sptn is the list that contains $\mathrm{SPT}_{60}$ values while $\mathrm{i}$ and $\mathrm{j}$ parameters refer to each SPT $\mathrm{N}_{60}$ value at a time.

As mentioned in Geometry section (section 4.2.8) soil layers are partitioned according to SPT N measurement locations and Plaxis names each soil layer after partition operation (Ex: Soil_1, Soil_2 etc.). In these partitioned regions (soil layers of Ankara clay) there may be more than one polygon and soils of these polygons are named with the number of the region plus another following number that shows the arrangement of the polygons inside (Ex: Soil_1_1, Soil_1_2,..., Soil_1_5). During the for loop each soil layer will have different material properties which are related to each layers' corresponding SPT N value. The challenge about this task is that Plaxis does not allow the assignment of material properties to a soil layer (Ex: Soil_1) with a single line of code since the object g_i.Soils, which stores information about soil layers, give data of all individual soils. For example, g_i.Soils[0] will give information about the first soil that is Soil_1_1 not Soil_1, thus for identification of which soil is related to which soil layer, several string operations are performed using names of soils. Name of the soils are obtained by Name function of Plaxis applied to g_i.Soils object. During iterations, recent and future (value at the next iteration) soil names are obtained and 
their base numbers (1 for Soil_1_2,2 for Soil_2_1) are compared. Therefore, for soils with the same base number, same material properties will be assigned while if the recent and future base numbers do not match material properties related to following SPT $\mathrm{N}_{60}$ values will be assigned to the new soil. In order to ensure which SPT $\mathrm{N}_{60}$ value will be assigned a counter is set which increases by 1 when recent and future soil name bases do not match. Process of material property assignment is similar to what have been done in fill layer. For each soil, a list is filled with soil properties (Eref, Eurref, cref and phi have different values for each soil layer). Again, some additional parameters are included in these lists according to selection of material models and with soilmat function soil materials are created. Assignment to related soil is achieved by setmaterial function of Plaxis. Format of this function is as follows, g_i.setmaterial(g_i.Soils[n], g_i.InitialPhase, g_i.soilmat(*SoilProp)). In this format, $\mathrm{n}$ identifies the soil ( $\mathrm{n}=0$ for the first soil) and SoilProp is the list which contains soil properties. After counter exceeds the number of SPT N measurement points and SPT $\mathrm{N}$ values equal to 100 , remaining soils are assigned with claystone properties. After soil properties are assigned, lineloads are activated for the initial phase so that phase construction may start. This operation is performed with the following code:

$$
\text { g_i.LineLoads.activate(g_i.Phases[0]) }
$$

\subsubsection{Phase Construction}

Phase construction stage is part of the code in which deep excavation is simulated in Plaxis iteratively. Before phase construction, polygons and related soils which will be removed are identified. For this identification two for loops are created which are named as polygon and soil loops.

During polygon loop, corner coordinates of all polygons are obtained and by using the right bottom corner coordinates of polygons names of the ones in the construction area are found and stored in a list. Since some regions have more than one polygon, corner coordinates of these polygons are compared with the corner coordinates of the related region. Polygon names are stored until corner coordinates of the polygons are same 
with the bounding region's corner coordinates. Then loop continues with the search of polygon names in the following region. Resulting list contains list of polygon names for each soil layer. For attaining polygon corner coordinates, "BoundingBox" object is used with echo function. Format of this combination is g_i.Polygons[n].BoundingBox.echo() for which $\mathrm{n}$ defines the polygon sorting and the combination results in the following string; "min: $(x ; y ; z)$ max: $(x ; y ; z)$ ". In this string $\mathrm{x}, \mathrm{y}$ and $\mathrm{z}$ are the coordinate values and $\mathrm{x} \_$max and $\mathrm{y} \_$min gives the right bottom corner coordinate which is obtained by several string operations. For attaining polygon names, "Name" object and "value" attribute are utilized. Format is as follows; g_i.Polygons[n].Name.value.

During soil loop, soils which corresponds to polygons in excavation regions are determined by searching all the soils. While doing so, soil numbers which show the sorting of soils and soil names are grouped in lists and stored in a main list for further use. Similar to polygon list, soil name and numbers are grouped according to soil layers. Finding soils which are related to polygons is achieved by using "Parent" object of Plaxis. Following code line gives the polygon name of a soil that is utilized for this task; g_i.Soils[n].Parent.Name.value. For example, if $n$ is zero this line will give Polygon_1 which is the polygon of Soil_1_1.

After polygon and soil loops, as polygons and soils that will be removed are identified phase construction may start. There are twenty-five (25) phases in phase construction and these are iteratively implemented to Plaxis. During odd numbered phases, soil extraction operation is performed while during even numbered phases, anchors and geogrids of the related soil layer are activated and preloads are applied. Automation of the phase construction is based on phase numbers being odd or even. Before any stage, following code lines should be performed:

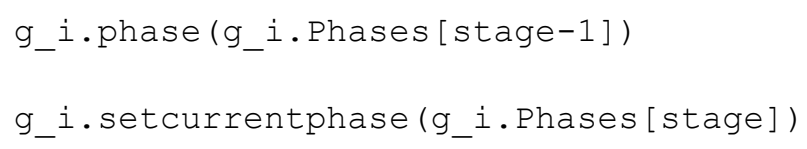


Here in above code, stage is the identifier number of phases and it starts with " 1 ". This code ensures that Plaxis passes to the current phase. For stage $=1$, program passes to Phase_1.

Identification of phases (odd or even) is achieved by if-elif block and by checking the following statement; (stage $-2 * \operatorname{int}($ stage/2)). If this statement is larger than zero it means that the stage is odd number while stage is even numbered if this statement turns out be zero.

As mentioned above, during odd numbered phases soil removal is performed. This operation is accomplished by the following code line:

g_i.Soils[n].deactivate (g_i.Phases[stage])

In above line, $\mathrm{n}$ is the number which identifies the soil in excavation region, and which is stored in a list during soil loop. Again, if region has more than one polygon, above line is performed for each soil in that region with a for loop.

For the first stage (Stage_1) of odd numbered stages additional operations are required after passing to the current phase which are activating plate (pile) and interfaces of the plate. These operations are carried out with following code lines:

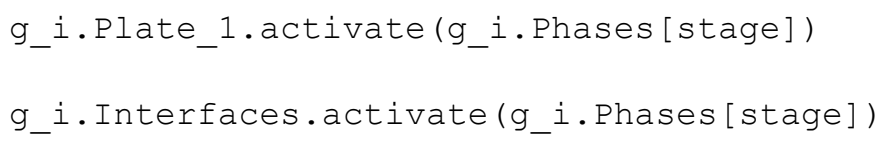

In the first line "Plate_1" is used as there is only one plate and it is used for simulating the pile.

During even numbered stages; anchors, preloads and geogrids are activated in order. These operations are performed with the following code lines:

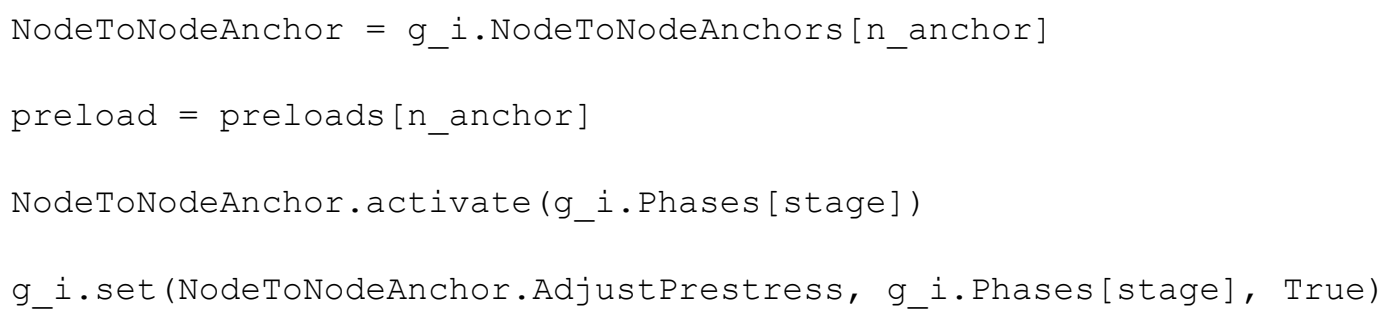


g_i.set (NodeToNodeAnchor.PrestressForce, g_i.Phases[stage], preload)

g_i.Geogrids[n_geogrid].activate (g_i.Phases[stage])

In the first two lines anchors and related preload values are assigned to parameters. Then, the parameter "NodeToNodeAnchor" parameter is used for activating the anchors in the third line. Following two lines are utilized for applying the prestress value to the related anchor by using set function. First, the object AdjustPrestress is appointed to "True" for Plaxis to allow applying prestress. Second, with the used of PrestressForce object preload value of the anchor is applied. Geogrids are activated like anchors as seen from the code lines. An important thing to mention her is that counters of anchors and geogrids are different (n_anchor and $\left.n \_g e o g r i d\right)$. This is due to the naming of geogrids which is like soils (Geogrid_1_1, Geogrid_1_2 etc.) and results from partitioning of the soil layers. Therefore, activation of geogrids is performed with another for loop.

After phases and operations that will be done during phases are implemented to the code, Plaxis requires the command g_i.calculate() for performing phase constructions. After phase constructions are completed, project can be saved into directory specified with the following command g_i.save(Project_path).

\subsubsection{Getting Results}

When phase constructions finish, part of the Python code with Plaxis input module ends. In order to obtain results, passing to output module of Plaxis is necessary. For this task, like in input module Plaxis objects (s and g) should be defined. However, this time hostport will be related to the phase from which results will be extracted (For input module localhostport is 10000). Since final state of the phase construction is the main concern, phase will be the last one (Phase_25). Hostport and Plaxis output objects are defined with the following code lines:

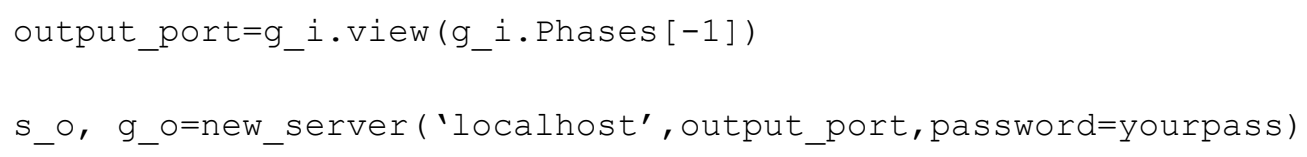


Similar to input object s_i, output object s_o is used for opening new output projects from the analysis results. This task is performed with the command; s_o.open(project_path).

Again like in Plaxis input, g object (g_o) is related with operations about the model. Therefore, g_o object is used for data extraction and the function to be utilized is getresults. For the back analysis, horizontal displacements of pile are retrieved with labels and y coordinates of the nodes. Following code lines are used for this task:

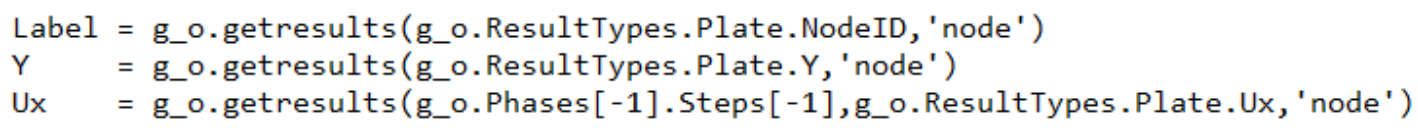

As seen from the code lines, in order to access information about nodes, elements and finite element results "ResultTypes" object is used along with the location (may be plate, soil etc.) from which data will be extracted. Objects "NodeId", "Y" and "Ux" are used for getting node numbers, $\mathrm{y}$-coordinates and $\mathrm{x}$-displacements respectively along with string "node" for stating that data will be received from nodes.

Then, these three data are stored in a list and displacement values which are along $0.5 \mathrm{~m}$ are selected by using the y-coordinates of the nodes and written to a text file (results file) along with related node numbers and y-coordinates. Format of the results files can be seen below:

$\begin{array}{lll}\text { NodeID } & \text { Y-Coord }[\mathrm{m}] & \text { X-Disp }[\mathrm{m}] \\ 81969 & 885.720000 & -0.014227 \\ 82190 & 885.220000 & -0.015181 \\ 82213 & 884.720000 & -0.016135\end{array}$

After data extraction is completed and results are written, iteration ends with closing the output project with the command s_o.close(). This operation is important as Plaxis may crash after several iterations without using this command. At the end of iteration, time data is again taken with time.time() and by taking the difference time passes during analysis may be found and printed. Following code line is used for this task:

end=time.time () 
time=end - start

In the above lines, time parameter is in seconds and may be written in terms of hours and minutes with several math operations.

\subsection{Post-processing with Matlab}

After solving the system for different material parameters and storing the displacements, a post-process is required to identify the condition for which the optimum solution is obtained. For post-processing of Plaxis results, a MATLAB code is written which reads .txt files. Details of the MATLAB code are explained below.

Since three soil models are analyzed in the thesis result file names contain these models' abbreviation and MATLAB code initiates with the call of the model used. User shall input "MC", "HS" or "HSsmall". Then code identifies all the result file names that contain the specified model name in the current directory. Plaxis result file names start with "Ux_Result_for" prefix. Identification of result file names is performed by using the following functions and with the use of this prefix:

Model = 'HS';

File_ID $=\operatorname{strcat}($ 'Ux_Result_for*', Model, '*.txt');

File_Pr $=$ dir (File_ID);

Here File_ID creates a string by strcat that includes model name and the initial words that each Plaxis output share. For parts in the file names that make file names unique are completed with "*" symbol as these parts are unknown. Similar file names of the specified string is obtained by using dir function and stored in the parameter File_Pr. After storing file names, code calculates the number of files in the directory with length function.

Then, a for loop starts for storing the data in all the result files. For reading the files, a function called 'File_Read' is called which takes the File_ID as input and gives the file name, number of columns in the file and the data in the file for the specified order 
stored in a cell array. For each file read with this function, data is assigned to string variables by using eval and strcat functions of MATLAB. A demostration of this process is explained below for the ith step of the for loop:

[File_Name,column_name,File, ]=File_Read (File_Pr(i).name);

eval(strcat(['File' '_' num2str(i)], '=', 'File;')));

In the first line of the example, result file name is given as input to the function File Read and required outputs are taken. The symbol “ " is used for ignoring the unnecessary outputs which is the file data as strings. In the second line, data in the result file which is the cell array named "File" is assigned to a string with the current counter of the for loop. For example, if "i" is 3, than the string variable will be File_3 and it will store the third result files' data. This method is very usefull for loops and naming the variables.

After storing the data of all the result files in the directory for loop ends and same procedure is applied for the inclinometer measurements file which includes the displacements obtained from the field with related depths and has the same format with Plaxis result files.

Back analysis is performed by comparing the inclinometer measurements with displacements obtained from Plaxis and error is calculated for each data. This process is achieved with another for loop and again by using the eval and strcat functions. Errors are stored in another cell array for later use. Error is defined as follows:

Error $(\%)=($ Inclonometer_disp - Plaxis_disp $) /$ Inclonometer_disp*100

For evaluating the performance of each Plaxis run, total error is used as a base of compasion which is defined as the sum of absolute errors up to the depth of bottom excavation level $(861.72 \mathrm{~m})$. Total error of each result file is stored in an array and the minimum is found with min function in MATLAB. 
After error calculations, calculated errors are written in ttxt files with file names initiate with "Error_for_" prefix and followed by the suffix of result files that include the information about model name used and the date of the analysis. An example error file name is "Error_for_HS_Sat_6_Apr_2019_13_44". The format of error files is consistent with the Plaxis results file and is illustrated in Figure 4.4.

\begin{tabular}{lll}
\hline NodeID & Y-Coord[m] & Error[요 \\
82213 & 884.720000 & 2.368785 \\
82128 & 884.220000 & 0.990933 \\
81602 & 883.720000 & 0.749245
\end{tabular}

Figure 4.4. Format of Error Files

Finally, displacements obtained from Plaxis and inclonometer with respect to depth of soil is plotted for visualisation of the results. Each plot is saved in "-tiff" format with 300dpi resolution by using the print function of MATLAB. Figure names start with the prefix "Figure_Analysis_" and ends with the information of the model used and the date of analysis like in the naming of error files. Use of print command is shown below:

print(gcf, Figure_Name, '-dtiff', '-r300') 



\section{CHAPTER 5}

\section{RESULTS AND COMPARISON}

In this section of the thesis, the wall deflection, ground surface settlement, moment and shear values predicted by MC, HS and HSsmall analyses will be given and results will be compared with each other. Also, inclinometer and load cell measurements obtained from the site are evaluated.

Inclinometer measurement results shows that the maximum horizontal displacement is about $3.5 \mathrm{~cm}$ and it was measured approximately $18.0 \mathrm{~m}$ below the top elevation of the pile. This corresponds to $0.13 \mathrm{H} \%$ horizontal displacement and this value is within the expected limits for anchor supported shoring systems in stiff clays recommended by Long (2001) and Clough and O'Rourke (1990). Also load cell which is placed only to the $4^{\text {th }}$ anchor level $(878.98 \mathrm{~m})$ of the pile section measurements shows that the load of the anchorage at this level is approximately $406 \mathrm{kN}$.

\subsection{Mohr Coulomb Analysis Results}

As a first approximation to the problem MC model analysis results are presented in this section. After several trials, the closest estimation to the inclinometer measurements are obtained. Each trial took approximately 8 minutes and 30 seconds, which is the minimum time required to solve this problem as this method is the fastest among the ones investigated. In order to show the soil layers (clarified with three different colors in the model), retaining system and the final excavation depth, deformed shape of the model is given in Figure 5.1. 


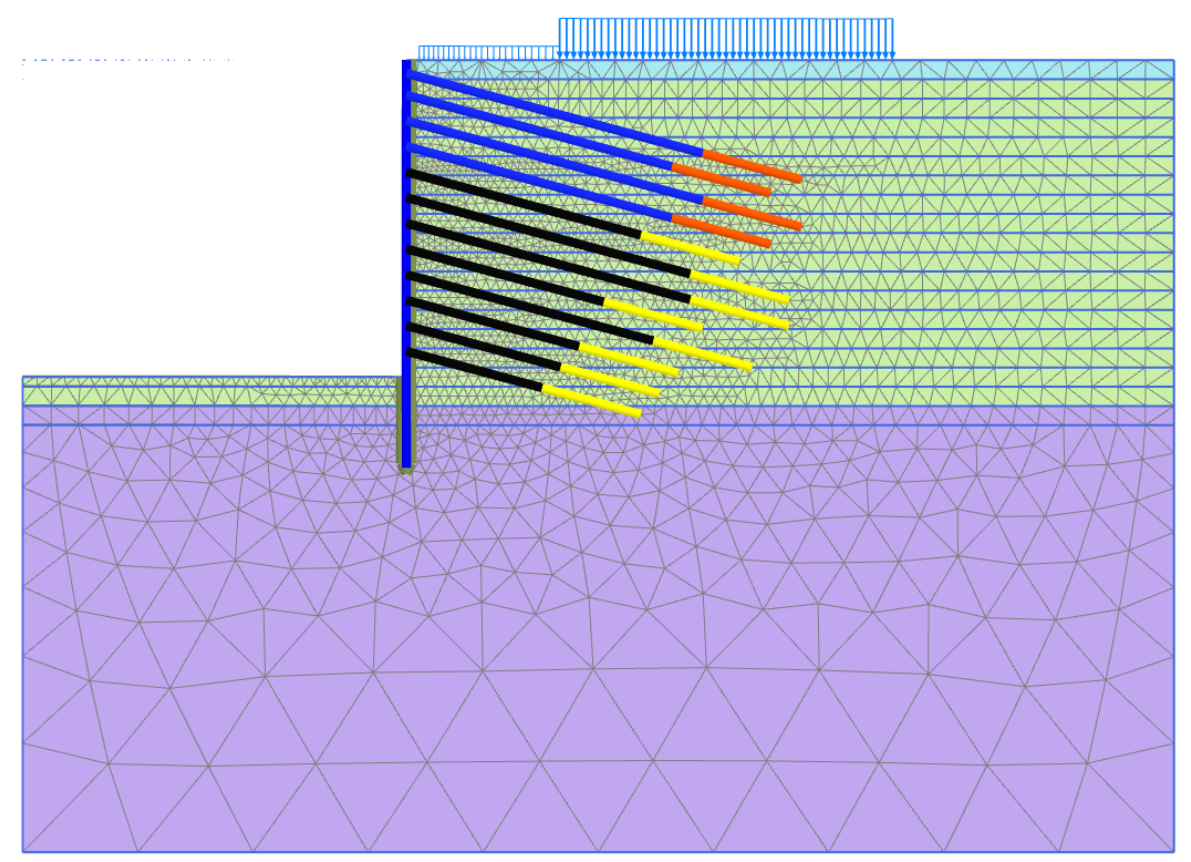

Figure 5.1. Deformed Mesh of the Final Excavation Stage (Scale: 1/750)

As mentioned in Section 4, parametric analyses are performed by changing deformation modulus parameter of Ankara clay layer with a python code whose SPT $\mathrm{N}$ value is smaller than 100 . Correlation of deformation modulus parameter with SPT $\mathrm{N}_{60}$ value shows that closest displacement curve to the inclinometer measurements is obtained as;

$E^{\prime}=1020 \times$ SPT $\mathrm{N}_{60}(\mathrm{kPa})$

Figure 5.2 shows the comparison of Mohr Coulomb model with inclinometer measurements in A direction in terms of horizontal wall displacements in accordance with ground elevation. Moreover, Plaxis outputs of horizontal wall deflections, vertical displacements of the soil at the final excavation stage, moment and shear diagrams of the pile are given between Figure 5.3 and Figure 5.6, respectively. 


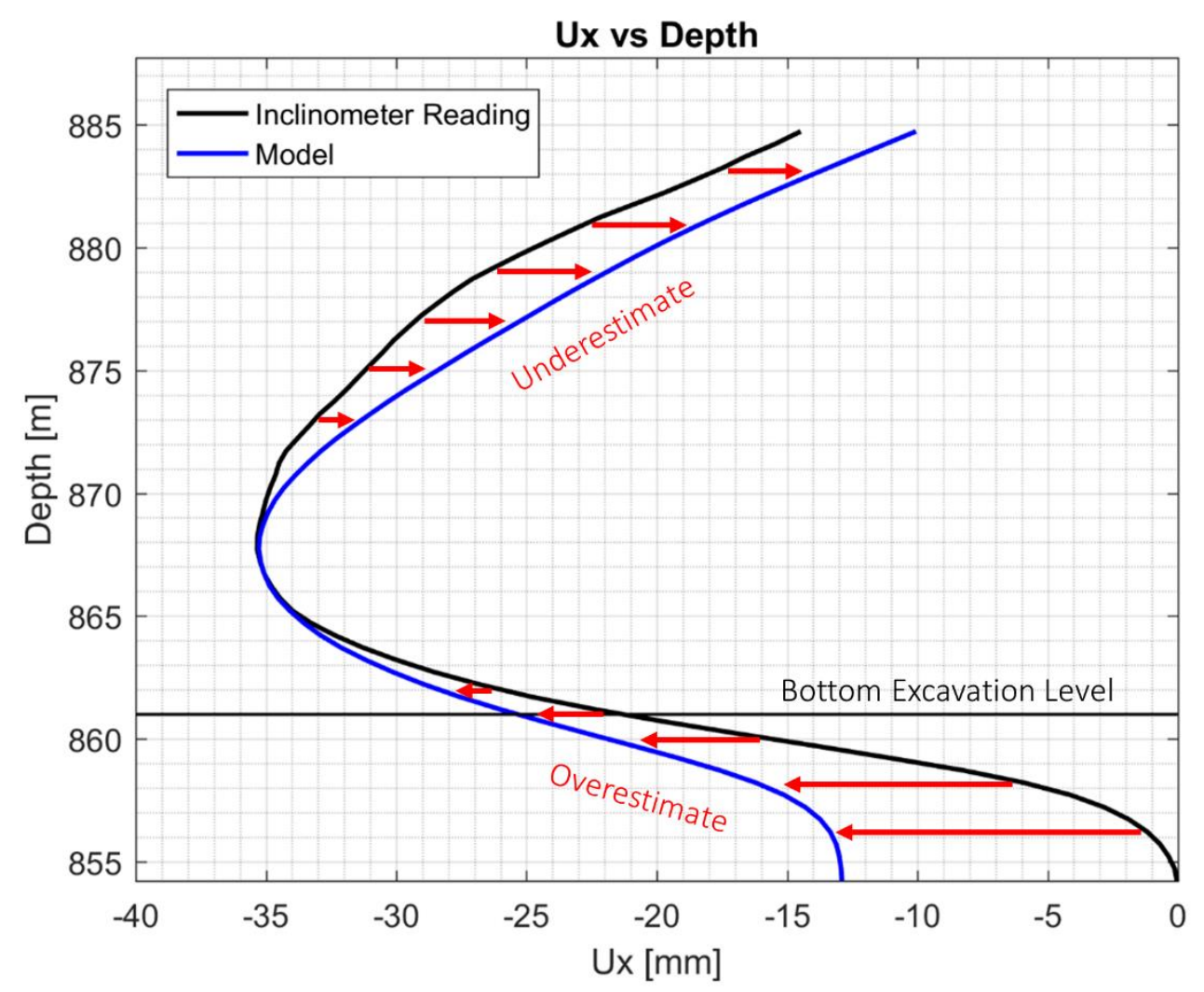

Figure 5.2. Comparison of Horizontal Displacements - Mohr Coulomb Model-

According to back analysis results of the $\mathrm{MC}$ model, $\sim 3.5 \mathrm{~cm}$ maximum horizontal displacement of the pile was obtained at the same max displacement location of inclinometer measurements with approximately $E^{\prime} \approx 1020 \times \mathrm{N}_{60}$ value (see Figure 5.2 and Figure 5.3). When the measured and predicted lateral wall movements are compared with each other, it can be understood that MC model overestimated horizontal wall displacements below the maximum displacement point. The reason behind this is related with the stiffness parameter of the model. As mentioned in Section 2.4.1 model uses only one deformation modulus parameter (E') for loading, unloading and reloading conditions. Therefore, it is expected that predicted deformation modulus parameter is in between loading and unloading-reloading stiffness parameter. Using smaller deformation modulus parameter for unloadingreloading region results with underestimation of passive resistance. $9.5 \mathrm{~cm}$ excessive 
heave of the surface settlement in MC model (see Figure 5.4) can be attributed to this reason. Also, this predicted excessive heave causes overestimation of the lateral wall movements on the pile below the excavation level. As it can be seen from Figure 5.2, above the inflection point MC model gives smaller horizontal displacements than the inclinometer measurements. This is again due to the use of only one stiffness parameter for loading and unloading/reloading conditions. However, in that case using average deformation modulus parameter which is higher than the loading deformation modulus results with the underestimation of the horizontal displacements.

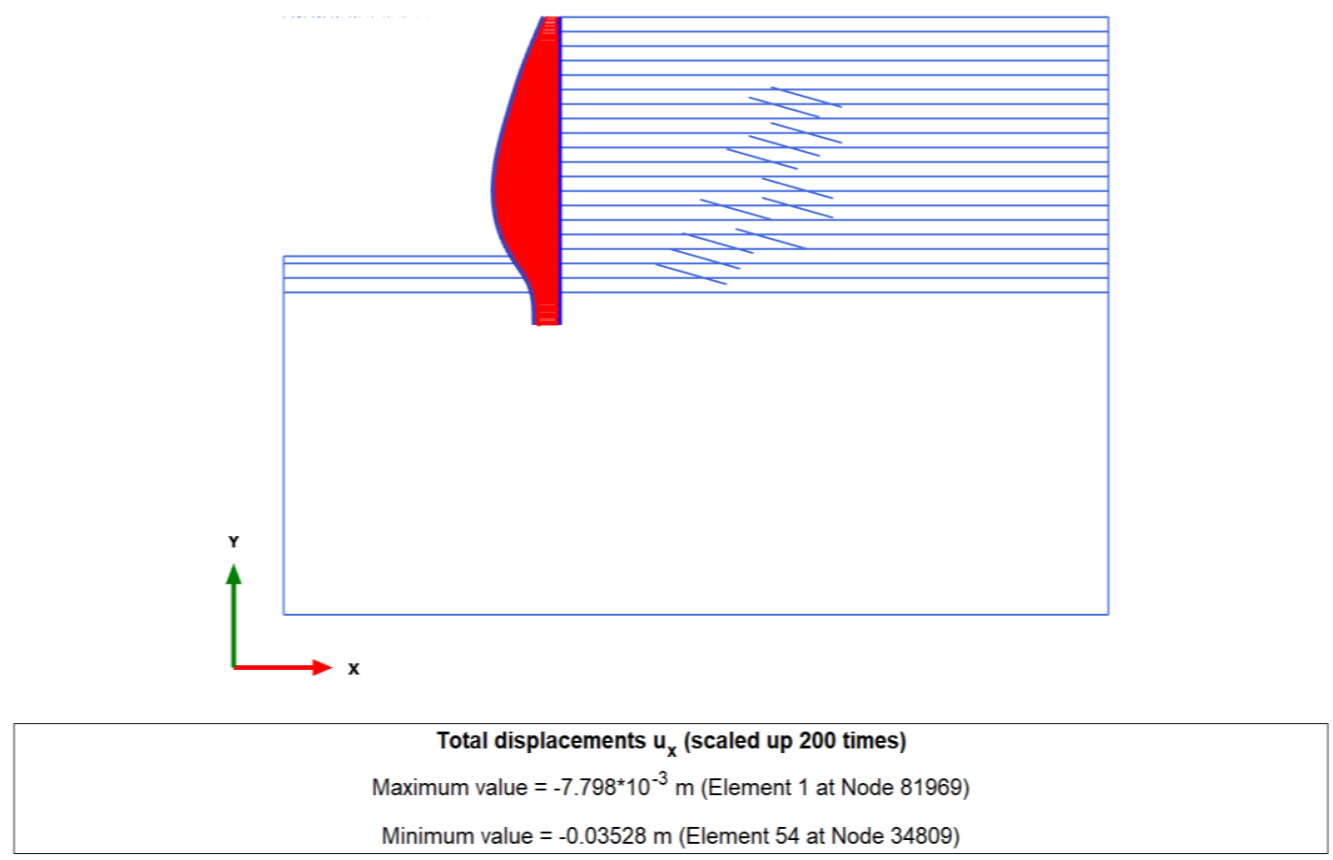

Figure 5.3. Horizontal Displacement of the Pile - Mohr Coulomb Model-

Maximum and minimum bending moment (Figure 5.5) values are obtained as 636.8 $\mathrm{kN} . \mathrm{m} / \mathrm{m}$ and $-375.4 \mathrm{kN} . \mathrm{m} / \mathrm{m}$ at $28.0 \mathrm{~m}$ and $24.0 \mathrm{~m}$ below the pile top elevation, respectively. Also, maximum and minimum shear forces are determined as 412.9 $\mathrm{kN} / \mathrm{m}$ and $-219.9 \mathrm{kN} / \mathrm{m}$ at $27.0 \mathrm{~m}$ and $29.5 \mathrm{~m}$ below the pile top elevation, respectively. Moreover, maximum anchor load at the $4^{\text {th }}$ anchorage level is determined as $419.0 \mathrm{kN}$ in the MC model. 
Note that Plaxis uses positive (+) sign convention on tensile stress for plates and anchorages.

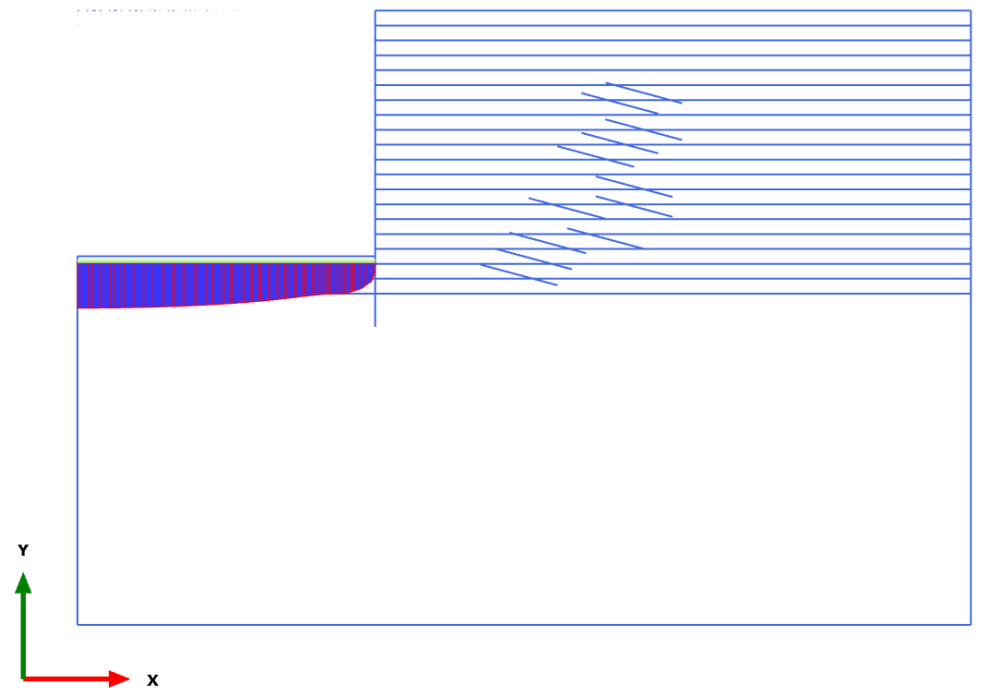

Total displacements $\mathrm{u}_{\mathrm{y}}$ (scaled up $\mathbf{5 0 . 0}$ times)

Maximum value $=0.09483 \mathrm{~m}$

Minimum value $=0.01921 \mathrm{~m}$

Figure 5.4. Vertical Displacement of the Soil in the Final Excavation Stage - Mohr Coulomb Model- 


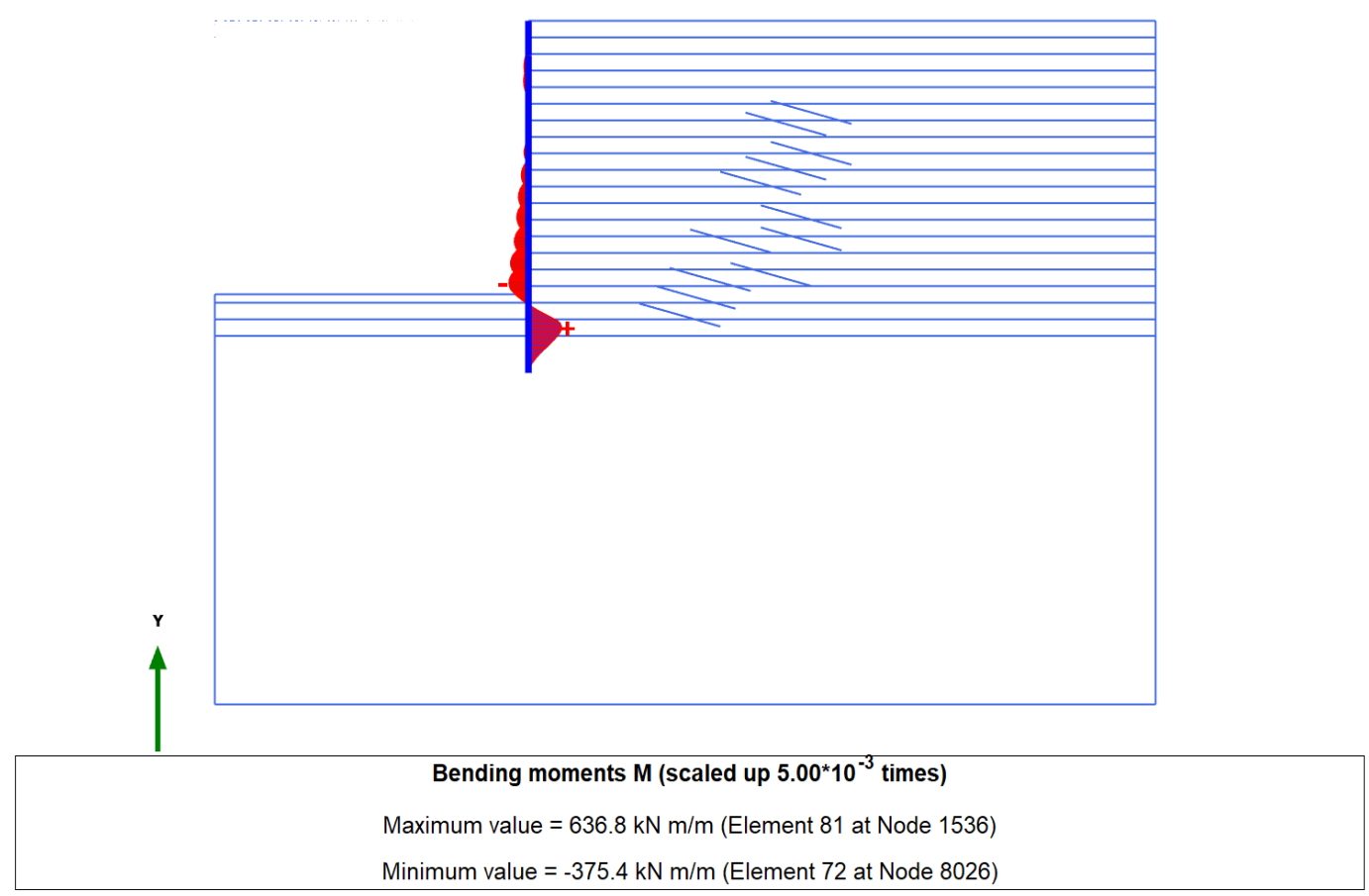

Figure 5.5. Bending Moment of the Pile - Mohr Coulomb Model-

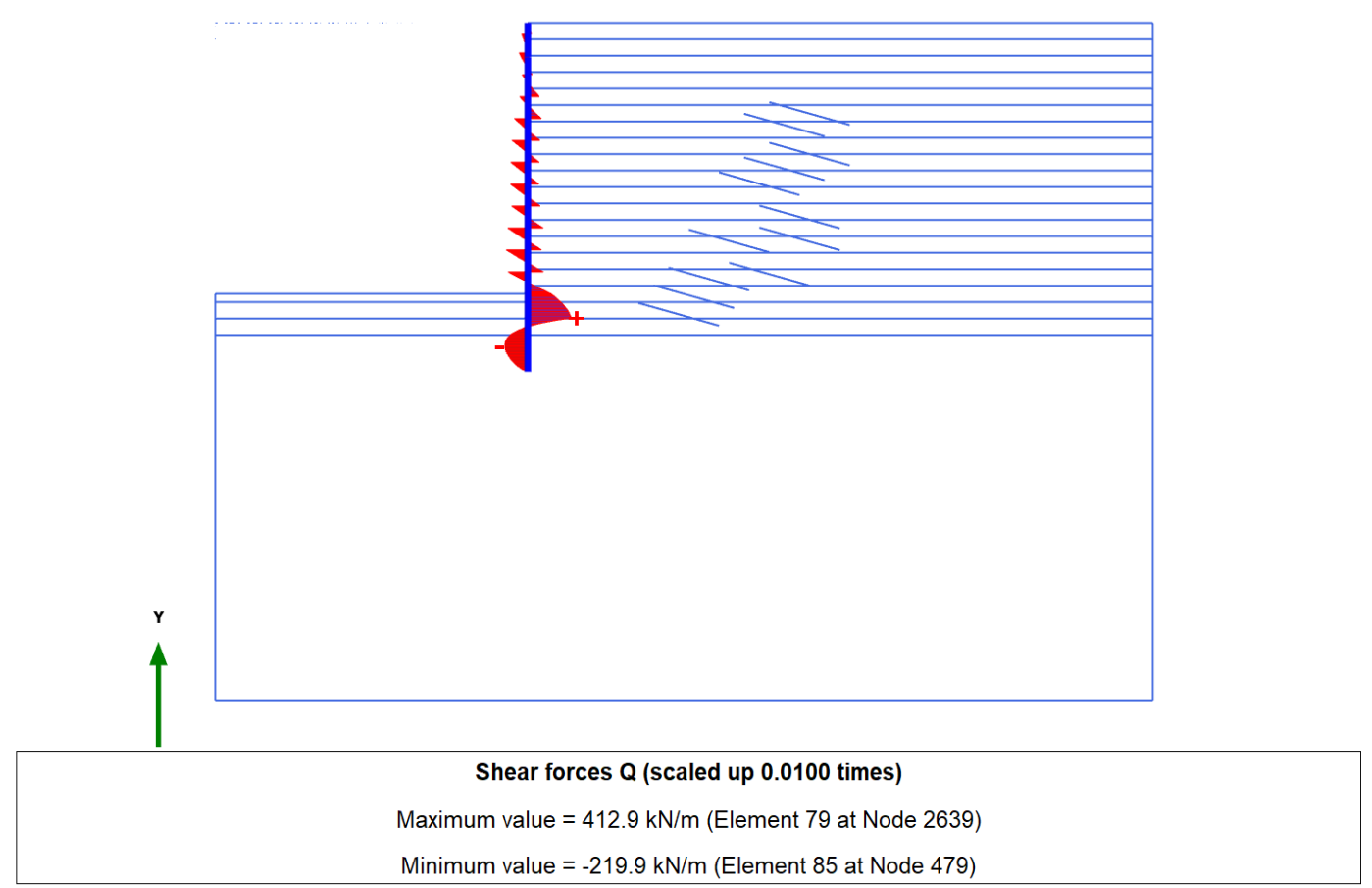

Figure 5.6. Shear Diagram of the Pile - Mohr Coulomb Model- 


\subsection{Hardening Soil Model Analysis Results}

The $\mathrm{E}_{50}{ }^{\text {ref }}$ of the Hardening Soil (HS) model is obtained by back analysis. Each HS model analysis took approximately 10 minutes and 30 seconds. After several trials, the best fit relation between $\mathrm{E}_{50}{ }^{\text {ref }}$ and SPT $\mathrm{N}_{60}$ value for Ankara clay is found as;

$$
\mathrm{E}_{50}{ }^{\mathrm{ref}}=780 \times \mathrm{SPT} \mathrm{N}_{60}(\mathrm{kPa})
$$

Also, $\mathrm{E}_{\mathrm{u}} / \mathrm{c}_{\mathrm{u}}$ ratio is determined as approximately 280.0 according to Equation 5.2 by using $\mathrm{E}^{\prime} / \mathrm{E}_{\mathrm{u}}=0.7$ and $\mathrm{c}_{\mathrm{u}}=4.0 \times \mathrm{SPT} \mathrm{N}_{60}$ relations. When Equation 5.2 is compared with similar studies (see Section 2.1 and Section 2.3), it can be understood that the correlation is consistent with the work of Stroud (1987) as the correlation constant lies between $E^{\prime}=700-900 \times S^{S P T} N_{60}(\mathrm{kPa})$. If the $\mathrm{E}_{\mathrm{u}} / \mathrm{c}_{\mathrm{u}}$ ratio of this study is compared with the work of Çalışan (2009) which is again performed in Ankara clay, it is seen that obtained value is less than the one found in Çalışan (2009). This result is due to several reasons;

- Çalışan (2009) used idealized soil profile and correlation was formed with an average SPT N value in his research while in this study stiffness correlation is achieved by dividing soil into several regions with $1.5 \mathrm{~m}$ distances and attributing soil properties to each region with respect to closest borehole SPT $\mathrm{N}$ measurements.

- In study of Çalışan (2009) SPT N values are counted up to 50; however, this study is performed with SPT N values counted up to 100 .

Figure 5.7 shows the comparison of Hardening Soil model with inclinometer measurements in terms of horizontal wall displacements in accordance with the ground elevation. Moreover, Plaxis outputs of the horizontal wall deflections, vertical displacements of the soil at the final excavation stage, moment and shear diagrams of the pile are given between Figure 5.8 and Figure 5.11, respectively. 
When the measured and predicted lateral wall movements are compared with each other (Figure 5.7), it is determined that maximum error between estimated displacements and the measured ones is below $10 \%$ (max. 6.2\%) in each data point above the bottom excavation level. On the other hand, although analyses were performed by using 3 stiffness modulus parameters $\left(\mathrm{E}_{50}{ }^{\mathrm{ref}}, \mathrm{E}_{\mathrm{oed}}{ }^{\mathrm{ref}}, \mathrm{E}_{\mathrm{ur}}{ }^{\text {ref }}\right)$ to simulate both loading and unloading-reloading behavior of soils, the predicted displacements are not close enough to measured ones under the excavation level. Although unloading-reloading stiffness parameter $\left(\mathrm{E}_{\mathrm{ur}}{ }^{\mathrm{ref}}\right)$ is included to this model, still higher displacement values are obtained at the bottom excavation level (see Figure 5.9). This situation is emphasized by several researchers [Benz (2006), Gouw (2014) and Schweiger et al. (2009)] and they claim that additional stiffness parameters are also needed $\left(\gamma_{0.7}\right.$ and $\left.\mathrm{G}_{0}{ }^{\text {ref }}\right)$ to predict more realistic surface settlements in front of the wall. Estimated and measured displacements with calculated errors in each data point of the pile are given in Appendix B. 


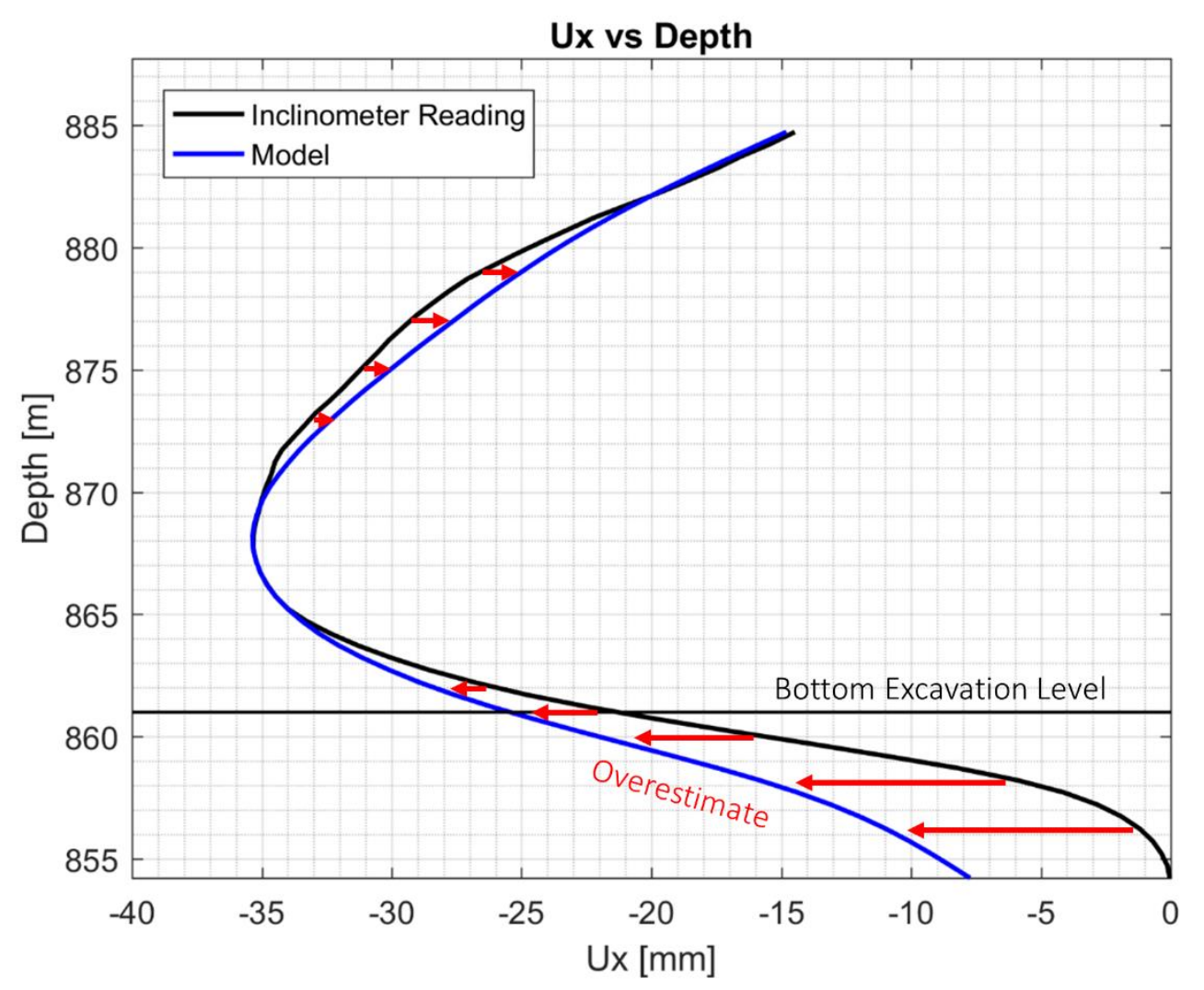

Figure 5.7. Comparison of Horizontal Displacements - HS Model -

Maximum and minimum bending moment (Figure 5.10) values are obtained as 384.3 $\mathrm{kN} . \mathrm{m} / \mathrm{m}$ and $-369.7 \mathrm{kN} . \mathrm{m} / \mathrm{m}$ at $28.0 \mathrm{~m}$ and $24.0 \mathrm{~m}$ below the pile top elevation, respectively. Also, maximum and minimum shear forces (Figure 5.11) are determined as $303.0 \mathrm{kN} / \mathrm{m}$ and $-199.5 \mathrm{kN} / \mathrm{m}$ at $27.0 \mathrm{~m}$ and $21.0 \mathrm{~m}$ below the pile top elevation, respectively. Moreover, maximum anchor load at the $4^{\text {th }}$ anchorage level is determined as $410.0 \mathrm{kN}$ in the HS model. 


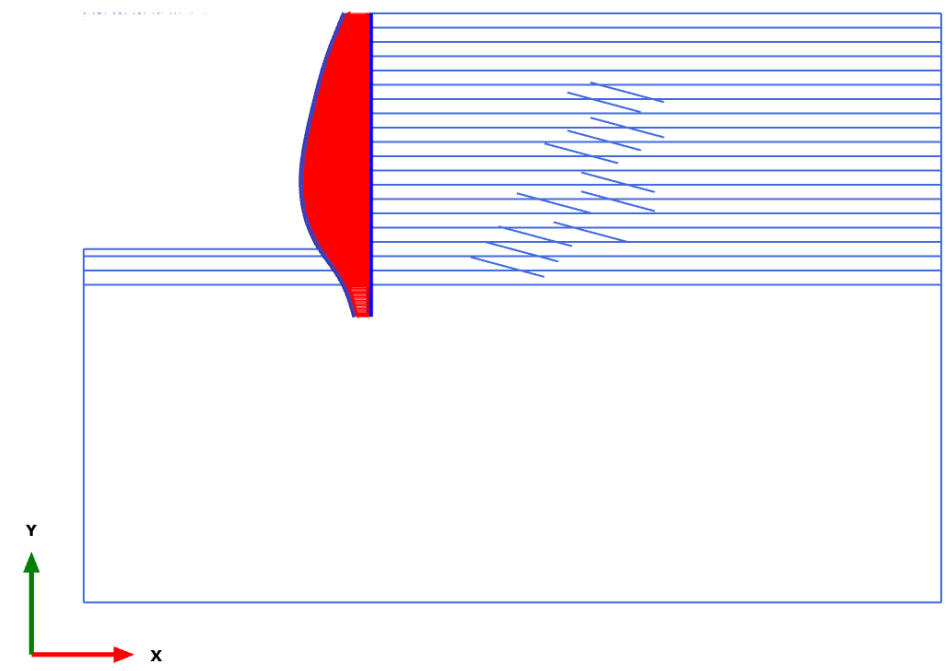

Total displacements $u_{x}$ (scaled up 200 times)

Maximum value $=-7.213^{*} 10^{-3} \mathrm{~m}$ (Element 89 at Node 1$)$

Minimum value $=-0.03537 \mathrm{~m}$ (Element 54 at Node 34811)

Figure 5.8. Horizontal Displacement of the Pile - HS Model -

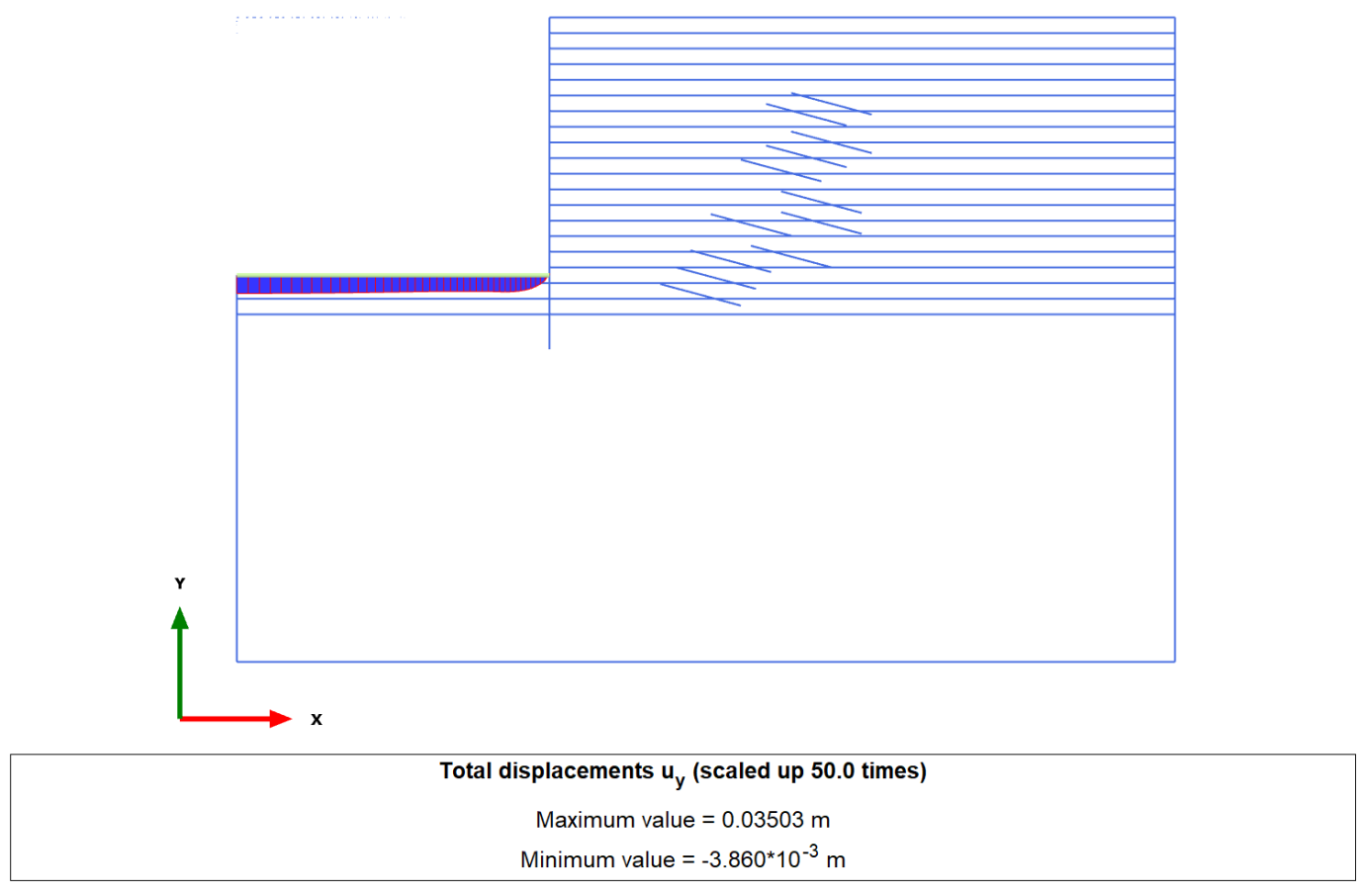

Figure 5.9. Vertical Displacement of the Soil in the Final Excavation Stage - HS Model - 


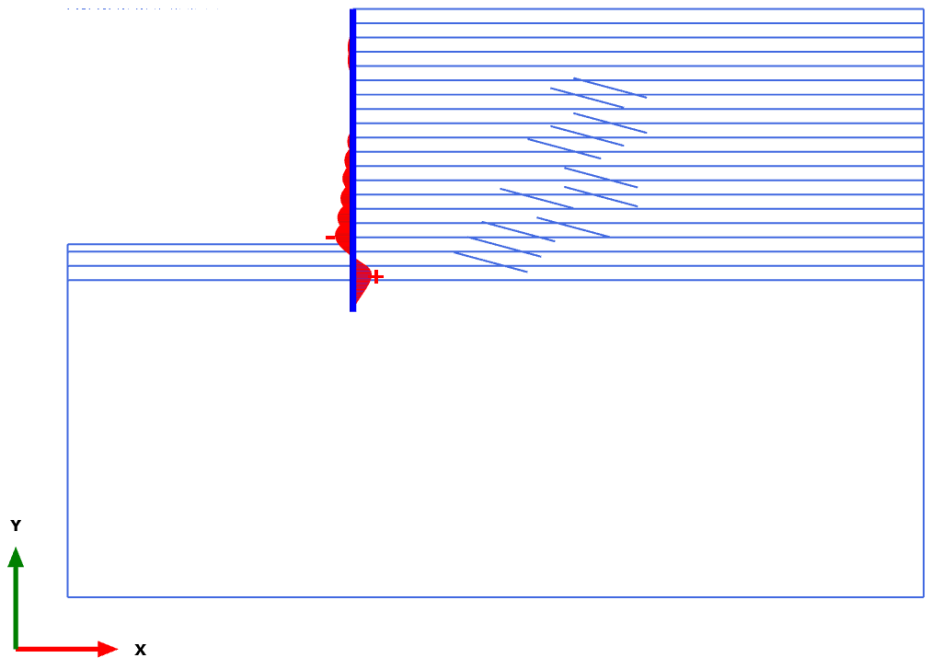

Bending moments $\mathbf{M}$ (scaled up $\mathbf{5 . 0 0} \mathbf{1 0}^{-3}$ times)
Maximum value $=384.3 \mathrm{kN} \mathrm{m} / \mathrm{m}$ (Element 82 at Node 1534)
Minimum value $=-369.7 \mathrm{kN} \mathrm{m} / \mathrm{m}$ (Element 72 at Node 8027$)$

Figure 5.10. Bending Moment of the Pile - HS Model -

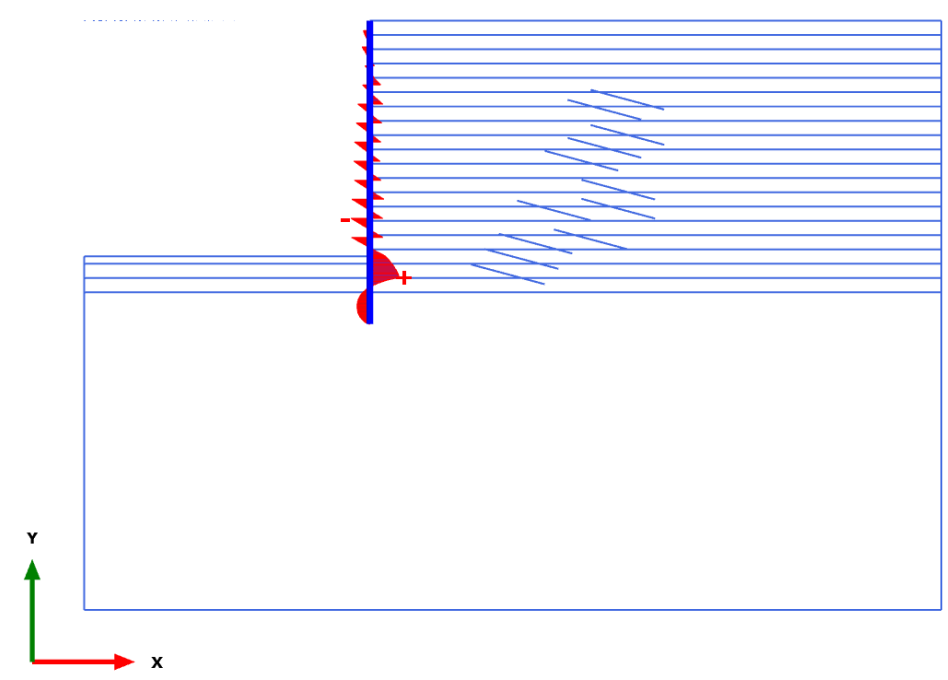

Shear forces $Q$ (scaled up 0.0100 times)

Maximum value $=303.0 \mathrm{kN} / \mathrm{m}$ (Element 79 at Node 2639)

Minimum value $=-199.5 \mathrm{kN} / \mathrm{m}$ (Element 63 at Node 21072)

Figure 5.11. Shear Diagram of the Pile - HS Model - 


\subsection{Hardening Soil Model with Small Strain Stiffness}

After the $\mathrm{E}_{50}{ }^{\text {ref }}$ parameter was obtained from the HS analysis, it is utilized in HSsmall model and kept constant. In addition, two stiffness parameters are included in this model namely $\gamma_{0.7}$ and $\mathrm{G}_{0}{ }^{\text {ref }}$. Due to these additional parameters, calculation time increases and it took 12 minutes and 30 seconds for one HSsmall analysis. The parameter $\mathrm{G}_{0}{ }^{\text {ref }}$ is taken as $2 \mathrm{x} \mathrm{E}_{50}{ }^{\text {ref }}$ which is the relation proposed by Look (2007). Values of $\gamma_{0.7}$ are iteratively changed between 0.0001 and 0.001 , which is the range proposed by Benz (2006) for each soil layer in order to obtain the optimal solution. Final parameters are shown in Table 5.1.

Table 5.1. HSsmall Model Obtained yo.7 Values

\begin{tabular}{ccc}
\hline $\begin{array}{c}\text { Parametric } \\
\text { Analysis }\end{array}$ & $\mathrm{Y}_{0.7}$ & $\mathrm{G}_{0}{ }^{\text {ref }}$ \\
\hline Clay_1 & 0.0003 & 25500 \\
Clay_2 & 0.0003 & 30000 \\
Clay_3 & 0.0003 & 36000 \\
Clay_4 & 0.0003 & 52500 \\
Clay_5 & 0.0002 & 58500 \\
Clay_6 & 0.0002 & 63000 \\
Clay_7 & 0.0002 & 52500 \\
Clay_8 & 0.0001 & 66000 \\
Clay_9 & 0.0001 & 69000 \\
Clay_10 & 0.0001 & 75000 \\
Clay_11 & 0.0001 & 76500 \\
Clay_12 & 0.0001 & 82500 \\
Clay_13 & 0.0001 & 85500 \\
Clay_14 & 0.0001 & 90000 \\
Clay_15 & 0.0001 & 84000 \\
Clay_16 & 0.0001 & 87000 \\
Clay_17 & 0.0001 & 90000 \\
\hline
\end{tabular}

Figure 5.12 shows the comparison of HSsmall with inclinometer measurements in terms of horizontal wall displacements in accordance with the ground elevation. 
Moreover, Plaxis outputs of the horizontal wall deflections, vertical displacements of the soil at the final excavation stage, moment and shear diagrams of the pile are given between Figure 5.13 and Figure 5.16, respectively.

When the measured and predicted lateral wall movements are compared with each other (Figure 5.12), it is determined that maximum error between estimated displacements and the measured ones is below 5.0\% (max. 2.9\%) in each data point above the bottom excavation level. Although addition of two more stiffness parameters increase the accuracy of calculations below the bottom excavation level, displacement values are still much higher than the measured ones.

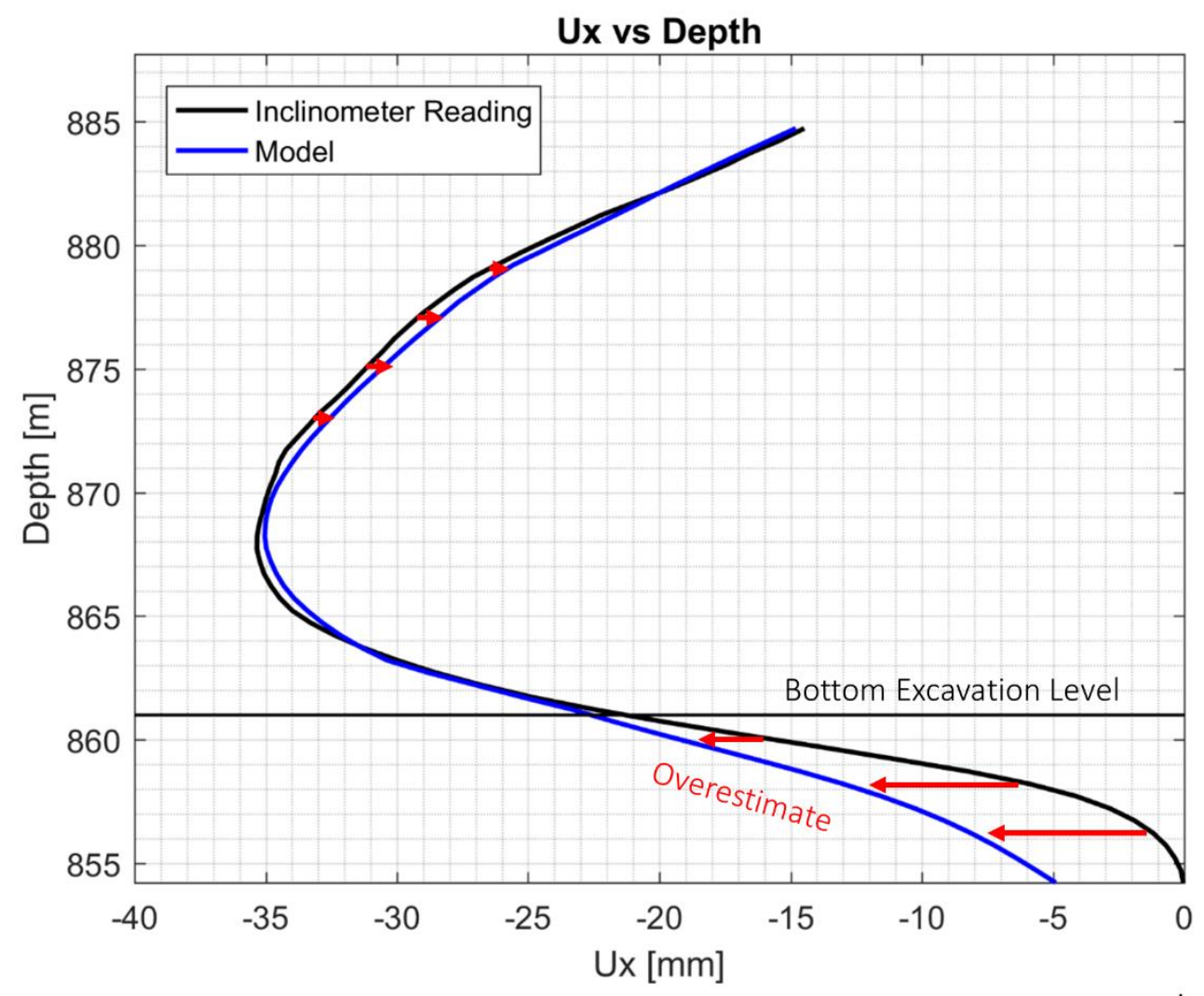

Figure 5.12. Comparison of Horizontal Displacements - HSsmall Model - 


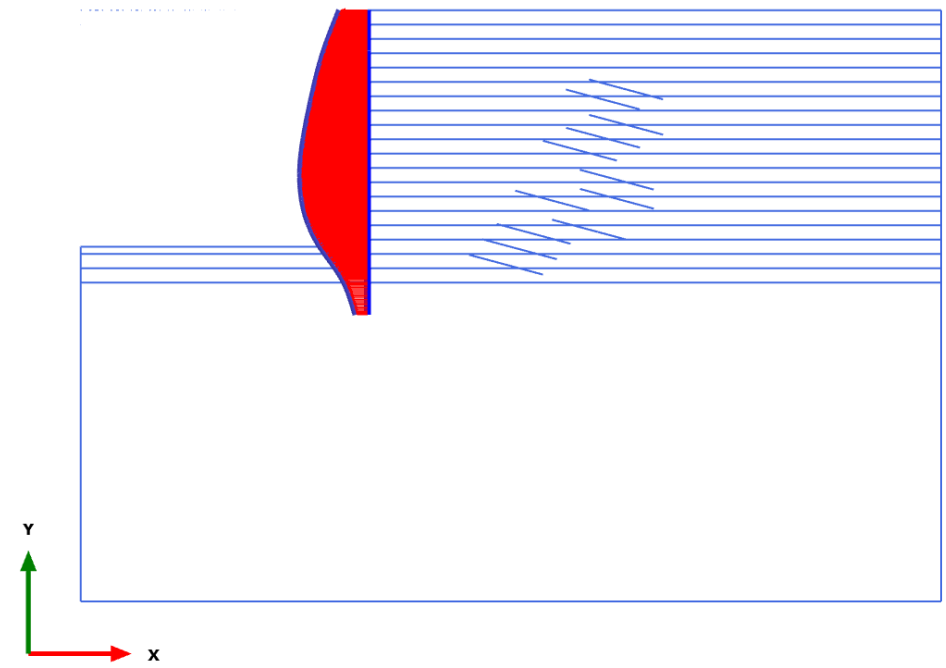

Total displacements $u_{x}$ (scaled up 200 times)

Maximum value $=-6.054^{*} 10^{-3} \mathrm{~m}($ Element 89 at Node 1$)$

Minimum value $=-0.03504 \mathrm{~m}$ (Element 53 at Node 35258$)$

Figure 5.13. Horizontal Displacement of the Pile - HSsmall Model -

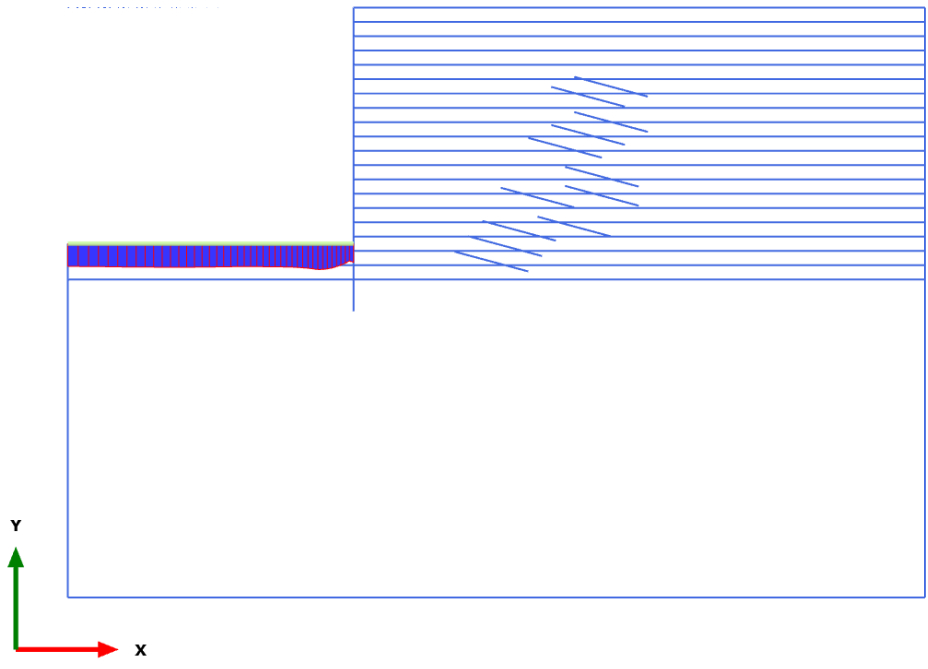

Total displacements $|\mathrm{u}|$ (scaled up 100 times)

Maximum value $=0.02717 \mathrm{~m}$

Figure 5.14. Vertical Displacement of the Pile - HSsmall Model - 
Maximum and minimum bending moment (Figure 5.15) values are obtained as 389.7 $\mathrm{kN} . \mathrm{m} / \mathrm{m}$ and $-365.1 \mathrm{kN} . \mathrm{m} / \mathrm{m}$ at $28.0 \mathrm{~m}$ and $24.0 \mathrm{~m}$ below the pile top elevation, respectively. Also, maximum and minimum shear forces (Figure 5.16) are determined as $308.5 \mathrm{kN} / \mathrm{m}$ and $-199.4 \mathrm{kN} / \mathrm{m}$ at $27.0 \mathrm{~m}$ and $21.0 \mathrm{~m}$ below the pile top elevation, respectively. Moreover, maximum anchor load at the $4^{\text {th }}$ anchorage level is determined as $408.0 \mathrm{kN}$ in the HSsmall model.

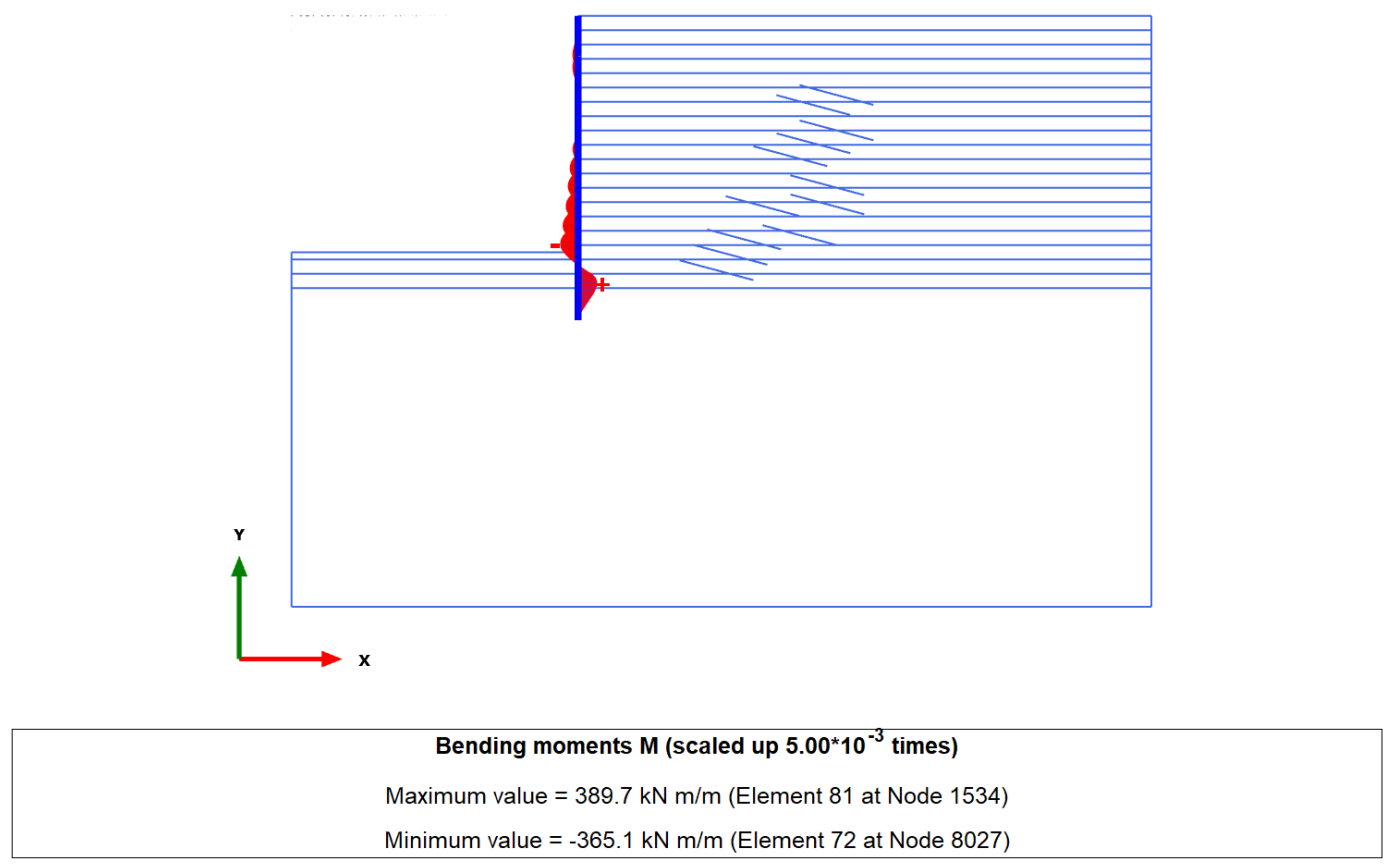

Figure 5.15. Bending Moment of the Pile - HSsmall Model - 


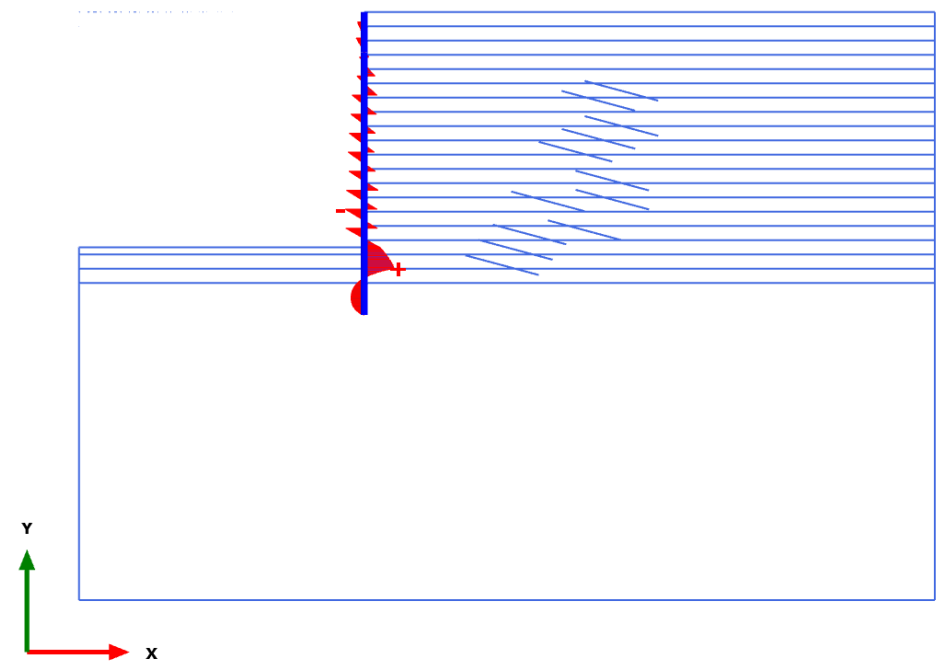

Shear forces $Q$ (scaled up 0.0100 times)

Maximum value $=308.5 \mathrm{kN} / \mathrm{m}$ (Element 79 at Node 2639)

Minimum value $=-199.4 \mathrm{kN} / \mathrm{m}$ (Element 63 at Node 21072)

Figure 5.16. Shear Forces of the Pile - HSsmall Model -

\subsection{Comparison of the Models}

Maximum horizontal displacement is measured as $3.5 \mathrm{~cm}$ in the site. This value is in the expected limits of stiff clays predicted by Clough et al. (1990) and Long (2001). This maximum displacement is obtained by changing stiffness parameter of Ankara clay in MC, HS and HSsmall models. The best estimation of each model and inclinometer measurements are shown in Figure 5.17.

A parametric study of E', $\mathrm{E}_{50}{ }^{\text {ref }}$ and $\gamma_{0.7}$ are conducted by using MC, HS and HSsmall models, respectively. As mentioned previously HSsmall model is the extended version of the HS model with two additional stiffness parameters $\left(\mathrm{G}_{0}{ }^{\text {ref }}\right.$ and $\left.\gamma_{0.7}\right)$, therefore in HSsmall analyses deformation modulus parameters $\left(\mathrm{E}_{50}{ }^{\mathrm{ref}}, \mathrm{E}_{\mathrm{oed}}{ }^{\mathrm{ref}}, \mathrm{E}_{\mathrm{ur}}{ }^{\text {ref }}\right)$ are kept constant and $\gamma_{0.7}$ parameters are tried to find. Maximum $3.5 \mathrm{~cm}$ horizontal displacement is obtained with $\mathrm{E}^{\prime}=1020 \times \mathrm{SPT}_{60}$ value in MC model and $\mathrm{E}_{50}{ }^{\mathrm{ref}}=780$ $x$ SPT $N_{60}$ in HS and HSsmall models. It is clear that the correlation constant in MC model is $30 \%$ higher when compared to advance soil models (HS and HSsmall). This 
outcome seems reasonable since MC model uses single deformation modulus parameter for all loading types; therefore, it is expected that estimated correlation constant for $\mathrm{E}^{\prime}$ in $\mathrm{MC}$ model will be higher than the constant for $\mathrm{E}_{50}{ }^{\mathrm{ref}}$ in advance models.

When the horizontal displacement curves obtained from MC, HS and HSsmall analyses are compared with each other and with inclinometer measurements (see Figure 5.17), it is understood that displacements of the advanced soil models are very close to the measured displacements while MC model gives close displacement values only near proximity of the maximum displacement depth.

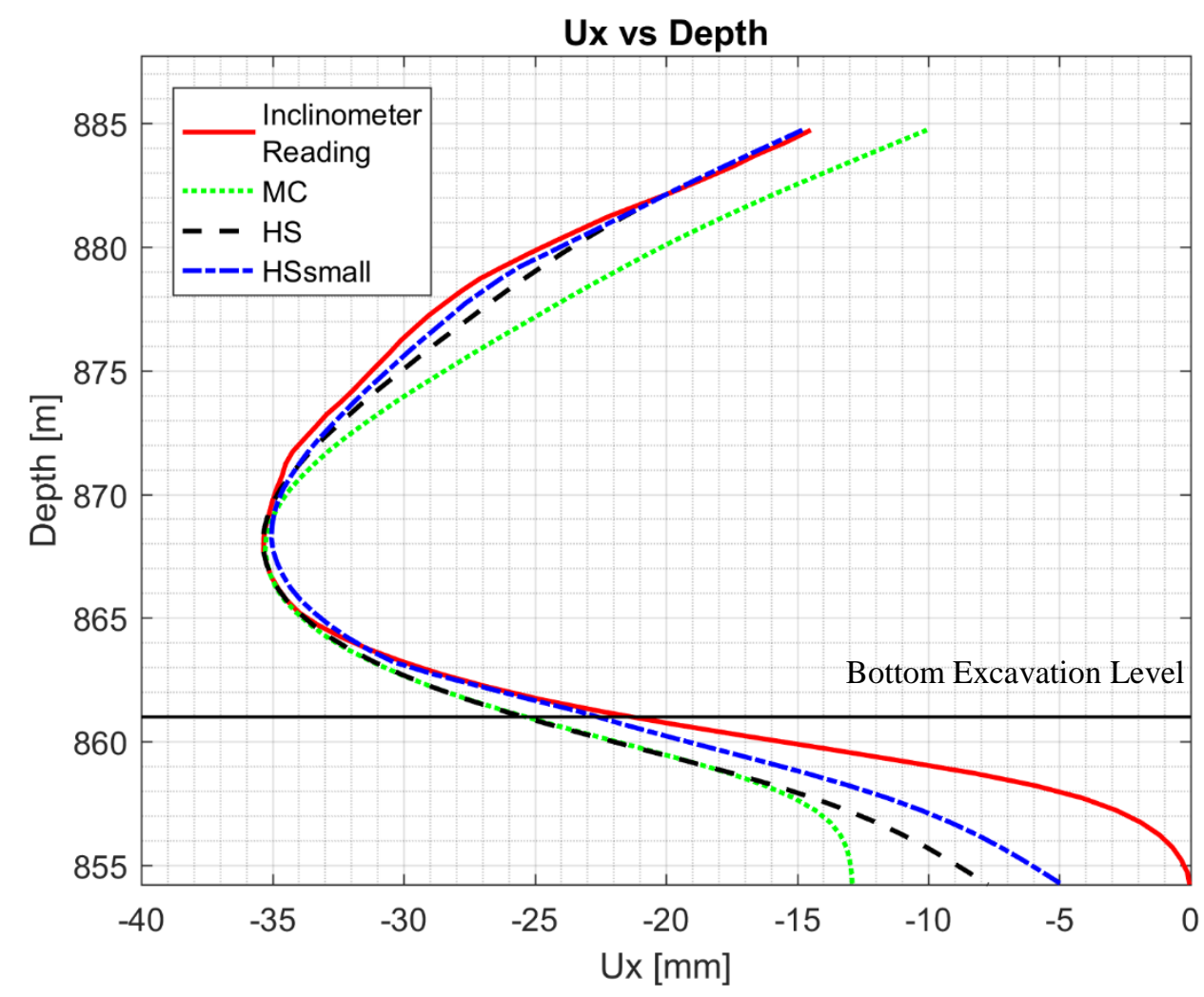

Figure 5.17. Comparison of Material Models in terms of Horizontal Displacements 
As shown in Figure 5.18, maximum surface heave in front of the wall is predicted as $9.5 \mathrm{~cm}, 3.5 \mathrm{~cm}$ and $2.7 \mathrm{~cm}$ by MC, HS and HSsmall models, respectively. MC model gives non-realistic surface heave in front of the wall. The reason behind this is related that model uses only one deformation modulus parameter for loading, unloading and reloading cases. Also, it neglects hardening of the soils. On the other hand, advanced soil models (HS and HSsmall) show similar heave results.

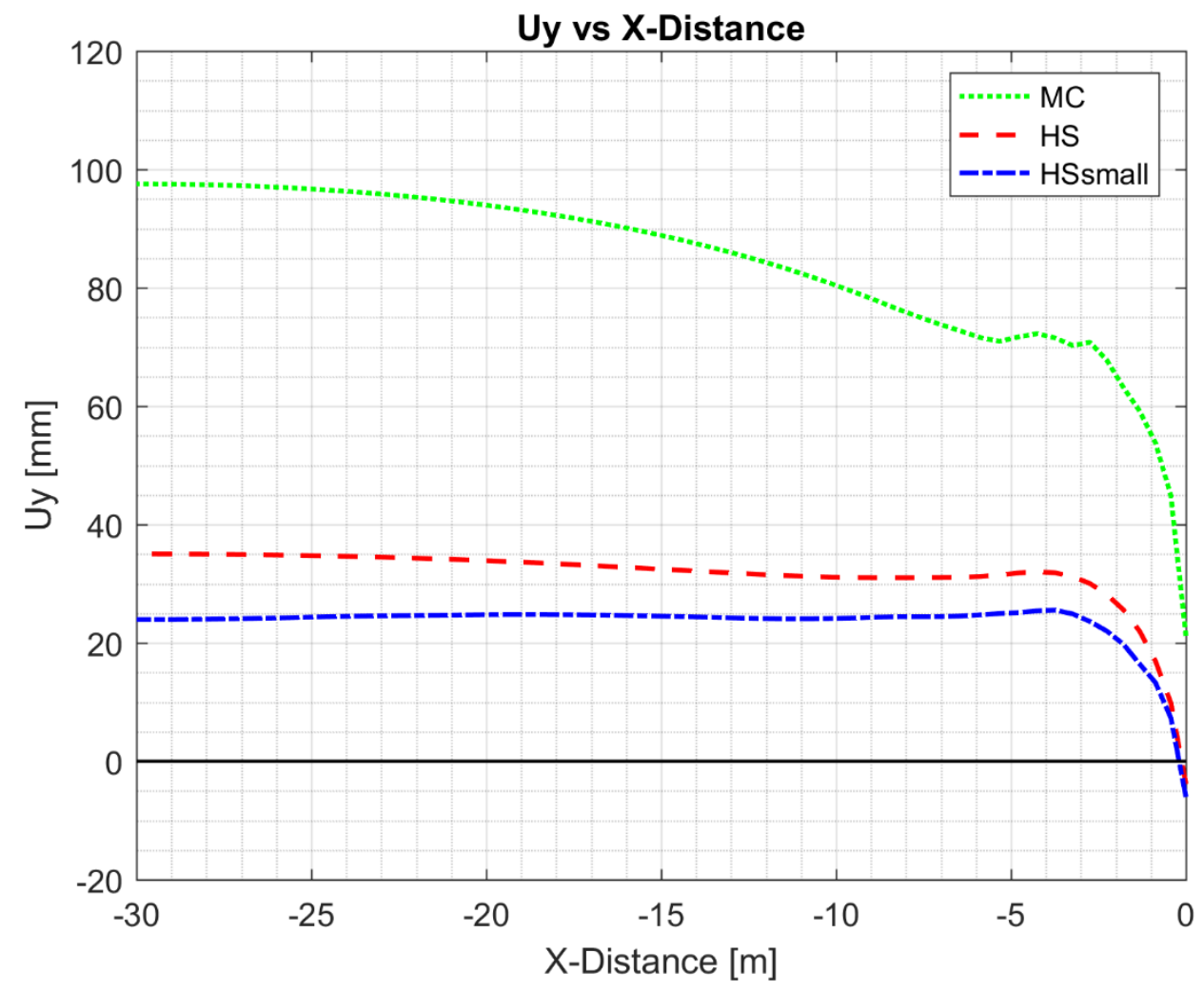

Figure 5.18. Comparison of Material Models in terms of Surface Heave in front of the Wall

Horizontal and vertical displacement curves of HS and HSsmall models are very close to each other and to inclinometer measurements. This is because both models simulate the soil behavior with a hyperbolic relation for loading and also for unloading/reloading situations with three stiffness parameters. On the other hand, 
since HSsmall model includes the effects of small strain behavior, predictions with HSsmall are slightly better than HS model.

Figure 5.17 shows that even when advanced soil models are used, it is not likely to obtain exactly the same displacement curve measured from inclinometers. This is due to several reasons which are given below:

- Dissimilarity of prestressing from design to practice

- Temperature effect

- Human effect

- Non-homogenous nature of soil

Calculated moment and shear values of HS and HSsmall model are close to each other. On the other hand, the moment and shear values of the MC model shows differences due to having different displacement curve.

Anchor forces obtained are $419.0 \mathrm{kN}$ for MC, 410.0 and $408.0 \mathrm{kN}$ for HS and HSsmall models, respectively. Differences in earth pressure distributions between the models are not significant. 



\section{CHAPTER 6}

\section{CONCLUSION}

Deep excavations gain importance each passing day to meet basic requirements of the high rising population of the world. This causes rise of underground structures while excavation depths also increase. However, some risks about the excavation, surrounding buildings and utilities may emerge due to deepening of excavation depths. Excessive horizontal displacements in the deep excavation system being the major risk may lead to severe damage to surrounding structures and failure of the deep excavation system. There are many examples of deep excavation failures in the world and if the reasons behind these failures are investigated, it is understood that uncertainties in soil properties, poor workmanship, inappropriate modelling and design are the main causes of these failures. Deformation of soils is mainly affected from stiffness parameters of soils; however, determination of soil modulus with laboratory test results may not give realistic results because of the soil disturbance and differences between laboratory and site conditions (size effect, water condition, nonhomogeneous nature of soils). In addition, there are limited data on stiffness parameters of soils owing not only to the inaccuracy of laboratory tests but also to their significant expenses. For obtaining more precise soil stiffness parameters back analysis method comes into prominence, which utilizes field measurements as feedbacks for numerical analysis. There are several numerical analysis models to simulate soil behavior in the literature; however, there is no universal material model. Therefore, it has been a problem of selecting the appropriate soil model for the problem to be handled.

The main objective of this study is to linearly correlate stiffness parameters with SPT $\mathrm{N}_{60}$ values and to obtain correlation constant by using three material models of Plaxis 2D namely Mohr Coulomb (MC) model, Hardening Soil model (HS) and Hardening 
Soil model with Small Strain Stiffness (HSsmall) and by using back analysis method. Other objectives of this study are to evaluate the performance of these material models with respect to their capability of estimating the measured displacement distribution along the depth and to compare the models with each other. For these purposes, a back analysis of a $25.0 \mathrm{~m}$ depth of excavation which are supported by multilayered anchorages in an Ankara clay was performed by using Plaxis 2D software. To be more precise in numerical analysis, instead of using the idealized soil profile the soil is divided into layers according to SPT-N distances. Additionally, each displacement measured by the inclinometer along the depth is compared with the analysis results to minimize the error. When trial-error method is used in the study, considering time loss and the possibility of not reaching the correct result, the analysis was done by writing the Python code.

When the back analyses results are compared with each other and with inclinometer measurements, following conclusions are made:

- Calculation time of the MC model is the shortest among the three models investigated which is due to the first order approximation of the model. When HS and HSsmall models are compared, HSsmall model is slower than HS model as it considers small strain stiffness behavior of soils with two additional parameters $\left(\mathrm{G}_{0}{ }^{\text {ref }}\right.$ and $\left.\gamma_{0.7}\right)$.

- Estimated horizontal displacement curve of HSsmall model found out to be closest to the inclinometer measurements while HS model gives very similar results being slightly worse than HSsmall model. On the other hand, MC model gives close results only near the proximity of maximum displacement depth. HS and HSsmall models resulting in close approximations to the inclinometer measurements is due to the use of hyperbolic soil behavior with isotropic hardening formulation and the inclusion of unloading/reloading stiffness parameters.

- When vertical displacement estimations of the models are compared, it is understood that MC model analysis gives unrealistic surface heave in front of 
the wall while the results of the advance soil models are close to each other and their predictions are in the expected range proposed in the literature.

- Maximum horizontal displacement is obtained with E'=1020 x SPT N60 value in MC model and $\mathrm{E}_{50}{ }^{\mathrm{ref}}=780 \mathrm{x}$ SPT $\mathrm{N}_{60}$ in HS and HSsmall models in the back analysis of the case study in Ankara clay. It is clear that the correlation constant in MC model is $30 \%$ higher when compared to advance models (HS and HSsmall). This outcome seems reasonable since MC model uses single deformation modulus parameter for all loading types.

- When these results are compared with the study of Çalışan, which is focused on only HS model, it is seen that author has obtained a higher value of $E_{u} / c_{u}$ ratio being 520 that corresponds to $\mathrm{E}_{50}{ }^{\text {ref }}=1450 \times$ SPT N. This consequence is due to the use of idealized soil profile in his study. Therefore, we may conclude that the procedure followed in this study results in more conservative estimations of soil parameters.

- Even if advanced soil models are used, the predicted displacements below the excavation level does not coincide with the measured displacements. This is due to the underestimation of passive resistance which causes overestimation of the lateral movements of the pile below the excavation level.

- It is seen that with advanced soil models predicted displacements are calculated with an error below 5\% percent which is very close to the measured displacements. This result may be addressed to the use of different soil parameters along the depth related to SPT $\mathrm{N}_{60}$ values instead of using single soil parameter obtained from idealized soil profile.

In this thesis, correlation of Ankara clay is determined by using data taken from one construction site. In the future, back analysis study may be performed for other construction sites in Ankara clay and according to obtained values the coefficients may be developed. Also, since the ground is unsaturated, it may be appropriate to have a future research with a model that takes into account the unsaturated state (such as the Barcelona basic model). 


\section{REFERENCES}

Alexandre, J. (2014). Numerical Analysis of the Excavation of a Shaft in London Clay.

Arda, Ş., 1966, Preconsolidation of Ankara Clay, M.S. Thesis, METU, Civil Engineering Department, Ankara.

Benz, T. (2007). Small-Strain Stiffnes of Soils and its Numerical Consequences. Retrieved September 20, 2006.

Birand, A. (1977). Ankara Yöresi Zeminlerde Ön Yükleme İsotropisi. 4. Tubitak Teknik Kongresi, İzmir

Birand, A. (1978). Soils of Ankara and Geotechnical Problems. Proceedings of the Symposium on Earthsciences Related Problems of Ankara, Turkey, pp-55-60.

Bowles, J.E. (1988). Foundation Analysis and Design, McGraw-Hill, Singapore.

Brinkgreve, R. B. (2005). Selection of Soil Models and Parameters For Geotechnical Engineering Application

Burland, J. B., Simpson, B., \& John, H. D. (1979). Movements around Excavations in London Clay. Design Parameter in Geotechnical Engineering, 1.

Butler, F.G. (1975). General report and state-of-the art review. Session 3-Proceedings of the Conference on settlement of structures, Cambridge. Pentech Press. London 1975

CIRIA. (1995). The Standard Penetration Test (SPT): Methods and Use (Rep. No. 143). London

Clayton, C.R.I., (1995), The Standard Penetration Test (SPT): Methods and Use, CIRIA, Report 143

Clough, G. W. (1990). Construction Induced Movements of in situ walls. Specialty Conference on Design and Performance of Earth Retaining Structures, 439470 .

Charles, W. W., Simpson, B., Lings, M. L., \& Nash, D. F. (1998). Numerical Analysis of a Multipropped Excavation in Stiff Clay. Canadian Geotechnical Journal, 35, 115-130.

Christian, J. T. (1989). Design of lateral support system. Proc. BSCE Symposium on Design, Construction and Performance of Deep Excavations in Urban Areas. Boston Society of Civil Engineers, 1-31. 
Çalışan, O. (2009). Ankara Kilinde $20 \mathrm{~m}$ Derinliğindeki Bir Kazının Geri Analizi. Prof. İsmet Ordemir'i Anma Toplantısı ve 5. ODTÜ Geoteknik Mühendisliği Sempozyumu.

Çokça, E. (1991). Swelling potential of expansive soils with a critical appraisal of the identification of swelling of Ankara soils by methylene blue tests. Ankara: Phd. Thesis, METU.

Duncan, J.M. and Chang, C.Y. (1970). Nonlinear analysis of stress and strain in soils. Journal of Soil Mech. and Foundation Division, ASCE, pp. 1629-1653.

Duncan, J.M. \& Buchignani, A.L. (1976). An Engineering Manual for Settlement Studies. Department of Civil Engineering, University of California at Berkeley.

Ekmekçioğlu, O. (1975). A Study on the Strength Behaviour of Two Clay Formatons from the General Ankara Region. Ankara: M.S. Thesis, METU.

Ergüler, Z.A., \& Ulusay, R., (2003). A Simple Test and Predictive Models for Assesing Swell Potential of Ankara (Turkey) Clay. Engineering Geology, Vol.67, pp. 331-352

Ergun, M. U. (2008). Deep Excavations. EJGE.

Goldberg, D. T., Jaworski, W. E., and Gordon, M. D. _1976_. Lateral support systems and underpinning. Rep. No. FHWA-RD-75-129, Federal Highway Administration, Washington, D.C.

Goldscheider, M. (1984). True Triaxial Tests on Dense Sands. Constitutive Relations for Soils. Balkema, Rotterdam

Gouw, T. L. (2014). Common Mistakes on the Application of Plaxis 2D in Analyzing Excavation Problems. International Journal of Applied Engineering Research.

Günece, T. (1968). Stability of Unsupported Vertical Cuts in Ankara Clay. Ankara: M.S. Thesis, METU.

Hashash, Y. M., \& Marulanda, C. (2006). Novel Approach to Integration of Numerical Modeling and Field Observations for Deep Excavations. Journal of Geotechnical and Geoenvironmental Engineering.

Hsiung, B. B., \& Dao, S. D. (2014). Evaluation of Constitutive Soil Models for Predicting Movements Caused by a Deep Excavation in Sands. EJGE, 19.

Inal, T. (1967). A Study of the Shear Strength Characteristics of Ankara Clay in terms of Effective Stresses. Ankara: M.S. Thesis, METU.

Karatağ, H. (2012). Ankrajlı Bir İstinat Yapısının Hesaplanan ve Gözlenen Davranışının Karşılaştırılması. Ankara: M.S. Thesis, Gazi University. 
Kaynar, A. T. (1972). Ratio of Swelling Index to Compression Index in Clay Soils. Ankara: M.S. Thesis, METU.

Kiper, O.B., 1983, Etimesgut-Batıkent Yöresindeki Üst Pliosen Çökellerinin Jeomühendislik Özellikleri ve Konsolidasyonu. Phd Thesis, Hacettepe University, Ankara

Kocabayoğlu, E. (1971). Contribution of Dessication to the Preconsolidation of Ankara Clay. Ankara: M.S. Thesis, METU.

Kondner, R.L. (1963). Hyperbolic Stress-Strain Response: Cohesive Soils. ASCE Journal of the Soil Mechanics and Foundation Division., Vol.89, 115-143

Long, M. (2001). Database for Retaining Wall and Ground Movements Due to Deep Excavations. Journal of Geotechnical and Geoenvironmental Engineering, 203-224.

Mana, A. I., \& Clough, G. W. (1981). Prediction of Movements of Braced Cuts in Clay. Journal of the Geotechnical Division, 107, 759-778.

Ma'ruf, M. F., \& Darjanto, H., 2017. Back calculation of excessive deformation on deep excavation. Elsevier.

Means, W. E., \& Parcher, J. V. (1963). Physical Properties of Soils. 476

Mirata T., 1976. Short Term Stability of Slopes in Ankara Clay. Joint PhD Thesis, University of London and Middle East Technical University, Ankara.

Ordemir, I., Alyanak, I., \& Birand, A. (1965). Report on Ankara Clay. Ankara: Faculty of Engineering, METU.

Ou, C. (2006). Deep Excavation Theory and Practice. London

Peck, R. B. _1969_. Deep excavation and tunneling in soft ground. Proc., 7th Int. Conf. on Soil Mechanics and Foundation Engineering, State-of-the-Art Vol., 225-290.

Plaxis (2019). Plaxis 2D Material Models Manual.

Santos, J.A. and Correia, A. (2001). Reference threshold shear strain of soil. Its application to obtain a unique strain-dependent shear modulus curve for soil. XV International Conference on Soil Mechanics and Geotechnical Engineering, Istanbul, Turkey.

Schanz, T. (1998). Zur Modellierung des Mechanischen Verhaltens von Reibungsmaterialen. Habilitation. Stuttgart University.

Schanz, T., \& Vermmer, P. A. (1999). The hardening soil model: Formulation and verification. Beyond 2000 in Computational Geotechnics-10 Years of Plaxis. 
Schweiger, H. F., Vermeer, P. A., \& Wehnert, M. (2009). On the design of deep excavations based on finite element analysis. Geomechanics and Tunneling 2.

Stroud, M.A. (1974). The Standard Penetration Test in Insensitive Clays and Soft Rocks. Proceedings, First European Conference on Penetration Testing, Stockholm, Vol.1, 367-375.

Stroud, M.A. (1987). The Control of Groundwater. General Report and State of the Art Review to Session 2 of IX ECSMFE Dublin

Surgel, A., 1976, A Survey of the Geotechnical Properties of Ankara Soils. M.S. Thesis, METU Civil Engineering Department

Topkara, E. (1974). Strength Characteristics of M.E.T.U. Campus Clay with Emphasis on Residual Behavior. Ankara: M.S. Thesis, METU.

Wang, J. H., Xu, H., \& Wang, W. D. (2010). Wall and Ground Movements due to Deep Excavations in Shanghai Soft Soils. Journal of Geotechnical and Geoenvironmental Engineering, 985-994. Retrieved July, 2010 


\section{APPENDICES}

\section{A. Laboratory Test Results}

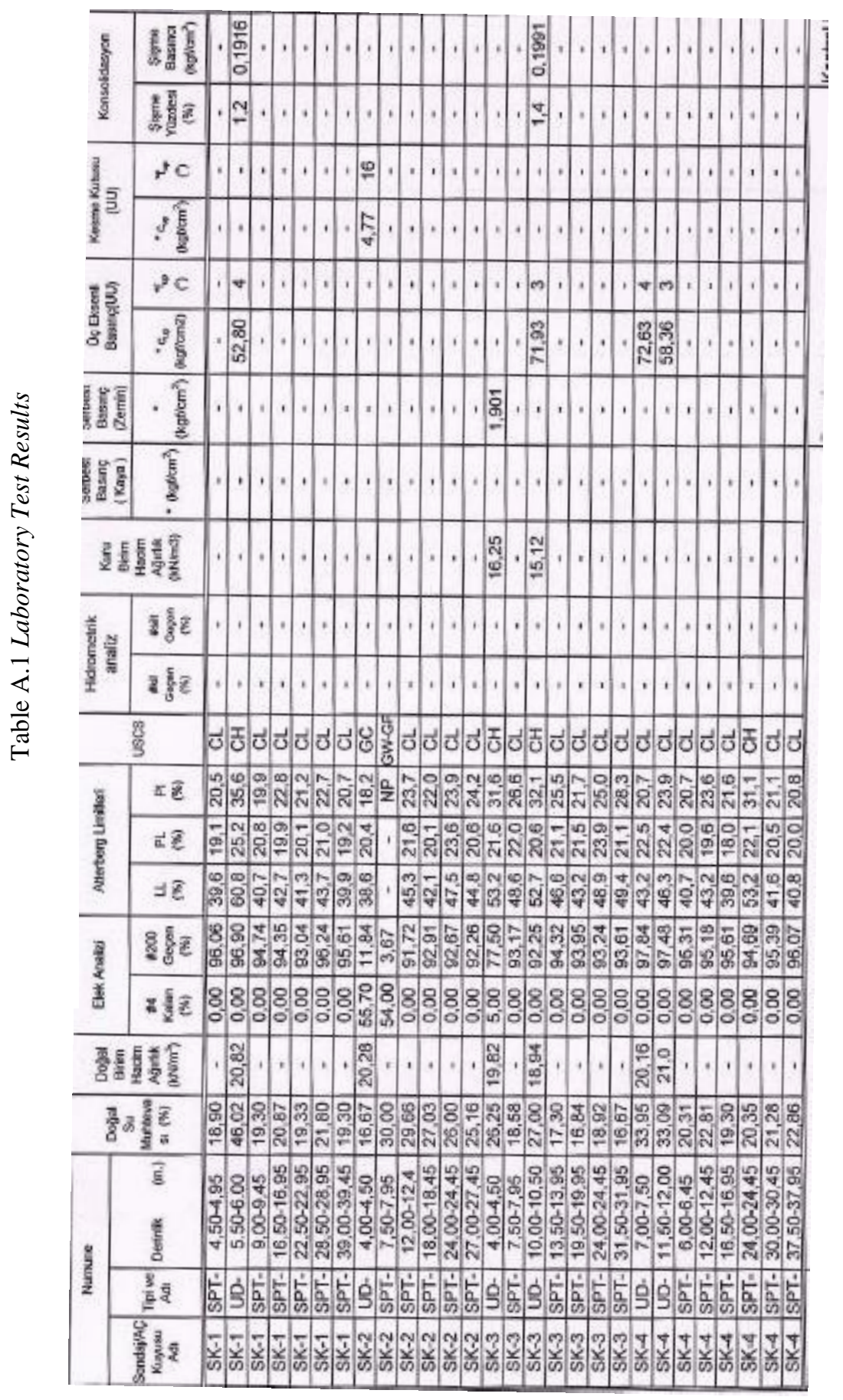




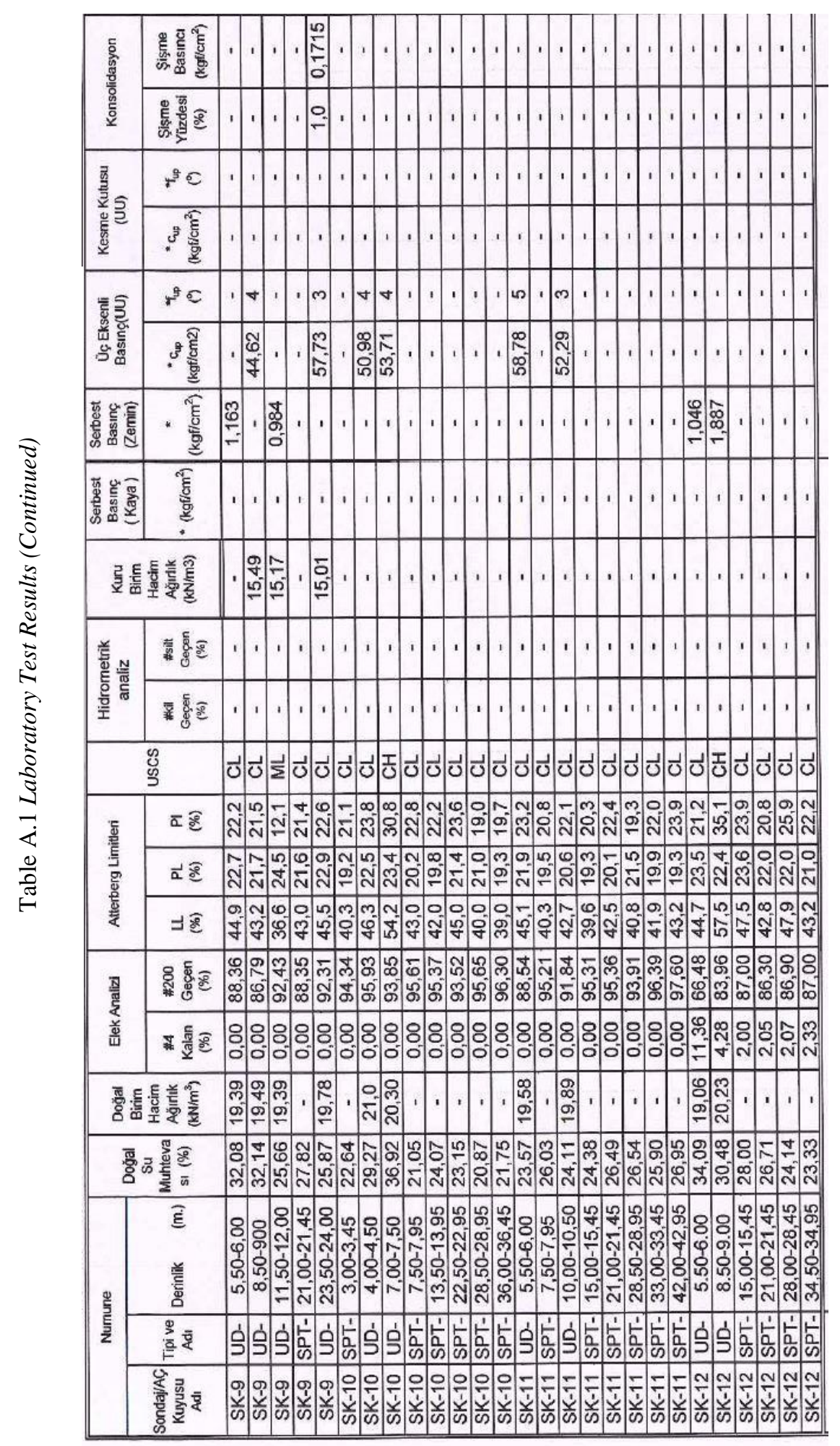




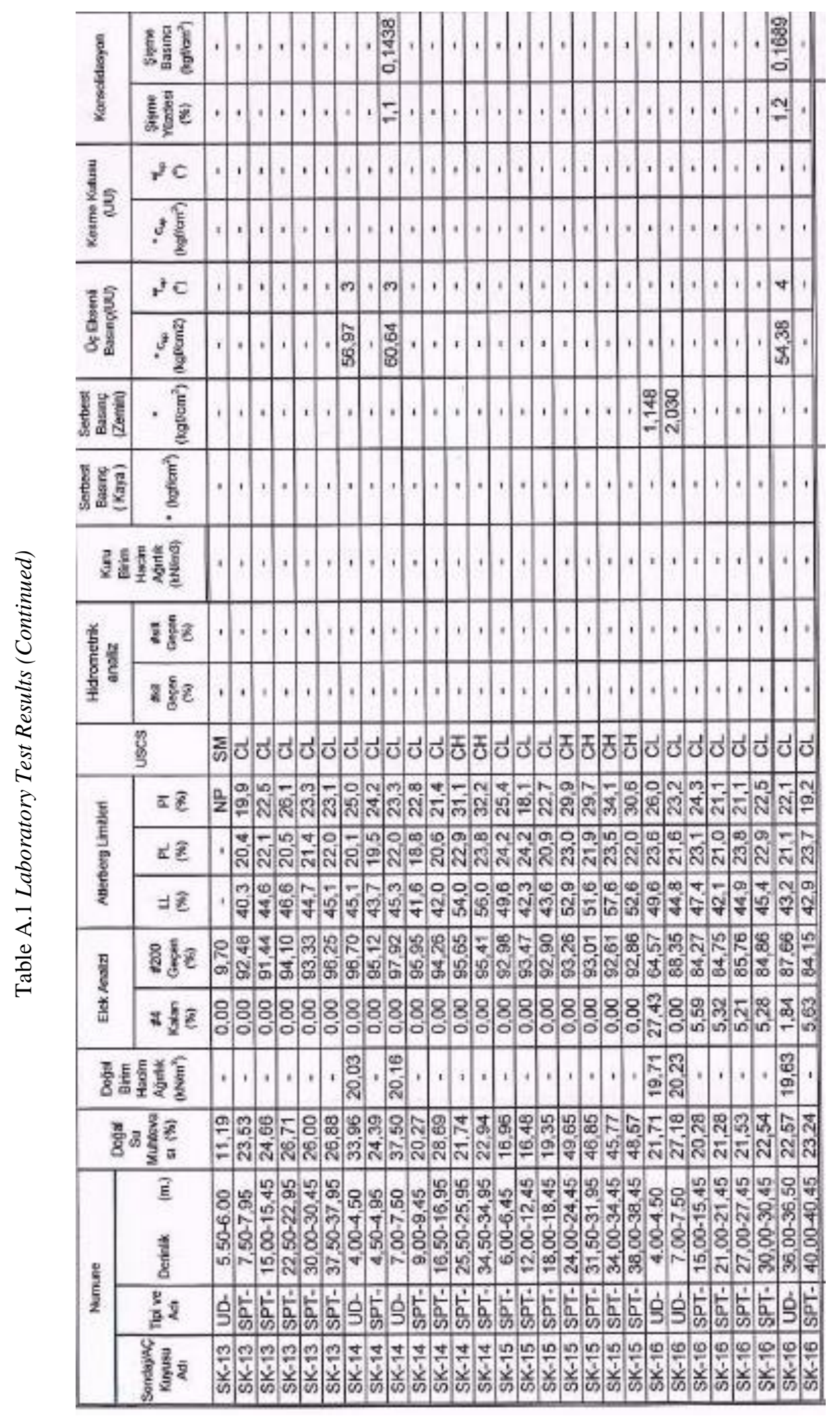




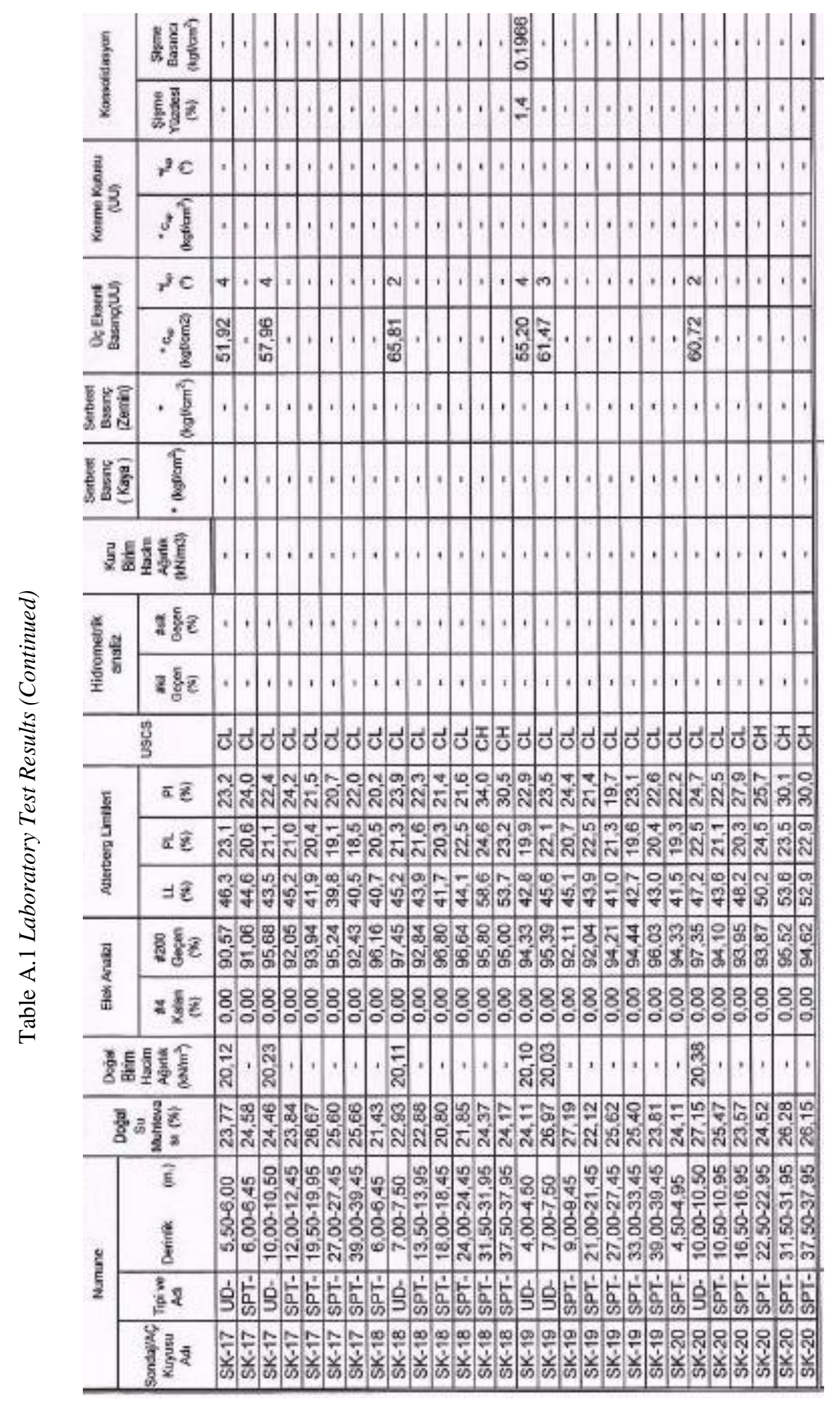




\section{B. Inclinometer Measurements, Estimated Displacements and Errors}

Table B.1. MC Model Estimated Displacements and Errors for Each Altitude

\begin{tabular}{|c|c|c|c|}
\hline $\begin{array}{l}\text { Altitude } \\
\text { (m) }\end{array}$ & $\begin{array}{c}\text { Measured } \\
\text { Displacement } \\
\text { (m) }\end{array}$ & $\begin{array}{c}\text { Estimated } \\
\text { Displacement } \\
\text { (m) }\end{array}$ & $\begin{array}{c}\text { Error } \\
\text { (\%) }\end{array}$ \\
\hline 884.72 & -0.014 & -0.010 & 30.5 \\
\hline 884.22 & -0.015 & -0.011 & 27.5 \\
\hline 883.72 & -0.017 & -0.012 & 25.5 \\
\hline 883.22 & -0.018 & -0.013 & 23.1 \\
\hline 882.72 & -0.019 & -0.015 & 21.7 \\
\hline 882.22 & -0.020 & -0.016 & 20.5 \\
\hline 881.72 & -0.021 & -0.017 & 20.1 \\
\hline 881.22 & -0.022 & -0.018 & 19.9 \\
\hline 880.72 & -0.023 & -0.019 & 19.2 \\
\hline 880.22 & -0.024 & -0.020 & 18.6 \\
\hline 879.72 & -0.025 & -0.021 & 18.2 \\
\hline 879.22 & -0.026 & -0.022 & 17.7 \\
\hline 878.72 & -0.027 & -0.022 & 17.2 \\
\hline 878.22 & -0.028 & -0.023 & 16.3 \\
\hline 877.72 & -0.028 & -0.024 & 15.3 \\
\hline 877.22 & -0.029 & -0.025 & 14.3 \\
\hline 876.72 & -0.030 & -0.026 & 13.1 \\
\hline 876.22 & -0.030 & -0.027 & 11.9 \\
\hline 875.72 & -0.031 & -0.027 & 10.5 \\
\hline 875.22 & -0.031 & -0.028 & 9.4 \\
\hline 874.72 & -0.031 & -0.029 & 8.3 \\
\hline 874.22 & -0.032 & -0.030 & 7.2 \\
\hline 873.72 & -0.032 & -0.030 & 6.4 \\
\hline 873.22 & -0.033 & -0.031 & 5.9 \\
\hline 872.72 & -0.033 & -0.032 & 5.1 \\
\hline 872.22 & -0.034 & -0.032 & 4.4 \\
\hline 871.72 & -0.034 & -0.033 & 3.9 \\
\hline 871.22 & -0.035 & -0.033 & 3.2 \\
\hline 870.72 & -0.035 & -0.034 & 2.2 \\
\hline 870.22 & -0.035 & -0.034 & 1.5 \\
\hline 869.72 & -0.035 & -0.035 & 1.0 \\
\hline 869.22 & -0.035 & -0.035 & 0.6 \\
\hline
\end{tabular}




\begin{tabular}{|c|c|c|c|}
\hline $\begin{array}{l}\text { Altitude } \\
\text { (m) }\end{array}$ & $\begin{array}{c}\text { Measured } \\
\text { Displacement } \\
\text { (m) }\end{array}$ & $\begin{array}{c}\text { Estimated } \\
\text { Displacement } \\
\text { (m) }\end{array}$ & $\begin{array}{c}\text { Error } \\
(\%)\end{array}$ \\
\hline 868.72 & -0.035 & -0.035 & 0.4 \\
\hline 868.22 & -0.035 & -0.035 & 0.2 \\
\hline 867.72 & -0.035 & -0.035 & 0.2 \\
\hline 867.22 & -0.035 & -0.035 & 0.1 \\
\hline 866.72 & -0.035 & -0.035 & 0.0 \\
\hline 866.22 & -0.035 & -0.035 & -0.2 \\
\hline 865.72 & -0.034 & -0.035 & -0.2 \\
\hline 865.22 & -0.034 & -0.034 & -0.3 \\
\hline 864.72 & -0.033 & -0.034 & -0.8 \\
\hline 864.22 & -0.032 & -0.033 & -1.7 \\
\hline 863.72 & -0.031 & -0.032 & -2.7 \\
\hline 863.22 & -0.030 & -0.031 & -3.9 \\
\hline 862.72 & -0.029 & -0.030 & -5.5 \\
\hline 862.22 & -0.027 & -0.029 & -7.9 \\
\hline 861.72 & -0.025 & -0.028 & -11.1 \\
\hline 861.22 & -0.022 & -0.026 & -16.0 \\
\hline 860.72 & -0.020 & -0.024 & -23.2 \\
\hline 860.22 & -0.017 & -0.023 & -33.9 \\
\hline 859.72 & -0.014 & -0.021 & -50.1 \\
\hline 859.22 & -0.011 & -0.019 & -73.7 \\
\hline 858.72 & -0.008 & -0.018 & -113.3 \\
\hline 858.22 & -0.006 & -0.016 & -173.8 \\
\hline 857.72 & -0.004 & -0.015 & -266.1 \\
\hline 857.22 & -0.003 & -0.014 & -405.4 \\
\hline 856.72 & -0.002 & -0.014 & -630.1 \\
\hline 856.22 & -0.001 & -0.013 & -1031.2 \\
\hline 855.72 & -0.001 & -0.013 & -1801.4 \\
\hline 855.22 & 0.000 & -0.013 & -3510.0 \\
\hline 854.72 & 0.000 & -0.013 & -9847.7 \\
\hline 854.22 & 0.000 & -0.013 & -32137.5 \\
\hline
\end{tabular}


Table B.2. HS Model Estimated Displacements and Errors for Each Altitude

\begin{tabular}{|c|c|c|c|}
\hline $\begin{array}{l}\text { Altitude } \\
(\mathrm{m})\end{array}$ & $\begin{array}{c}\text { Measured } \\
\text { Displacement } \\
(\mathrm{m})\end{array}$ & $\begin{array}{c}\text { Estimated } \\
\text { Displacement } \\
\text { (m) }\end{array}$ & $\begin{array}{c}\text { Error } \\
(\%)\end{array}$ \\
\hline 884.72 & -0.014 & -0.015 & -2.22 \\
\hline 884.22 & -0.015 & -0.016 & -2.54 \\
\hline 883.72 & -0.017 & -0.017 & -1.83 \\
\hline 883.22 & -0.018 & -0.018 & -1.97 \\
\hline 882.72 & -0.019 & -0.019 & -1.24 \\
\hline 882.22 & -0.020 & -0.020 & -0.36 \\
\hline 881.72 & -0.021 & -0.021 & 1.19 \\
\hline 881.22 & -0.022 & -0.022 & 2.72 \\
\hline 880.72 & -0.023 & -0.022 & 3.43 \\
\hline 880.22 & -0.024 & -0.023 & 4.19 \\
\hline 879.72 & -0.025 & -0.024 & 4.97 \\
\hline 879.22 & -0.026 & -0.025 & 5.62 \\
\hline 878.72 & -0.027 & -0.025 & 6.23 \\
\hline 878.22 & -0.028 & -0.026 & 6.18 \\
\hline 877.72 & -0.028 & -0.027 & 6.01 \\
\hline 877.22 & -0.029 & -0.027 & 5.87 \\
\hline 876.72 & -0.030 & -0.028 & 5.43 \\
\hline 876.22 & -0.030 & -0.029 & 4.96 \\
\hline 875.72 & -0.031 & -0.029 & 4.30 \\
\hline 875.22 & -0.031 & -0.030 & 3.86 \\
\hline 874.72 & -0.031 & -0.030 & 3.40 \\
\hline 874.22 & -0.032 & -0.031 & 2.92 \\
\hline 873.72 & -0.032 & -0.032 & 2.66 \\
\hline 873.22 & -0.033 & -0.032 & 2.66 \\
\hline 872.72 & -0.033 & -0.033 & 2.32 \\
\hline 872.22 & -0.034 & -0.033 & 2.09 \\
\hline 871.72 & -0.034 & -0.034 & 1.97 \\
\hline 871.22 & -0.035 & -0.034 & 1.55 \\
\hline 870.72 & -0.035 & -0.034 & 0.85 \\
\hline 870.22 & -0.035 & -0.035 & 0.44 \\
\hline 869.72 & -0.035 & -0.035 & 0.13 \\
\hline 869.22 & -0.035 & -0.035 & -0.08 \\
\hline 868.72 & -0.035 & -0.035 & -0.10 \\
\hline 868.22 & -0.035 & -0.035 & -0.09 \\
\hline 867.72 & -0.035 & -0.035 & -0.02 \\
\hline 867.22 & -0.035 & -0.035 & -0.02 \\
\hline
\end{tabular}




\begin{tabular}{|c|c|c|c|}
\hline $\begin{array}{l}\text { Altitude } \\
(\mathrm{m})\end{array}$ & $\begin{array}{c}\text { Measured } \\
\text { Displacement } \\
\text { (m) }\end{array}$ & $\begin{array}{c}\text { Estimated } \\
\text { Displacement } \\
\text { (m) }\end{array}$ & $\begin{array}{c}\text { Error } \\
(\%)\end{array}$ \\
\hline 866.72 & -0.035 & -0.035 & 0.02 \\
\hline 866.22 & -0.035 & -0.035 & -0.05 \\
\hline 865.72 & -0.034 & -0.034 & -0.02 \\
\hline 865.22 & -0.034 & -0.034 & -0.04 \\
\hline 864.72 & -0.033 & -0.033 & -0.53 \\
\hline 864.22 & -0.032 & -0.033 & -1.36 \\
\hline 863.72 & -0.031 & -0.032 & -2.38 \\
\hline 863.22 & -0.030 & -0.031 & -3.69 \\
\hline 862.72 & -0.029 & -0.030 & -5.38 \\
\hline 862.22 & -0.027 & -0.029 & -7.88 \\
\hline 861.72 & -0.025 & -0.028 & -11.20 \\
\hline 861.22 & -0.022 & -0.026 & -16.37 \\
\hline 860.72 & -0.020 & -0.025 & -23.84 \\
\hline 860.22 & -0.017 & -0.023 & -34.71 \\
\hline 859.72 & -0.014 & -0.021 & -50.89 \\
\hline 859.22 & -0.011 & -0.019 & -74.10 \\
\hline 858.72 & -0.008 & -0.017 & -112.04 \\
\hline 858.22 & -0.006 & -0.016 & -167.69 \\
\hline 857.72 & -0.004 & -0.014 & -248.31 \\
\hline 857.22 & -0.003 & -0.013 & -362.58 \\
\hline 856.72 & -0.002 & -0.012 & -535.85 \\
\hline 856.22 & -0.001 & -0.011 & -827.97 \\
\hline 855.72 & -0.001 & -0.010 & -1357.25 \\
\hline 855.22 & 0.000 & -0.009 & -2466.39 \\
\hline 854.72 & 0.000 & -0.008 & -6417.69 \\
\hline 854.22 & 0.000 & -0.008 & -19227.50 \\
\hline
\end{tabular}

Table B.3. HSsmall Model Estimated Displacements and Errors for Each Altitude

\begin{tabular}{|c|c|c|c|}
\hline $\begin{array}{c}\text { Altitude } \\
(\mathrm{m})\end{array}$ & $\begin{array}{c}\text { Measured } \\
\text { Displacement } \\
(\mathrm{m})\end{array}$ & $\begin{array}{c}\text { Estimated } \\
\text { Displacement } \\
(\mathrm{m})\end{array}$ & $\begin{array}{c}\text { Error } \\
(\%)\end{array}$ \\
\hline 884.72 & -0.014 & -0.015 & -2.21 \\
\hline 884.22 & -0.015 & -0.016 & -2.54 \\
\hline 883.72 & -0.017 & -0.017 & -1.82 \\
\hline
\end{tabular}




\begin{tabular}{|c|c|c|c|}
\hline $\begin{array}{l}\text { Altitude } \\
\text { (m) }\end{array}$ & $\begin{array}{c}\text { Measured } \\
\text { Displacement } \\
\text { (m) }\end{array}$ & $\begin{array}{c}\text { Estimated } \\
\text { Displacement } \\
\text { (m) }\end{array}$ & $\begin{array}{c}\text { Error } \\
(\%)\end{array}$ \\
\hline 883.22 & -0.018 & -0.018 & -1.95 \\
\hline 882.72 & -0.019 & -0.019 & -1.23 \\
\hline 882.22 & -0.020 & -0.020 & -0.35 \\
\hline 881.72 & -0.021 & -0.021 & 1.18 \\
\hline 881.22 & -0.022 & -0.022 & 2.38 \\
\hline 880.72 & -0.023 & -0.023 & 2.58 \\
\hline 880.22 & -0.024 & -0.024 & 2.68 \\
\hline 879.72 & -0.025 & -0.025 & 2.73 \\
\hline 879.22 & -0.026 & -0.026 & 2.44 \\
\hline 878.72 & -0.027 & -0.026 & 2.92 \\
\hline 878.22 & -0.028 & -0.027 & 2.95 \\
\hline 877.72 & -0.028 & -0.028 & 2.78 \\
\hline 877.22 & -0.029 & -0.028 & 2.93 \\
\hline 876.72 & -0.030 & -0.029 & 2.78 \\
\hline 876.22 & -0.030 & -0.029 & 2.59 \\
\hline 875.72 & -0.031 & -0.030 & 2.19 \\
\hline 875.22 & -0.031 & -0.030 & 2.02 \\
\hline 874.72 & -0.031 & -0.031 & 1.80 \\
\hline 874.22 & -0.032 & -0.031 & 1.57 \\
\hline 873.72 & -0.032 & -0.032 & 1.55 \\
\hline 873.22 & -0.033 & -0.032 & 1.78 \\
\hline 872.72 & -0.033 & -0.033 & 1.66 \\
\hline 872.22 & -0.034 & -0.033 & 1.64 \\
\hline 871.72 & -0.034 & -0.034 & 1.72 \\
\hline 871.22 & -0.035 & -0.034 & 1.49 \\
\hline 870.72 & -0.035 & -0.034 & 0.97 \\
\hline 870.22 & -0.035 & -0.035 & 0.73 \\
\hline 869.72 & -0.035 & -0.035 & 0.59 \\
\hline 869.22 & -0.035 & -0.035 & 0.54 \\
\hline 868.72 & -0.035 & -0.035 & 0.67 \\
\hline 868.22 & -0.035 & -0.035 & 0.82 \\
\hline 867.72 & -0.035 & -0.035 & 1.04 \\
\hline 867.22 & -0.035 & -0.035 & 1.17 \\
\hline 866.72 & -0.035 & -0.035 & 1.35 \\
\hline 866.22 & -0.035 & -0.034 & 1.40 \\
\hline 865.72 & -0.034 & -0.034 & 1.56 \\
\hline 865.22 & -0.034 & -0.033 & 1.68 \\
\hline 864.72 & -0.033 & -0.033 & 1.34 \\
\hline
\end{tabular}




\begin{tabular}{|c|c|c|c|}
\hline $\begin{array}{l}\text { Altitude } \\
(\mathrm{m})\end{array}$ & $\begin{array}{c}\text { Measured } \\
\text { Displacement } \\
\text { (m) }\end{array}$ & $\begin{array}{c}\text { Estimated } \\
\text { Displacement } \\
\text { (m) }\end{array}$ & $\begin{array}{c}\text { Error } \\
(\%)\end{array}$ \\
\hline 864.22 & -0.032 & -0.032 & 0.66 \\
\hline 863.72 & -0.031 & -0.031 & -0.18 \\
\hline 863.22 & -0.030 & -0.030 & -1.29 \\
\hline 862.72 & -0.029 & -0.029 & -1.02 \\
\hline 862.22 & -0.027 & -0.027 & -0.79 \\
\hline 861.72 & -0.025 & -0.025 & -1.54 \\
\hline 861.22 & -0.022 & -0.023 & -3.78 \\
\hline 860.72 & -0.020 & -0.022 & -9.56 \\
\hline 860.22 & -0.017 & -0.020 & -18.00 \\
\hline 859.72 & -0.014 & -0.018 & -30.58 \\
\hline 859.22 & -0.011 & -0.016 & -48.48 \\
\hline 858.72 & -0.008 & -0.015 & -77.71 \\
\hline 858.22 & -0.006 & -0.013 & -119.90 \\
\hline 857.72 & -0.004 & -0.012 & -179.81 \\
\hline 857.22 & -0.003 & -0.010 & -262.61 \\
\hline 856.72 & -0.002 & -0.009 & -385.37 \\
\hline 856.22 & -0.001 & -0.008 & -588.22 \\
\hline 855.72 & -0.001 & -0.007 & -947.25 \\
\hline 855.22 & 0.000 & -0.006 & -1680.56 \\
\hline 854.72 & 0.000 & -0.006 & -4241.54 \\
\hline 854.22 & 0.000 & -0.005 & -12155.00 \\
\hline
\end{tabular}

